University of Rhode Island

DigitalCommons@URI

Open Access Master's Theses

2017

\title{
Dynamic Collapse of Double Hull Composite Cylinders: Hydrostatic and Shock-Initiated Implosion
}

Nicholas A. DeNardo

University of Rhode Island, ndenardo@uri.edu

Follow this and additional works at: https://digitalcommons.uri.edu/theses

\section{Recommended Citation}

DeNardo, Nicholas A., "Dynamic Collapse of Double Hull Composite Cylinders: Hydrostatic and ShockInitiated Implosion" (2017). Open Access Master's Theses. Paper 1075.

https://digitalcommons.uri.edu/theses/1075

This Thesis is brought to you for free and open access by DigitalCommons@URI. It has been accepted for inclusion in Open Access Master's Theses by an authorized administrator of DigitalCommons@URI. For more information, please contact digitalcommons-group@uri.edu. 
DYNAMIC COLLAPSE OF DOUBLE HULL COMPOSITE CYLINDERS:

HYDROSTATIC AND SHOCK-INITIATED IMPLOSION

BY

NICHOLAS A. DENARDO

A THESIS SUBMITTED IN PARTIAL FULFILLMENT OF THE REQUIREMENTS FOR THE DEGREE OF

MASTER OF SCIENCE

IN

MECHANICAL ENGINEERING AND APPLIED MECHANICS

UNIVERSITY OF RHODE ISLAND 


\section{MASTER OF SCIENCE THESIS}

OF

\section{NICHOLAS A. DENARDO}

\section{APPROVED:}

Thesis Committee:

Major Professor $\quad$ Arun Shukla
James M. LeBlanc
James Miller
Nasser H. Zawia
DEAN OF THE GRADUATE SCHOOL




\begin{abstract}
An experimental investigation of double-hull composite cylinders during underwater implosion is performed. Composite materials offer several unique advantages for underwater applications, including greater specific strength and stiffness than metals, as well as better corrosion resistance. Double hull composite structures, which feature a low density core between two facesheets of comparatively higher density, increase these benefits further by adding increased bending strength and acoustic attenuation. Despite these advantages, there exists a large knowledge gap with regards to the underwater implosion behavior of double hull composite structures. To that end, a series of experimental studies is performed to address said knowledge gaps and help provide fundamental understanding of the behavior of these structures during implosion.
\end{abstract}

First, the dynamic collapse of hollow and filled double hull composite cylinders is investigated experimentally. Carbon-fiber/epoxy double cylinders with and without parametrically-graded PVC foam cores in between are collapsed in a large-diameter pressure vessel, and dynamic pressure data is used in conjunction with underwater DIC to determine the effect of the double hull structure on implosion mechanics. Buckling initiation and overall collapse behavior of the specimen are studied, as well as the pressure pulse from the implosion released into the fluid. Incidents of the outer tube imploding but not the inner are reported, in addition to cases where both collapse. Results show heavier foam cores increase collapse pressure dramatically, and this increase in collapse pressure is predictively related to the mechanical and geometric properties of the foam cores themselves. Normalized dynamic pressure emitted from implosions is shown to occur in distinct phases, with an additional under- and overpressure region present if the inner tube collapses. When normalized for hydrostatic pressure, fluid impulses from various core densities are shown to remain constant. Energy flux from the implosions, presented as a percentage of available hydrostatic energy, is shown to increase as a function of core density. Increased foam crushing energy at higher core 
densities, and increased damage observed in post-mortem specimens from heavier cores, are identified as mechanisms responsible for these behaviors.

Second, an experimental study is performed which investigates the dynamic collapse of double hull composite cylinders under external hydrostatic pressure and shock loading. All experiments are performed underwater in a $2.1 \mathrm{~m}$ diameter semi-spherical pressure vessel that approximates a free-field environment, and Digital Image Correlation (DIC) is used in conjunction with blast transducers to study collapse mechanics. Specimens have carbon-fiber / epoxy facesheets and a PVC foam core that is removed for control in some instances, and are brought to $80 \%$ of their natural buckling pressure before being subjected to an underwater explosion (UNDEX) at varying standoff distances. Results show that double hull specimens implode below their natural collapse pressure when subject to explosive loading, but that the addition of the PVC foam core prevents implosion in some cases and substantially increases structural stability in others. The double hull configuration with foam core is also shown to emit significant pressure pulses despite the noisy environment of the pressure vessel. 


\section{ACKNOWLEDGMENTS}

The work in this thesis would not have been possible without the help and support of several individuals, to whom I am very grateful.

I would like to start by thanking my advisor, Professor Arun Shukla, whose support and mentorship have been invaluable to me. Dr. Shukla has taught me a great deal about science and engineering, as well as how to be successful as a professional. Dr. Shukla helps, challenges, and inspires his students, and I am better for knowing him.

In addition, I would like to thank Dr. James LeBlanc, Dr. James Miller, and Dr. Gopu Potty for agreeing to serve on my thesis committee.

I would also like to acknowledge and thank my peers at the Dynamic Photomechanics Lab, whose input and experience have been immensely beneficial to me: Erin Gauch, Carlos Javier, Shyamal Kishore, Emad Makki, Helio Matos, Prathmesh Parrikar, Michael Pinto, Koray Senol, Chris Shillings, Craig Tilton, and Jefferson Wright. I would also like to thank

Jim Byrnes, Jen Cerullo, Nancy Dubee, Dave Ferreira, Joe Gomez, Nancy Santucci, and the rest of the mechanical engineering department and staff at URI for their help throughout the years.

I would like to thank my family and friends, for their continued love and support.

Finally, I would like to acknowledge the Office of Naval Research and Dr. Yapa D.S. Rajapakse for providing financial support for this research under Grant No. N00014-10-10662. 


\section{PREFACE}

This thesis addresses gaps in understanding of the implosion behavior of double hull composite cylinders. Manuscript format is used. Two experimental studies are presented, on the hydrostatic and shock-initiated implosion of the aforementioned structures.

Chapter 1 investigates the hydrostatic implosion of double-hull composite cylinders. These structures have potentially extensive benefit for use in underwater structures, but their underwater collapse behavior has not been investigated extensively, and no experimental studies on the subject exist. To that end, a series of experiments is performed on cylinders of filament wound, carbon-fiber/epoxy facesheets with PVC foam cores of parametrically graded density. Mechanics unique to the collapse of these structures are observed for the first time, with different overarching collapse behaviors linked to changing system parameters. This paper is prepared for submission to Journal of the Mechanics and Physics of Solids.

Chapter 2 investigates the shock-initiated implosion of double-hull composite structures at subcritical hydrostatic pressures. It is shown that there is a gap in understanding with regards to the underwater buckling and implosion behavior of these structures under shock loading, though they have several unique benefits for applications where underwater shock loading may be a factor. This study seeks to address such gaps experimentally, by investigating the dynamics of carbon-fiber / epoxy tubes, with and without PVC foam cores, at varying magnitudes of shock loading. This paper is prepared for submission to Journal of the Mechanics and Physics of Solids. 


\section{TABLE OF CONTENTS}

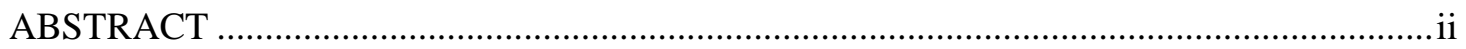

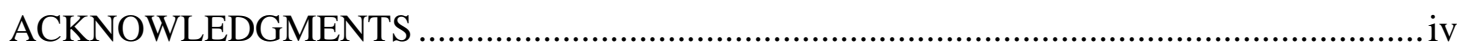

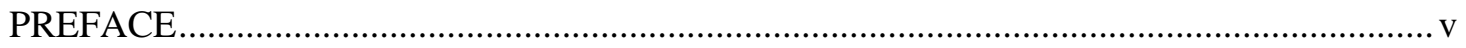

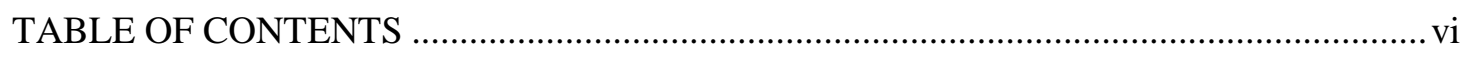

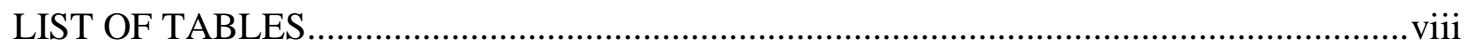

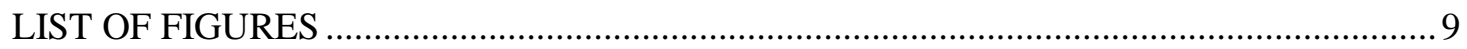

CHAPTER 1: DYNAMIC INSTABILITIES IN DOUBLE HULL COMPOSITE

CYLINDERS UNDER HYDROSTATIC PRESSURE .................................................... 1

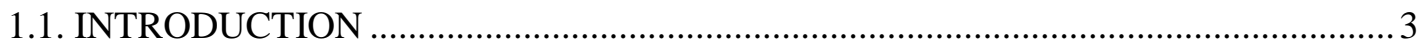

1.2. MATERIAL SELECTION AND SPECIMEN DESIGN ........................................... 6

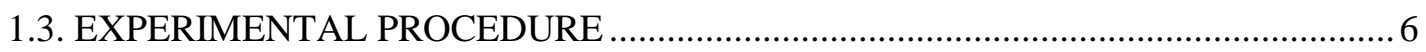

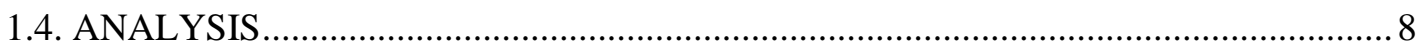

1.4.1. INCREASE IN COLLAPSE PRESSURE......................................................... 8

1.4.2. COMPOSITE THICKNESS EFFECTS ON COLLAPSE PRESSURE ................. 9

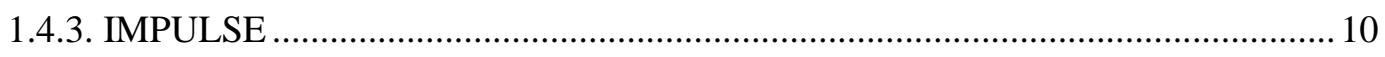

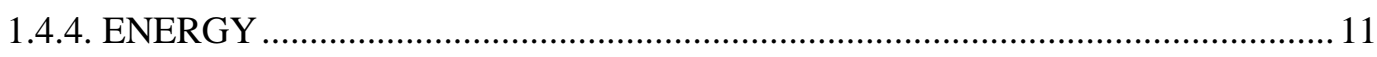

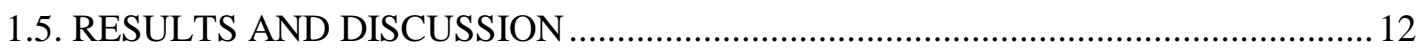

1.5.1. PREDICTING COLLAPSE PRESSURE......................................................... 12

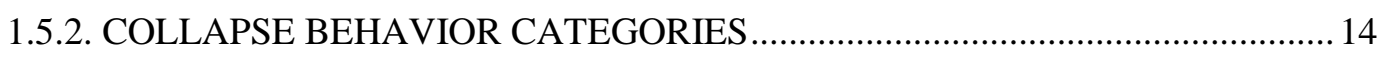

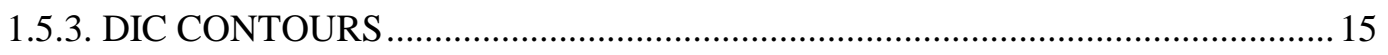

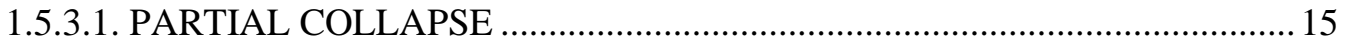

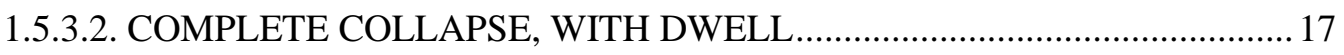

1.5.3.3. COMPLETE COLLAPSE, WITHOUT DWELL.......................................... 19

1.5.4. DOUBLE HULL IMPLOSION PRESSURE PULSE .........................................20 


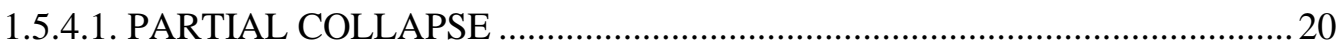

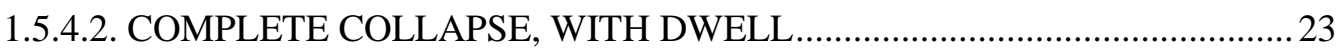

1.5.4.3. COMPLETE COLLAPSE, WITHOUT DWELL...........................................26

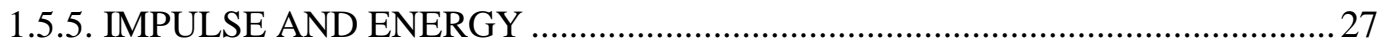

1.5.6. POST-MORTEM SPECIMEN EVALUATION ..................................................2 28

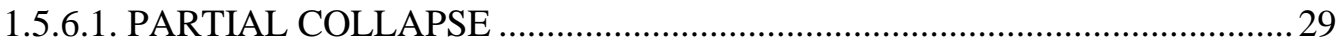

1.5.6.2. COMPLETE COLLAPSE, WITH DWELL .................................................... 30

1.5.6.3. COMPLETE COLLAPSE, WITHOUT DWELL............................................ 31

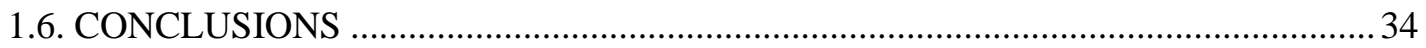

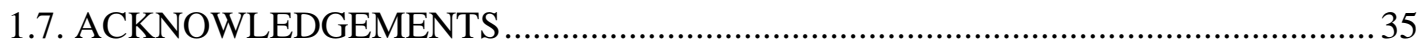

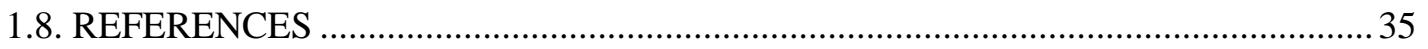

CHAPTER 2: SHOCK INITIATED IMPLOSION OF DOUBLE HULL COMPOSITE

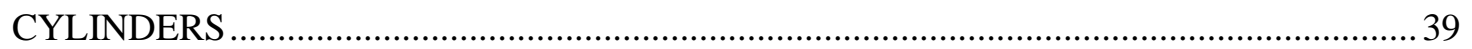

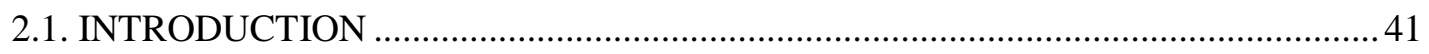

2.2. MATERIAL SELECTION AND SPECIMEN DESIGN ............................................ 43

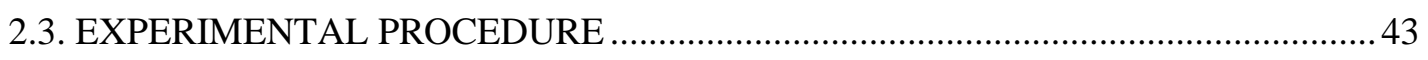

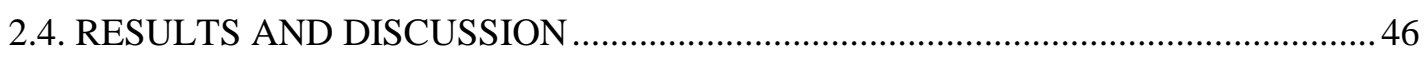

2.4.1. FEATURES OF THE PRESSURE HISTORY ................................................. 46

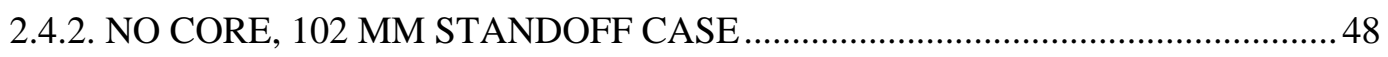

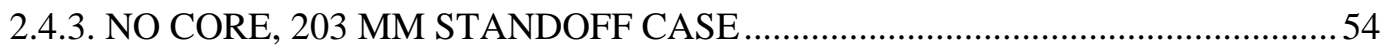

2.4.4. FOAM CORE, 102 MM STANDOFF CASE ….................................................59

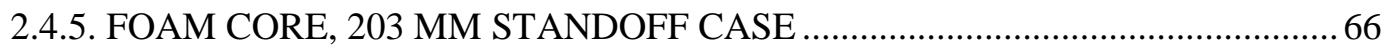

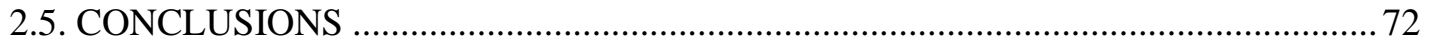

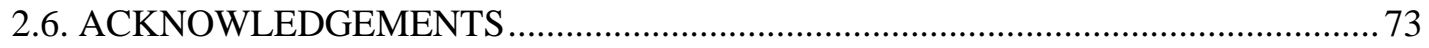

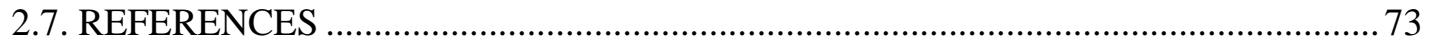




\section{LIST OF TABLES}

Table 1: Relevant quasi-static foam core properties and data ............................................. 13

Table 2: Summary of experiments performed …............................................................ 45 


\section{LIST OF FIGURES}

Figure 1: Experimental facility; (left) section through mid-height; (right) longitudinal section7 Figure 2: Increase in collapse pressure as a function of (A) foam core crushing strength; (B) foam core density .13

Figure 3: Example collapse mode shapes; (left) mode 2; (right) mode 3.

Figure 4: DIC data for outer tube only collapse cases; (A) dR/dt line extraction for no core case; (B) dR/dt line extraction for H35 core case; (C) [-2.003 ms] Image of H35 core specimen prior to buckling, with $\mathrm{dR}$ contours superimposed; (D) [-0.003 ms] complete core crushing at midpoint; (E)[0.417 ms] buckle propagation of collapsed outer tube against inner tube;

(F)[1.017 ms] completed collapse, with profile of uncollapsed inner tube visible;..... 17

Figure 5: DIC data for complete collapse with dwell cases; (A) dR/dt line extraction for H60 core case; (B) dR/dt line extraction for H100 core case; (C)[-1.0115 ms] Image of H100 core specimen prior to buckling, with $\mathrm{dR}$ contours superimposed; (D)[0.4818 ms] complete core crushing at midpoint; (E) $[0.8818 \mathrm{~ms}]$ end of buckle propagation of outer tube along inner tube; (F)[1.4685 ms] initiation of collapse of inner tube; (G)[2.0018 ms] completed collapse;

Figure 6: DIC data for complete collapse without dwell case; (A) dR/dt line extraction for H80 core case; (B)[-0.8160 ms] Image of H80 core specimen prior to buckling, with dr contours superimposed; (C)[0.1173 ms] complete crushing of foam core at midpoint; (D) $[0.6240 \mathrm{~ms}$ ] collapsing inner tube - note lack of buckle propagation of outer tube against inner; (E)[1.1040 ms] completed collapse;.

Figure 7: Normalized pressure pulses from cases where only the outer tube collapsed; (top) No-core case, measured at midsection; (bottom) H35 foam core case, measured at midsection; (inset, top left, both figures) outer tube buckling mode shape and sensor location...... .23 
Figure 8: Normalized pressure pulses from cases where the outer tube collapsed, dwelled briefly, then the inner tube collapsed; (top) H60 foam core case, measured at midsection; (bottom) H100 foam core case, measured at midsection; (inset, top left, each plot) outer tube buckling mode shape and sensor location.

Figure 9: Normalized pressure pulse from case where the outer tube and inner tube collapsed in a singular motion, measured at midsection; (inset, top left) outer tube buckling mode shape and sensor location

Figure 10: Implosion emissions as a function of core density showing (a) normalized underpressure impulse; (b) normalized waveform energy .28

Figure 11: H35 core post-mortem specimen photographs; (top left) isometric view; (bottom left) top view; (right) right view; (A) longitudinal through-thickness cracks in outer tube, corresponding to mode 3 buckling shape; (B) circumferential through-thickness cracks from endcaps; (C) Intact inner tube; (D) foam core crushing in mode 3 shape. 30

Figure 12: H100 core post-mortem specimen photographs; (top left) isometric view; (bottom left) front view; (right) right view; (A) longitudinal through-thickness cracks in outer tube, corresponding to mode 3 buckling shape; (B) Edge of through thickness tear, where the outer tube has completely cracked and folded under itself; (C) Delamination at tear edge; (D) Torn foam core; (E) Incomplete elastic recovery; (F) circumferential through-thickness cracking from endcap shear.

Figure 13: H80 core specimen post-mortem photographs; (top left) isometric view; (center left) front view; (bottom left) bottom view; (right) right view; (A) longitudinal cracking corresponding to lobes of mode 3 buckling shape; (B) center of fold where buckling directions of tubes aligned; (C) Through-thickness tearing of both the tubes and core corresponding to collapse of the inner tube; (D) Delamination and fiber pullout along tear edges; (E) Circumferential cracking from endcaps .33 
Figure 14: Schematic of buckling mode shapes in case where both tube collapse without a dwell; note collinear buckling direction of inner and outer tubes

Figure 15: Experimental setup; (left) top section view of pressure vessel through mid-height, showing high speed cameras, specimen, UNDEX, and lighting; (right) section view showing specimen and charge locations .44

Figure 16: Schematic of sensor position relative to specimen and charge locations .46

Figure 17: Centerpoint radial displacement data $(\mathrm{dR})$ for a no-core specimen with $102 \mathrm{~mm}$ standoff. .49

Figure 18: High speed imagery with DIC contours superimposed for a no-core specimen with $102 \mathrm{~mm}$ standoff. Letter-labels to the left of the images correspond to those in Figure 17. ...50 Figure 19: Pressure-time history for a no-core specimen with $102 \mathrm{~mm}$ standoff. Dynamic pressure is plotted, such that 0 on the vertical axis corresponds to ambient hydrostatic pressure.

Figure 20: Post-mortem photographs of a no-core specimen with $102 \mathrm{~mm}$ standoff; (i) top view of outer tube; (ii) back view of outer tube; (iii) back view of inner tube; (iv) bottom view of inner tube. .53

Figure 21: Centerpoint radial displacement (dR) data for the no-core case with $203 \mathrm{~mm}$ standoff .

Figure 22: High speed imagery with DIC contours superimposed for the no-core case, with $203 \mathrm{~mm}$ standoff. Letter-labels to the left of the images correspond to labels in Figure $21 \ldots . .56$ Figure 23: Pressure-time history for no-core case, with $203 \mathrm{~mm}$ standoff. Dynamic pressure is plotted, such that 0 on the vertical axis corresponds to ambient hydrostatic pressure.

Figure 24: Post-mortem photographs of a no-core specimen, with $203 \mathrm{~mm}$ standoff; (i) front view of outer tube; (ii) back view of outer tube; (iii) bottom view of outer tube; (iv) front view of inner tube; (v) bottom view of inner tube. .59 
Figure 25: Centerpoint radial displacement (dR) data for the H100 core case, with $102 \mathrm{~mm}$ standoff

Figure 26: High speed imagery with DIC contours superimposed for the H100 core case, with $102 \mathrm{~mm}$ standoff. Letter-labels to the left of the images correspond to labels in Figure 25.... 62 Figure 27: Pressure-time history for H100 core case, with 102 mm standoff; (top) pressure for duration of collapse; (bottom) inset detailing first $7.5 \mathrm{~ms}$ of pressure history; Dynamic pressure is plotted in both graphs, such that 0 on the vertical axis corresponds to ambient hydrostatic pressure

Figure 28: Post-mortem photographs of the foam core specimen with 102 mm standoff; (i) front view; (ii) back view; (iii) bottom view; (iv) side view .66

Figure 29: Centerpoint radial displacement (dR) data from the H100 core cases and a $203 \mathrm{~mm}$ standoff. The specimen did not implode in trial 1, plotted in red. The specimen did implode in trial 2, plotted in blue. Important stages of the collapse in trial 2 are labeled. .68

Figure 30: High speed imagery with DIC contours superimposed, from the H100 foam core specimen with $203 \mathrm{~mm}$ standoff. Letter-labels to the left of the images correspond to labels in Figure 29.

Figure 31: Pressure-time history from the foam core, $203 \mathrm{~mm}$ case; (top) pressure for the entire duration of the collapse; (bottom) pressure for the first $7.5 \mathrm{~ms}$, showing reflections and bubble pulses; Dynamic pressure is plotted, such that 0 corresponds to ambient hydrostatic pressure; data is taken from case where specimen imploded.

Figure 32: Post-mortem photographs of the foam-core specimens with $203 \mathrm{~mm}$ standoff; (i) front view; (ii) back view; (iii) bottom view; (iv) side view; (v) side view of specimen that did not implode .72 
CHAPTER 1: DYNAMIC INSTABILITIES IN DOUBLE HULL COMPOSITE CYLINDERS UNDER HYDROSTATIC PRESSURE

Prepared for submission to Journal of the Mechanics and Physics of Solids

By:

Nicholas DeNardo, Michael Pinto, and Arun Shukla*

Dynamic Photomechanics Laboratory

Deparment of Mechanical, Industrial, and Systems Engineering

University of Rhode Island, Kingston, RI 02881

*Corresponding author: shuklaa@egr.uri.edu, Phone: 401-874-2283, Fax: 401-874-2355 


\section{ABSTRACT}

The dynamic collapse of hollow and filled double hull composite cylinders is investigated experimentally. Carbon-fiber/epoxy double cylinders with and without parametrically-graded PVC foam cores in between are collapsed in a large-diameter pressure vessel, and dynamic pressure data is used in conjunction with underwater DIC to determine the effect of the double hull structure on implosion mechanics. Buckling initiation and overall collapse behavior of the specimen are studied, as well as the pressure pulse from the implosion released into the fluid. Incidents of the outer tube imploding but not the inner are reported, in addition to cases where both collapse. Results show heavier foam cores increase collapse pressure dramatically, and this increase in collapse pressure is predictively related to the mechanical and geometric properties of the foam cores themselves. Normalized dynamic pressure emitted from implosions is shown to occur in distinct phases, with an additional under- and overpressure region present if the inner tube collapses. When normalized for hydrostatic pressure, fluid impulses from various core densities are shown to remain constant. Energy flux from the implosions, presented as a percentage of available hydrostatic energy, is shown to increase as a function of core density. Increased foam crushing energy at higher core densities, and increased damage observed in post-mortem specimens from heavier cores, are identified as mechanisms responsible for these behaviors. 


\subsection{INTRODUCTION}

Implosion is a fluid-structure interaction problem that involves the buckling, collapse, and subsequent pressure pulse emission of an enclosed shell when external fluid pressure around the structure reaches critical value and the shell collapses dynamically. This process happens in distinct stages, with the first phase of instability initiation followed by a second phase in which the walls buckle inward at high velocities and local pressure in the surrounding fluid drops via Bernoulli's principle. After a point, these walls make contact with one another, and abruptly decelerate to zero velocity. As buckle propagation occurs, the sudden change in momentum of the walls simultaneously causes an immense pressure spike in the fluid, and a high pressure wave is released outward [1], [2].

Implosion has been studied for several decades, with early work in the field primarily focused on evaluating the acoustic pulses from deep sea implosions [3]-[5]. Following a series of high profile accidents and developing interest from the naval community, however, implosion research has been reinvigorated in recent years. In the first of these events, a photomultiplier tube at the Super-Kamiokande Neutrino Observatory imploded during filling, causing a chain reaction of pressure pulses that destroyed a total of 7000/11000 such tubes within the facility and cost an estimated $\$ 20$ million dollars of damage [6]. Later, the AUV Nereus imploded while on a deep-sea research dive off the coast of New Zealand. The vehicle had been expected to reach the deepest depths of the ocean consistently; its failure resulted in a substantial loss of confidence in the subsea engineering community, in addition to the monetary and opportunity cost of the vehicle itself [7]. Jointly, these accidents emphasize the need for increased understanding of the implosion phenomenon, in terms of both the bucklingbased initiation of implosion as well as prediction and mitigation of its associated pressure pulse. 
Several studies from the past decade partially address these gaps. Turner and Ambrico performed experimental and computational investigations of the implosion of both glass spheres and metal tubes, and were able to identify key stages in the implosion process, as well as develop effective computational models that agreed well with their experimental results [1], [2]. Farhat et al. investigated the implosion of metal cylinders, and demonstrated that changes in geometry affect both buckling pressure and collapse mode by performing wellcorroborated experimental and computational studies [8]. Ikeda et al. performed experiments on the effect of geometry of metal tubes on the emitted pressure pulse from implosion [9]. Gupta et al. performed an experimental investigation of implosion, and used high speed photography and digital image correlation to determine collapse velocities and displacements across the surface of the tube, and related that information to pressure pulse emission [10].

Composite materials have also been studied with regards to the implosion phenomenon. Because of their excellent strength- and stiffness-to-weight ratios, as well as their natural corrosion resistance, they make excellent candidates for marine engineering applications, including those where implosion is a matter for concern. In that vein, the buckling of composite cylinders has been studied by several authors analytically and computationally, in an effort to predict their buckling mode shapes and critical collapse pressures [11]-[16]. Additionally, Pinto et al. studied the implosion behavior of glass- and carbon-fiber composite tubes. This work included the performance of digital image correlation during the collapse process, and investigated both buckling behavior and pressure pulse mechanics [17], [18]. The mitigation of implosion pressure pulses via the application of polyurea coatings was also investigated [19].

That said, the previously mentioned works have only investigated the implosion of isotropic materials and classical composite laminates; there remains little work on the implosion of double hull-structured composite materials, where two facesheets of thin but 
strong material are concentrically assembled with a thick but comparatively low density core. Moreover, the work that does exist primarily focuses on the buckling of sandwich structures and doesn't address pressure pulse emission from the implosion process [20]-[26]. None of these studies include experimental verification of their analytical and computational results, and none address the effect of the sandwich construction on pressure pulse emission within the surrounding fluid.

The aim of this study is to experimentally investigate the implosion of double hull composite structures, considering both buckling performance, as well as pressure pulse analysis and mitigation. To most closely approximate the conditions of a submersible or other deep sea vehicle, cylindrical geometry will be investigated. Double hull composites have several unique advantages for this kind of application: in addition to the benefits of composite materials listed previously, double hull structures offer increased buckling resistance, excellent acoustic attenuation, and further increases in specific stiffness over monolayer composites [23].

This study marks the first time that the mechanics unique to a double hull implosion have ever been reported, with several key differences from the behavior of monolayer structures being observed. Double hull structures are found to emit "double pulses" during implosion wherein two distinct pressure pulses are registered, corresponding to the collapse of the outer and inner tubes, respectively. The facesheets are also found to collapse independently of one another, such that the inner tube may or may not survive the collapse of the outer tube, depending on external hydrostatic pressure. The outer tube is found to buckle and flatten against the inner tube, with a time delay sometimes occurring before the collapse of the inner tube, if it collapses at all. 


\subsection{MATERIAL SELECTION AND SPECIMEN DESIGN}

The specimens in this study use carbon-fiber/epoxy tubes manufactured by Rock West Composites (West Jordan, UT) for their inner and outer facesheets. The outer tube has a $[ \pm 15 / 0 / \pm 45 / \pm 15]$ layup, with a nominal $60.4 \mathrm{~mm}$ ID and $1.7 \mathrm{~mm}$ wall thickness. The inner tube has the same layup and nominal thickness, but a nominal ID of $38.6 \mathrm{~mm}$. Prior to assembly, the outer tube is painted by hand with a high-contrast, stochastic, black-and-white speckle pattern that covers half of its circumference and its entire length. During assembly, the tubes are mounted concentrically and sealed using aluminum endcaps such that their unsupported length is $279.4 \mathrm{~mm}$. In addition to being sealed from water, the tubes are also sealed between one another so that water may not enter the inner tube in the event that the outer tube fractures or its seal is otherwise broken.

The PVC foam cores used in the specimens are from the Divinycell $\mathrm{H}$ series of foams, as produced and provided by DIAB, Inc. (DeSoto, TX). Foam cores of different densities from this are parametrically graded across trials: experiments are performed with Divinycell $\mathrm{H} 35$, H60, H80, and H100 foam cores, as well as with the foam core removed. In all cases, the foam cores have a nominal $41.9 \mathrm{~mm}$ ID, and $9.2 \mathrm{~mm}$ thickness. The cores are machined from flat sheets by first creating small rings with the aforementioned radial dimensions. The rings are then stacked on top of each other during assembly to match the $279.4 \mathrm{~mm}$ unsupported length of the composite facesheets.

\subsection{EXPERIMENTAL PROCEDURE}

All experiments are performed using a semi-spherical pressure vessel of 2.1 meter diameter, with a maximum static pressure rating of $6.89 \mathrm{MPa}$, shown in Figure 1. The vessel is designed to maintain constant hydrostatic pressure through the collapse process, and has optical viewports mounted radially around its midsection for photography and lighting during 
experiments. Two high-speed cameras (Photron SA1, Photron USA, Inc., San Diego, CA) are mounted coaxially with the portholes of the tank, such that a stereoscopic viewing angle of $17^{\circ}$ is created toward the speckled surface of the double hull specimen after it is fixed within the vessel. This enables performance of underwater 3-D DIC in post processing, in the manner presented in [10], [17] and [18].

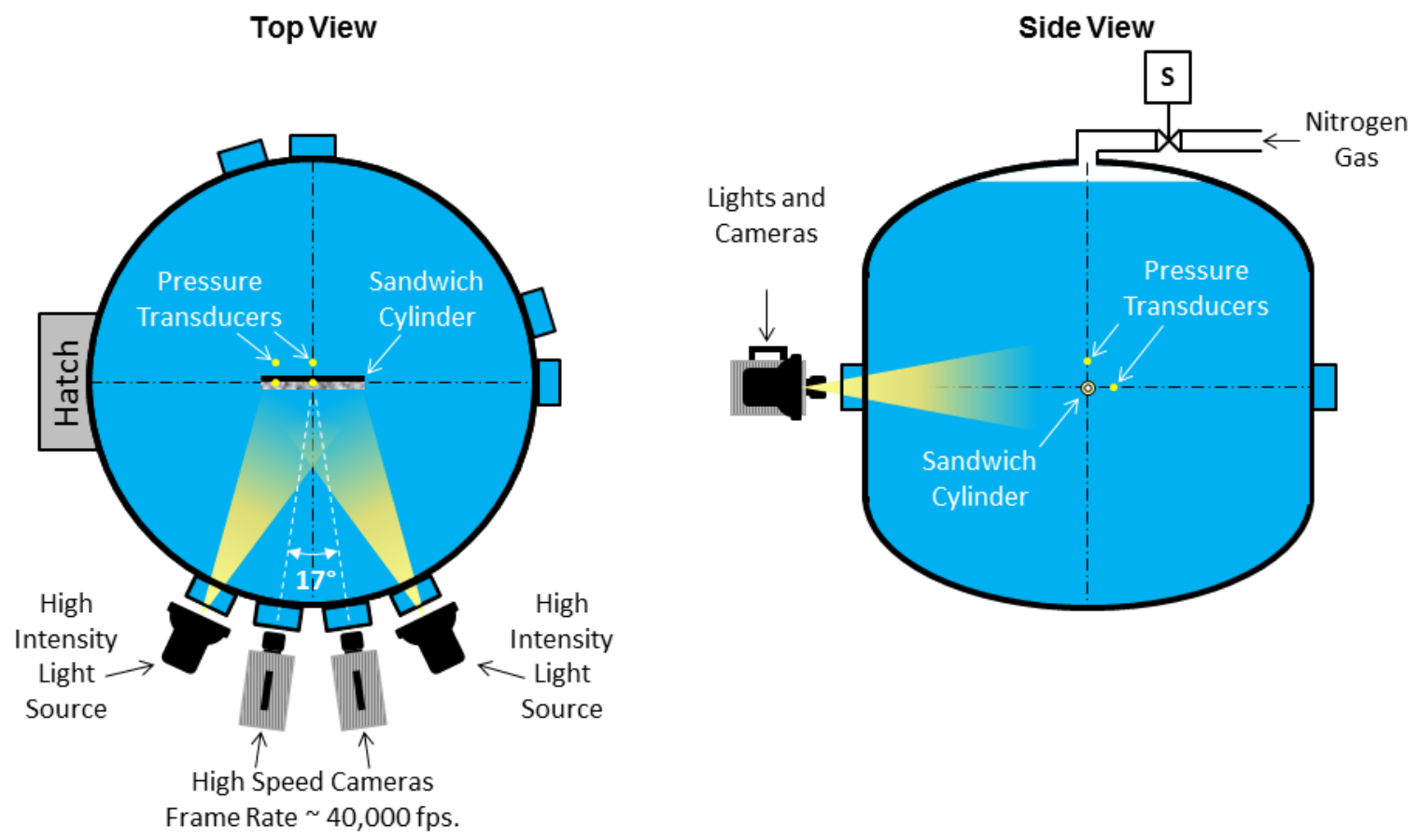

Figure 1: Experimental facility; (left) section through mid-height; (right) longitudinal section

To execute the experiments, specimens are mounted horizontally in the center of the vessel using thin steel cables that provide minimal acoustic reflections; the specimen is oriented such that the speckle pattern on the outer tube faces in the direction of the viewports and corresponding cameras. To monitor the pressure pulse emitted by the implosion, tourmaline high-pressure blast transducers (PCB 138A05, PCB Piezotronics, Inc., Depew, NY) are mounted above and behind the implodable on its center and ends. All sensors are mounted with their sensing elements at a nominal radial distance of $50 \mathrm{~mm}$ from the face of the outer tube, with those on the ends located at a longitudinal offset of $127 \mathrm{~mm}$ from the 
midsection of the tube. The amplified output from the pressure sensors is monitored using an Astro-Med Dash 8HF-HS portable data recorder (Astro-Med Inc., West Warwick, RI) at a sampling rate of $2 \mathrm{MHz}$. Once mounting is complete, the vessel is filled with filtered water, and sealed. Nitrogen gas is introduced to an air pocket at the top of the vessel to pressurize the fluid at a rate of approximately $0.083 \mathrm{MPa} / \mathrm{min}$. Once critical pressure is achieved and implosion occurs, the cameras and pressure sensors are simultaneously end-triggered and their data saved, such that image and pressure data are directly matched in time.

\subsection{ANALYSIS}

\subsubsection{INCREASE IN COLLAPSE PRESSURE}

The collapse pressure of double hull structures with a foam core increases with the stiffness of the foam. When listing collapse pressures in this study, only those of the outer tube are given. This allows for direct comparison between cases regardless of whether the inner tube collapses or not, and is used when listing all collapse pressures or changes thereof, unless otherwise noted.

In predicting the collapse pressures of double hull structures, it was decided to focus on the increase in collapse pressure of the tubes on account of the double hull structure, rather than absolute pressures. The increase in collapse pressure of a particular specimen is given by:

$$
\Delta P_{c r}=P_{c r}-P_{c r, 0}
$$

Where $\Delta \mathrm{P}_{\text {cr }}$ is the increase in collapse pressure of the outer tube due to the double hull structure, $\mathrm{P}_{\mathrm{cr}}$ is the experimentally measured collapse pressure of that specimen, and $\mathrm{P}_{\mathrm{cr}, \mathrm{o}}$ is the estimated collapse pressure of that same specimen if its foam core were to be removed. 


\subsubsection{COMPOSITE THICKNESS EFFECTS ON COLLAPSE PRESSURE}

In analyzing collapse pressure, it is necessary to account for thickness variation in the outer tubes: small inconsistencies in the manufacturing process of the tubes resulted in variation of average thickness by as much as $0.254 \mathrm{~mm}$, and the collapse pressures of composite tubes are sensitive to variations in thickness.

From literature, the following equation can be used to estimate the collapse pressure of a composite cylinder without a foam core [27]:

$$
P_{c r}=\frac{\gamma \sqrt{E_{1} E_{2}} t^{5 / 2}}{\left(1-\mu_{12} \mu_{21}\right)^{3 / 4} L R_{c}{ }^{1 / 2} R_{o}}\left(\frac{1}{1+\frac{\sqrt{E_{1} E_{2} I}}{R_{c} R_{o} t G}}\right)
$$

Where $\gamma$ is a constant that depends on geometry, $E_{1}$ and $E_{2}$ are the longitudinal and hoop moduli of the composite cylinder, $\mathrm{t}$ is average thickness, $\mu_{12}$ and $\mu_{21}$ are the anisotropic Poisson's ratios, $L$ is Length, $R_{c}$ is average cylinder radius, $R_{o}$ is outer cylinder radius, $I$ is moment of inertia about the centerline, and G is shear modulus. Equation (2) shows that critical collapse pressure scales by a factor of $t^{2.5}$. It follows that:

$$
\frac{P_{c r, 1}}{P_{c r, 2}}=\frac{t_{1}^{2.5}}{t_{2}^{2.5}}
$$

Where $\mathrm{P}_{\mathrm{cr}, 1}$ and $\mathrm{P}_{\mathrm{cr}, 2}$ are the collapse pressures of two similar tubes with different average thickness, and $t_{1}$ and $t_{2}$ are those thickness values. For the outer tubes used in this study, Equation (3) predicts the relationship between collapse pressures within $0.5 \%$ for the hollow

specimens. Equation (3) can be rearranged to predict the collapse pressure of the outer tube of a given specimen with its core removed:

$$
P_{c r, 0}=\frac{t_{0}^{2.5}}{t_{r e f}{ }^{2.5}} P_{c r, r e f}
$$

Where $\mathrm{P}_{\mathrm{cr}, \mathrm{o}}$ is the predicted collapse pressure of the outer tube of a given specimen, and $\mathrm{t}_{\mathrm{o}}$ is that specimen's measured thickness. $\mathrm{P}_{\mathrm{cr}, \mathrm{ref}}$ and $\mathrm{t}_{\mathrm{ref}}$ are the collapse pressure and thickness of 
the reference specimens in this study, which had their cores removed when experimented on. Thus the change in the collapse pressure of a double hull specimen is given by:

$$
\Delta P_{c r}=P_{c r}-\frac{t_{0}^{2.5}}{t_{r e f}{ }^{2.5}} P_{c r, r e f}
$$

Careful thickness measurements of the outer tube were needed to make accurate predictions of the collapse pressure of the double hull structure using Eq. (5).

$\Delta \mathrm{P}_{\mathrm{cr}}$ is critical in evaluating the true effect of core material on collapse pressure, as discussed later in Section 1.5.1. This is a very important quantity in the design of subsea vehicles, where avoiding collapse is paramount.

\subsubsection{IMPULSE}

The area under the pressure-time curve is often of more importance in terms of measuring implosion damage potential than the magnitude of the pressure alone. To that end, the following equation is employed [28]:

$$
I=\int_{0}^{t} d P d t
$$

Where I is the impulse per unit area imparted to the water by the wavefront, $\mathrm{dP}$ is dynamic pressure, and $t$ is an arbitrary time of interest. In order to simplify the problem, the total impulse is calculated here for the underpressure regions only, under the assumption that the impulse for the overpressure region will be equal in magnitude, as discussed in [1], [8], [10].

It will be shown in the results section of this paper that some double hull structures release "double pulses" during implosion wherein two distinct pressure pulses are emitted, each corresponding to the collapse of the outer and inner tubes. In such cases, the following formula is used: 


$$
I_{\text {total }}=\int_{0}^{t_{1}} d P d t+\int_{t_{2}}^{t_{3}} d P d t
$$

Where $\mathrm{I}_{\text {total }}$ is the total impulse per unit area of the double hull structure's collapse, $\mathrm{t}_{1}$ is the time at which the first underpressure region crosses the $t$-axis, $t_{2}$ is the time at which the second underpressure region begins as the pressure traces crosses below the t-axis again, and $t_{3}$ is the time at which the second underpressure region ends as the pressure trace crosses the taxis a third time.

In order to compare the impulse behavior of the various foam cores, it is necessary to account for differences in collapse pressure caused by differing core strengths. The following formula is used, which normalizes the impulse values from Equation (7) with respect to collapse pressure:

$$
I_{\text {norm }}=\frac{\int_{0}^{t_{1}} d P d t+\int_{t_{2}}^{t_{3}} d P d t}{\int_{0}^{t_{1}} P_{c r} d t+\int_{t_{2}}^{t_{3}} P_{c r} d t}
$$

Here, $\mathrm{I}_{\text {norm }}$ is the total impulse per unit area of the wavefront, normalized by an impulse term associated with the collapse pressure of the specimen in question. Generally, the impulse of an implosion scales with the ambient hydrostatic pressure at which the implosion occurred. Equation (8) removes this effect via normalization, and allows for direct comparison of impulse between cases with different collapse pressures.

\subsubsection{ENERGY}

An acoustic energy flux analysis is also performed to measure implosion damage potential, where the afterflow energy flux through a surface some arbitrary distance from the event is given by [29]:

$$
E_{F}=\frac{I_{\text {total }}^{2}}{2 \rho_{0} R_{S}}
$$


Where $E_{F}$ is acoustic energy flux, $\rho_{0}$ is the density of the fluid, and $R_{s}$ is the distance of the sensor from the surface of the collapsing tube. Assuming a spherical pressure wave, the energy flux given by Equation (9) can be multiplied by the surface area of a sphere of radius equivalent to the standoff distance of the sensor to yield the total afterflow energy of the implosion pulse:

$$
E_{A}=E_{F}\left(4 \pi R_{S}^{2}\right)
$$

To compare directly between cases with differing collapse pressures, it is necessary to normalize this value with available hydrostatic energy:

$$
E_{\text {norm }}=\frac{E_{A}}{E_{H}}
$$

Where $\mathrm{E}_{\mathrm{H}}$ is available hydrostatic energy prior to collapse, given by:

$$
E_{H}=P_{c r}\left(\Delta V_{\text {implosion }}\right)
$$

and $\Delta \mathrm{V}_{\text {implosion }}$ is the difference in displaced fluid volume before and after the implosion.

\subsection{RESULTS AND DISCUSSION}

\subsubsection{PREDICTING COLLAPSE PRESSURE}

It is important to be able to predict the buckling behavior of a double hull structure as a function of material and geometrical properties. To that end, a series of experiments were performed to determine the mechanical properties of the foam core materials (Table 1)[30]. Comparting the stress-strain curves from the tests to the maximum compressive strain in the core immediately prior to buckling (Table 1), it can be seen that buckling initiation always occurred in the foam-crushing region of the stress-strain curve. Plotting the measured crushing strengths of the foams against the $\Delta \mathrm{P}_{\mathrm{cr}}$ values measured previously, a linear trend is observed in Figure 2A, intersecting the origin and having a nondimensional slope of 2.6. This implies that for the given core geometry, it would be possible to find an even higher strength 
core than those studied here, and that applying such a core in the specimen would very likely increase buckling strength along the line in Figure 2A. Note that predeformation prior to buckling is sensitive to small irregularities in the geometry of the cylinders, so a trend is not observed between predeformation and core density in Table 1.

\begin{tabular}{cccc}
\hline Foam Name & $\begin{array}{c}\text { Measured Density } \\
\left(\mathbf{k g} / \mathbf{m}^{\mathbf{3}}\right)\end{array}$ & $\begin{array}{c}\text { Measured In-Plane } \\
\text { Crushing Strength } \\
(\mathrm{MPa})\end{array}$ & $\begin{array}{c}\text { Predeformation } \\
\text { Strain at Buckle } \\
\text { Initiation } \\
\mathbf{( \% )}\end{array}$ \\
\hline H35 & 38 & $0.228 \pm 0.008$ & $10.5 \pm 0.9$ \\
H60 & 60 & $0.445 \pm 0.015$ & $20.0 \pm 3.7$ \\
H80 & 80 & $0.653 \pm 0.018$ & $11.1 \pm 0.4$ \\
H100 & 100 & $0.967 \pm 0.044$ & $18.7 \pm 6.0$ \\
\hline
\end{tabular}

Table 1: Relevant quasi-static foam core properties and data

Plotting $\Delta \mathrm{P}_{\mathrm{cr}}$ values versus the measured density of each foam core (Table 1) gives the data shown in Figure 2B. The trend is nonlinear for this series of foams. This is noteworthy from an applications perspective because it is often desired to minimize the weight of underwater vehicles. This means that the mass-efficiency of the core increases with density for this series of foams, such that higher density cores are both stronger and more efficient per unit mass.

(A)

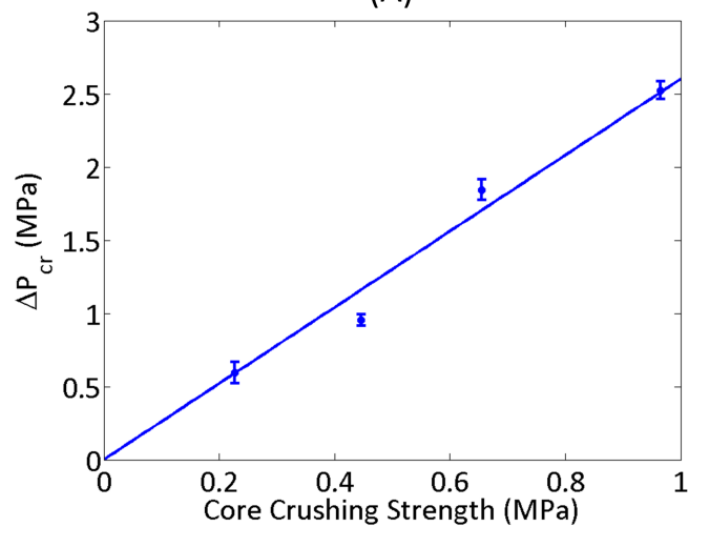

(B)

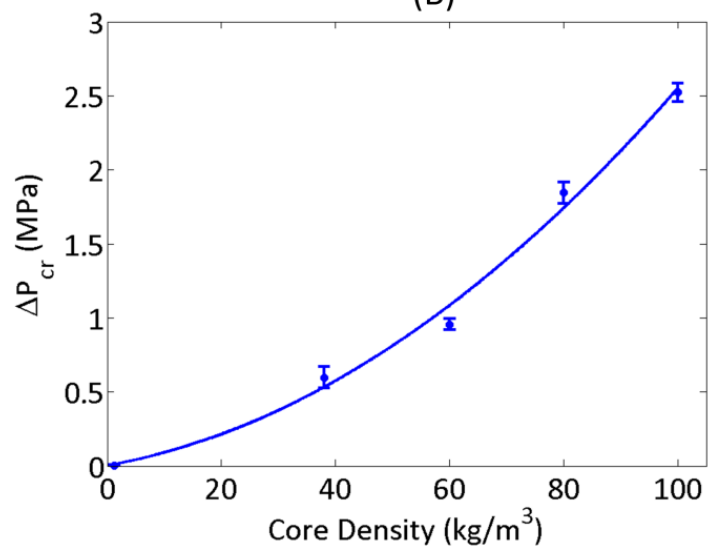

Figure 2: Increase in collapse pressure as a function of (A) foam core crushing strength; (B) foam core density 


\subsubsection{COLLAPSE BEHAVIOR CATEGORIES}

Three overarching behaviors were observed in the collapse of the double hull specimens. In 1), the outer tube collapsed and crushed the foam core but the inner tube did not collapse. In 2), the outer tube collapsed and crushed the foam core, after which there was a brief dwell time before the inner tube collapsed. In 3), the outer tube collapsed, crushed the foam core, and collapsed the inner tube in a singular motion, with no dwell in between.

The outer tubes in this study collapsed in mode 3 , whereas the inner tubes collapsed in an asymmetrical mode 2, if they collapsed at all (Figure 3). In all cases where the inner tube collapsed, the outer tube collapsed first, then remained crushed against the surface of the inner during the latter's collapse, conforming to its shape. In behaviors 1) and 2), the outer tubes formed around the shape of the inner tube, rendering the inner's shape clearly visible; there was not time for this to occur when the inner and outer tubes collapsed in a singular motion.
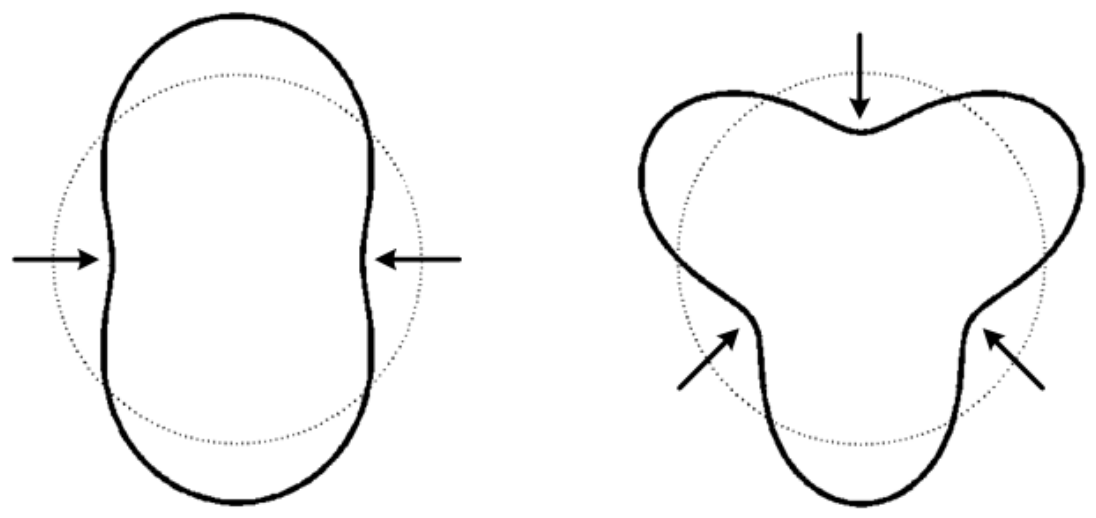

Figure 3: Example collapse mode shapes; (left) mode 2; (right) mode 3

The difference in collapse mode between the inner and outer tubes had no effect on the instability of the inner tube: collapse pressure of the inner tube was the dominant factor. The addition of a core increased the collapse pressure of the outer tube, sometimes to levels above that of the inner tube. The collapse pressure of the outer tube had to be higher than that 
of the inner tube (inner tube collapse pressure is approximately $2.4 \mathrm{MPa}$ ) for the inner tube to collapse.

Detailed results from each case are presented here, with data from similar collapse behaviors grouped together to enable comparison.

\subsubsection{DIC CONTOURS}

DIC was utilized to obtain velocity and position data for the imploding cylinder to provide insight into the collapse mechanics of the double hull structure. Radial velocity data was extracted from a line spanning the half-length of the tube, such that a longitudinal position of 0 corresponds to the tube's center. This data was taken from the duration of the collapse, allowing for comparison in time and longitudinal position. Images of the specimens at key stages of its collapse were also used in conjunction with DIC contours of radial displacement to gain further understanding of collapse mechanics.

\subsubsection{PARTIAL COLLAPSE}

Figure 4 (A) and (B) show velocity contours for cases where the outer tube collapsed and the inner did not. Both cases demonstrate this overarching behavior, though there is no foam core in (A) and there is one in (B). Typically during implosion, wall contact occurs first at the center, and then propagates longitudinally in a phase commonly referred to as buckle propagation, as has been reported in [10], [17], [18]. The same behavior can be seen here, though in this case wall contact is made between the outer and inner tubes, with the crushed foam core between the two. The center of the tube registers a velocity first, reaching a maximum of about $12 \mathrm{~m} / \mathrm{s}$ then dropping off to 0 when wall contact occurs. Following that, buckle propagation is observed as radial velocities of approximately $12 \mathrm{~m} / \mathrm{s}$ toward the center of the tube spread along the length of the tube in time, then drop to zero as wall contact is 
made at greater positions along the length of the tube. The result is a half-crescent shape that is curved to the right in each contour. The highest radial velocities are measured near the endcaps in both cases: this is because the slope of the buckle increases as it propagates along the length of the tube, leading to dramatically higher radial velocities near the end of the tube [Figure $4(\mathrm{C})$ through $(\mathrm{F})$ ]. Similar behavior has been observed in aluminum tubes [10]. Also of note are the higher overall radial velocities in (B), where those seen during buckle propagation are approximately $15 \mathrm{~m} / \mathrm{s}$. This is because collapse pressure in (B) is $0.9 \mathrm{MPa}$ higher than in (A), a difference of $64.3 \%$. 
(A) No Core $\mathrm{dR} / \mathrm{dt}$ Line Extraction, $\mathrm{P}_{\mathrm{cr}}=1.40 \mathrm{MPa}$

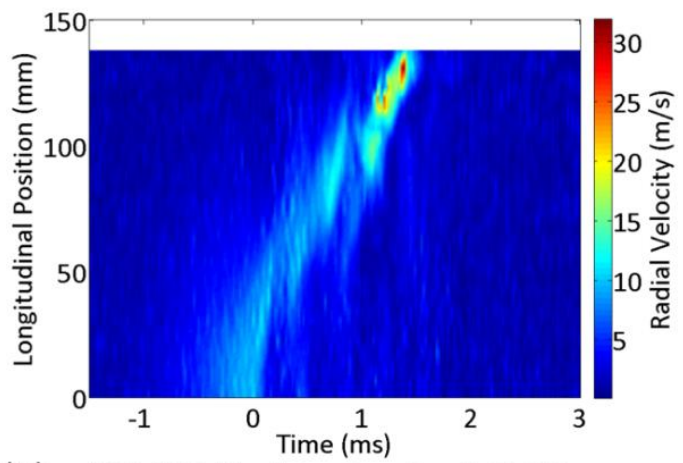

(B) $\quad \mathrm{H} 35 \mathrm{dR} / \mathrm{dt}$ Line Extraction, $\mathrm{P}_{\mathrm{cr}}=2.30 \mathrm{MPa}$
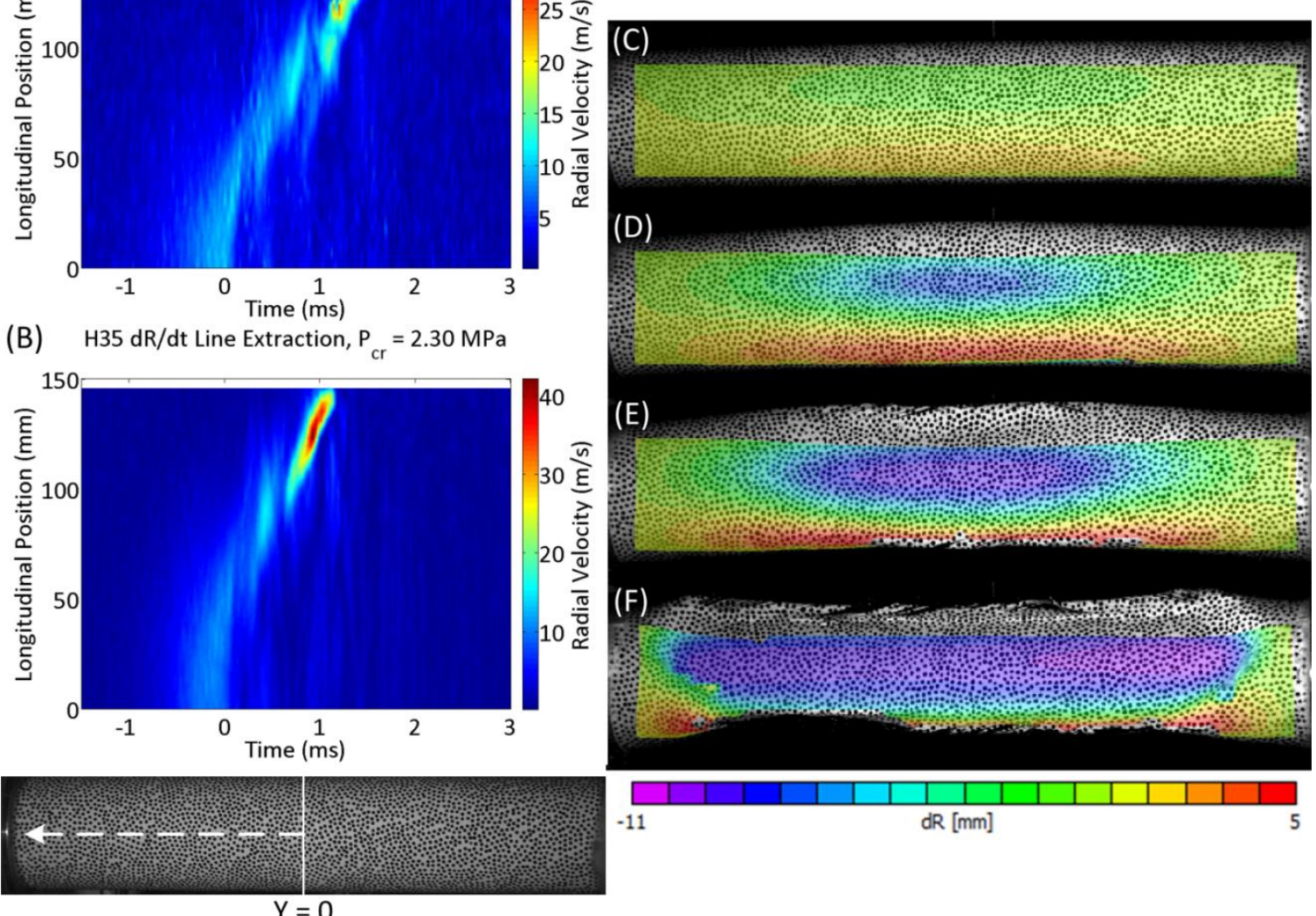

$(\mathrm{E})$

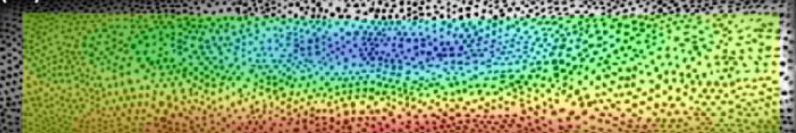

(F)

$\mathrm{dR} / \mathrm{dt}$ data extracted along dashed white line

Figure 4: DIC data for outer tube only collapse cases; (A) $d R / d t$ line extraction for no core case; $(B) d R / d t$ line extraction for H35 core case; (C)[-2.003 ms] Image of H35 core specimen prior to buckling, with dR contours superimposed; $(D)[-0.003 \mathrm{~ms}]$ complete core crushing at midpoint; (E)[0.417 ms] buckle propagation of collapsed outer tube against inner tube; $(F)[1.017 \mathrm{~ms}]$ completed collapse, with profile of uncollapsed inner tube visible;

\subsubsection{COMPLETE COLLAPSE, WITH DWELL}

Figure 5 (A) and (B) show velocity contours for cases where the outer tube collapsed, a brief dwell occurred, and then the inner tube collapsed. Here, the outer tube collapses with very similar mechanics to those seen in the previous section, exhibiting the same crescent shape seen in the velocity plots, with highest velocities at the endcaps. The inner tube demonstrates different collapse mechanics however, as it exhibits constant collapse velocities along its length, and does not undergo buckle propagation. This can be seen in the figure from 
around time $1.0 \mathrm{~ms}$ onwards in (A), and $1.3 \mathrm{~ms}$ in (B). In each instance, similar velocities occur along the tube length, with the result being a vertical line of high velocity instead of the half-crescent shape common to buckle propagation.

The collapse of the inner tube happens more slowly in (A) than in (B). In the H60 case, the inner tube implodes with velocities of $10-12 \mathrm{~m} / \mathrm{s}$ consistently being registered along the length of the tube, whereas in the H100 case, velocities are commonly 20-25 m/s along the length of the tube and occasionally reach as high as $30 \mathrm{~m} / \mathrm{s}$. Maximum velocities in (A) are also lower than those in (B), with the former demonstrating peak velocities of approximately $35 \mathrm{~m} / \mathrm{s}$ while the latter shows about $45 \mathrm{~m} / \mathrm{s}$. This is because collapse pressure in (B) is 1.74 MPa higher than in (A), a difference of $67.7 \%$.

Total collapse duration for the H60 specimen [Figure 4 (A)] is $3 \mathrm{~ms}$, greater than that for any other case. This occurs because the ratio between hydrostatic pressure and inner tube collapse pressure is about 1.1 in the H60 case, while being 1.7 for the H100 case. In the former, the ratio is small enough that the pressure exerted on the inner tube during the dwell takes longer to overwhelm it, so it doesn't collapse until about $1.5 \mathrm{~ms}$ after the implosion of the outer tube. Because the ratio is much higher for the $\mathrm{H} 100$ case, the duration of the dwell time is reduced, and the inner tube implosion begins about $1 \mathrm{~ms}$ after the implosion of the outer tube. For foam cores of lower strength, the outer/inner $\mathrm{P}_{\mathrm{cr}}$ ratio does not exceed 1, so the inner tube does not collapse. Because the ratio is just over 1 for the $\mathrm{H} 60$ specimens, that case features the longest dwell time.

The uniform longitudinal collapse of the inner tube is likely due to material damage in the inner tube causing an asymmetric collapse (visible from post-mortem specimens) that does not comply with the modal symmetry given by structural stability theory [31], [32]. 
(A) $\mathrm{H} 60 \mathrm{dR} / \mathrm{dt}$ Line Extraction, $\mathrm{P}_{\mathrm{cr}}=2.57 \mathrm{MPa}$

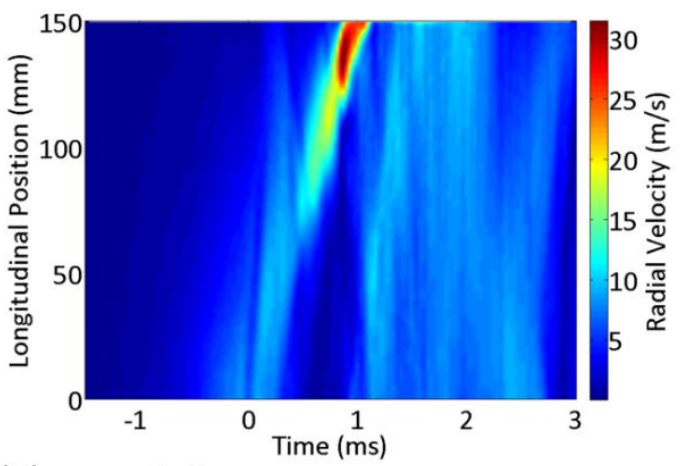

(B) $\mathrm{H} 100 \mathrm{dR} / \mathrm{dt}$ Line Extraction, $\mathrm{P}_{\mathrm{cr}}=4.31 \mathrm{MPa}$

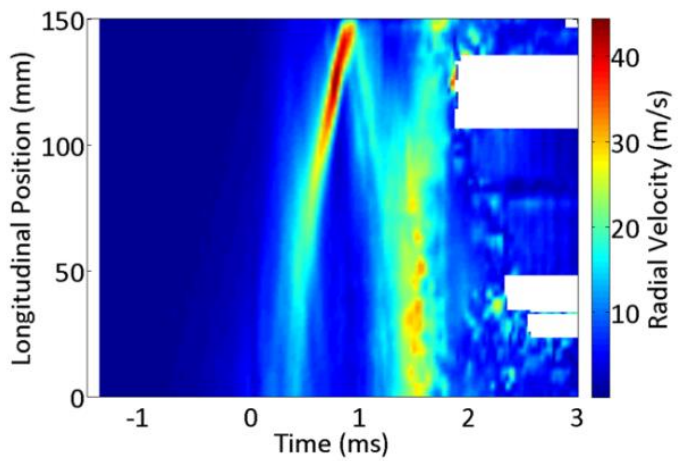

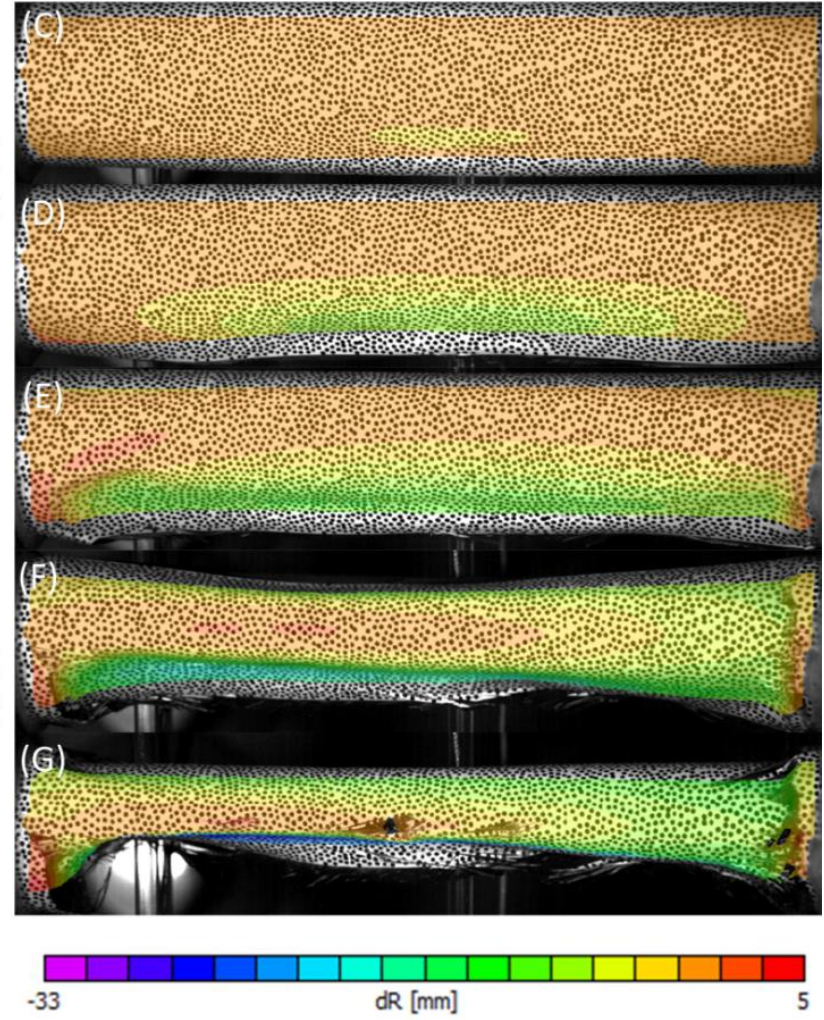

$-33$

Figure 5: DIC data for complete collapse with dwell cases; (A) dR/dt line extraction for $H 60$ core case; $(B) d R / d t$ line extraction for H100 core case; $(C)[-1.0115 \mathrm{~ms}]$ Image of H100 core specimen prior to buckling, with dR contours superimposed; $(D)[0.4818 \mathrm{~ms}]$ complete core crushing at midpoint; $(E)[0.8818 \mathrm{~ms}]$ end of buckle propagation of outer tube along inner tube; $(F)[1.4685 \mathrm{~ms}]$ initiation of collapse of inner tube; $(G)[2.0018 \mathrm{~ms}]$ completed collapse;

\subsubsection{COMPLETE COLLAPSE, WITHOUT DWELL}

Figure 6 (A) shows a velocity contour for the case where the outer tube collapses on the inner in a singular motion with no time delay in between. This type of collapse happens when the natural buckling modes of the inner and outer tubes align with one another, described in Section 1.5.6.3.

A unique feature of (A) is that maximum collapse velocity is on the order of $60 \mathrm{~m} / \mathrm{s}$, at least $50 \%$ higher than that seen in other cases. This velocity is located along the midsection of the tube, similar to the inner tube collapse mechanics described in Section 1.5.3.2. These velocities are achievable because, without the dwell observed in other cases, the pressure in the fluid continues to accelerate the structure inward through the duration of the structure's 
motion. Additionally, uniform high velocities are seen to occur along the length of the structure in time as the inner tube collapses, in much the same manner as described in the previous section. These similarities occur despite the removal of the dwell period. This implosion is also the fastest of all cases, with a total duration of $1.4 \mathrm{~ms}$.

(A) $\mathrm{H} 80 \mathrm{dR} / \mathrm{dt}$ Line Extraction, $\mathrm{P}_{\mathrm{cr}}=3.76 \mathrm{MPa}$

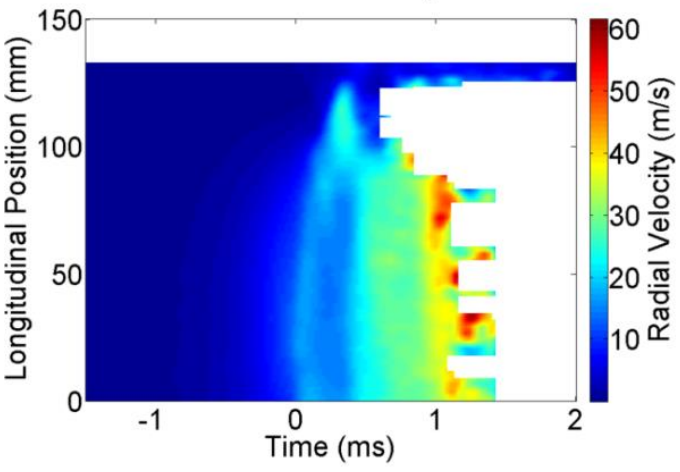

\section{(B)}

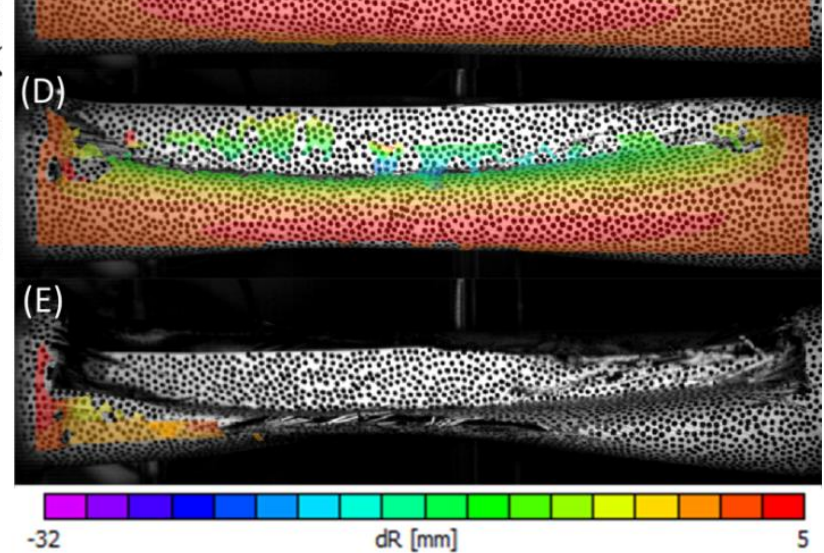

Figure 6: DIC data for complete collapse without dwell case; (A) dR/dt line extraction for H80 core case; (B)[-0.8160 ms] Image of H80 core specimen prior to buckling, with $\mathrm{dr}$ contours superimposed; $(C)[0.1173 \mathrm{~ms}]$ complete crushing of foam core at midpoint; (D) $[0.6240 \mathrm{~ms}]$ collapsing inner tube - note lack of buckle propagation of outer tube against inner; $(E)[1.1040 \mathrm{~ms}]$ completed collapse;

\subsubsection{DOUBLE HULL IMPLOSION PRESSURE PULSE}

\subsubsection{PARTIAL COLLAPSE}

Figure 7 shows the pressure pulse emitted in cases where only the outer tube collapses. Following buckling initiation at (A), there is a relatively smooth underpressure region until time 0 at (B), defined as the point at which matrix cracking begins in the tube. Defining the onset of matrix cracking in the outer tube as time 0 is convenient for composite double hull tubes, because it consistently occurs at similar radial deflections between cases, 
whereas complete foam crushing and wall contact can vary depending on foam core density. Crack initiation at (B) results in high frequency variations in pressure being introduced to the signal, as well as a drop in pressure immediately after cracking begins. At this point, the inner tube is still moving inwards radially, but eventually stops at $(\mathrm{C})$ : in the no-core case, this corresponds to wall contact, and in the H35 case, this corresponds to complete crushing of the foam core against the inner tube. After this point, the pressure in the fluid rapidly increases to a maximum at (D), which is concurrent with the collapsed zone of the buckle spreading outward. The pressure spike occurs on account of the sudden change in momentum of the fluid.

The characteristics of the pressure pulse seen for the double hull cylinders are similar to what has been reported in the literature for monolayer composite structures, but the "peakiness" of the behavior, as well as the maximum dynamic overpressure from the implosion, are reduced substantially in this configuration compared to the single-cylinder configuration of similar dimensions reported in [17]. This reduction in overpressure is due to the reduced potential energy of the event, shown with Equation (12): when the inner tube survives, the change in volume $\Delta \mathrm{V}_{\text {implosion }}$ from implosion is reduced, and the less energetic event results in measurable reductions in waveform amplitude. Additionally, the outer tubes in this study collapse entirely in a mode 3 shape, while the tubes in [17] initiate collapse in mode 3 but finish their collapse in mode 2. In this study, the presence of the inner tube prevents the dynamic mode change. Because of the 3-lobe shape here, one of the valleys collapses against the inner tube first, while the other two lobes wrap around the tube.

Displaced fluid volume continues to be reduced by this action, absorbing energy. The result is that the high-frequency pressure pulse observed in the single tube configuration is largely eliminated. 
In the H35 case, shown on the bottom of Figure 7, the presence of the foam core causes energy absorption from cell crushing, and prevents outright wall contact; instead, the foam core densifies to a point where it cannot be crushed more, and a quasi-wall contact is made. This causes a less abrupt change in fluid momentum which, combined with the aforementioned factors, reduces frequency and amplitude in the dynamic overpressure signal as compared with that of the reference. 

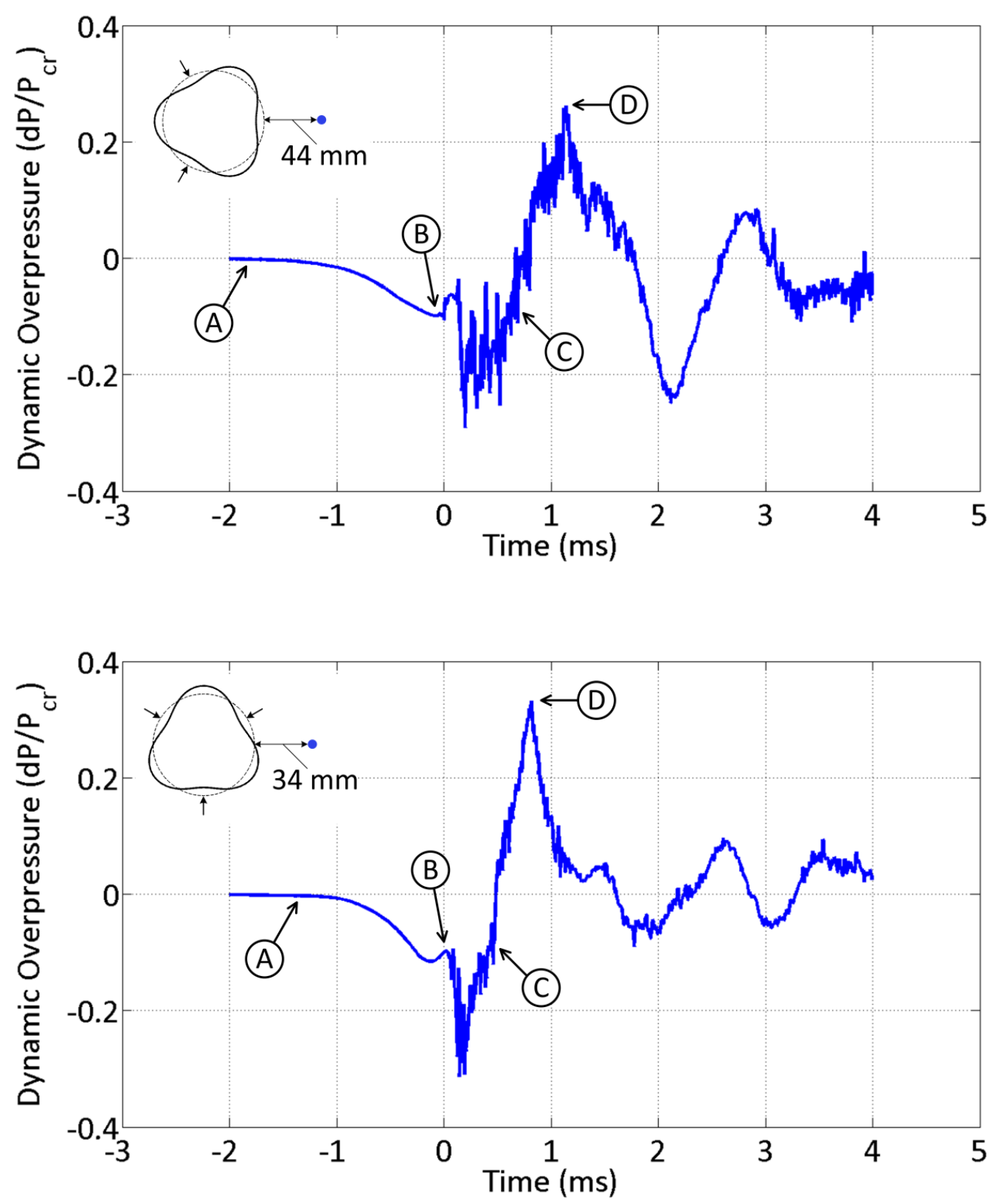

Figure 7: Normalized pressure pulses from cases where only the outer tube collapsed; (top) No-core case, measured at midsection; (bottom) H35 foam core case, measured at midsection; (inset, top left, both figures) outer tube buckling mode shape and sensor location

\subsubsection{COMPLETE COLLAPSE, WITH DWELL}

Figure 8 shows the pressure pulse recorded in cases where the outer tube collapses, a brief dwell occurs, and then the inner tube collapses. Here, buckling initiation of the outer 
tube occurs at (A), followed by a smooth underpressure region that exists until the onset of matrix cracking and associated drop in fluid pressure at (B). The underpressure region then continues until (C), where the pressure trace crosses the t-axis and an initial over-pressure corresponding to the collapse of the outer tube against the inner is recorded at (D). Following that, the inner tube begins to buckle because the hydrostatic pressure is greater than it can survive on its own. What follows is a secondary implosion pulse corresponding to the collapse of the inner tube, with a new underpressure region in the pressure signal being created at $(\mathrm{E})$. At $(\mathrm{F})$, there is a spike in pressure which corresponds to the development of damage in the inner tube as it collapses. The underpressure region continues until (G), where the inner tube makes wall contact with itself, and a secondary pressure peak is created which exceeds that of the first in amplitude.

In the H100 case, the amplitude of the first pressure spike is much lower than that of the H60 case, because more energy is absorbed through core compressive strain during implosion. This is because of the higher modulus and crushing strength of the H100 foam. However, the secondary spike is of much greater amplitude in the H100 case. This is because collapse pressure is substantially higher, for greater $\mathrm{E}_{\mathrm{H}}$. The foam core absorbs relatively little energy during the collapse of the inner tube because it is already crushed, so its mitigating effects are minimized during that portion of the collapse. Finally, the time delay between the inner- and outer-tube pulses is greater for the H60 case than any other. This is because of the uniquely long dwell time for the H60 case discussed in Section 1.5.3.2. 

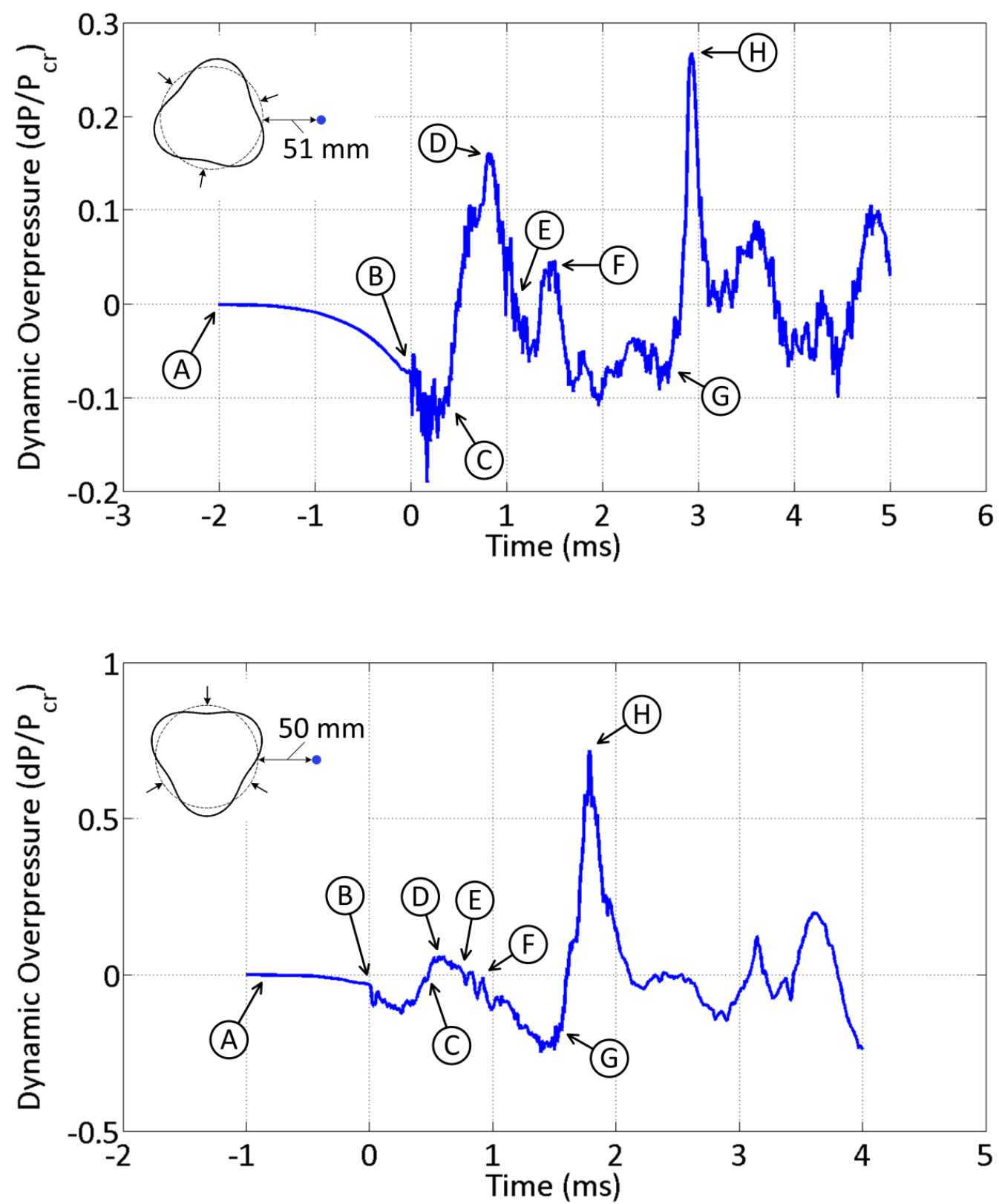

Figure 8: Normalized pressure pulses from cases where the outer tube collapsed, dwelled briefly, then the inner tube collapsed; (top) H60 foam core case, measured at midsection; (bottom) H100 foam core case, measured at midsection; (inset, top left, each plot) outer tube buckling mode shape and sensor location 


\subsubsection{COMPLETE COLLAPSE, WITHOUT DWELL}

Figure 9 shows the pressure pulse emitted when the inner and outer tubes collapse in a singular motion. At (A), buckling initiation occurs, followed by a smooth underpressure region until (B), where extensive damage begins in the outer tube. As the inner tube begins to collapse, a small spike in pressure is seen at (C), likely corresponding to the development of damage in the inner tube. At (D), the inner tube makes wall contact with itself, and a large pressure spike is registered at $(\mathrm{E})$.

The pressure pulse of a straight-through collapse appears qualitatively similar to that of the outer tube only collapse, but the underpressure region is of greater duration. This is because the tube collapses a greater distance radially in one motion, so the associated underpressure duration is increased. Additionally, the pressure spike recorded in this case is of greater amplitude than that where only the outer tube collapses. This is due to the greater potential energy of the event: change in volume is increased substantially when the inner tube implodes, so the pulse released is larger.

The peak amplitude of the straight through collapse is less than that reported in literature for composite tubes of similar geometry [17]. In the reference, specimens similar to the outer tube in this study emitted a maximum dynamic overpressure of approximately 0.8 , whereas the same value reported here is 0.6 . That is despite the substantial increase in collapse pressure in the double hull case (3.76 MPa vs 1.61 MPa in the reference). This reduction in maximum overpressure despite increases in collapse pressure clearly demonstrates the mitigating effect of the foam core. 


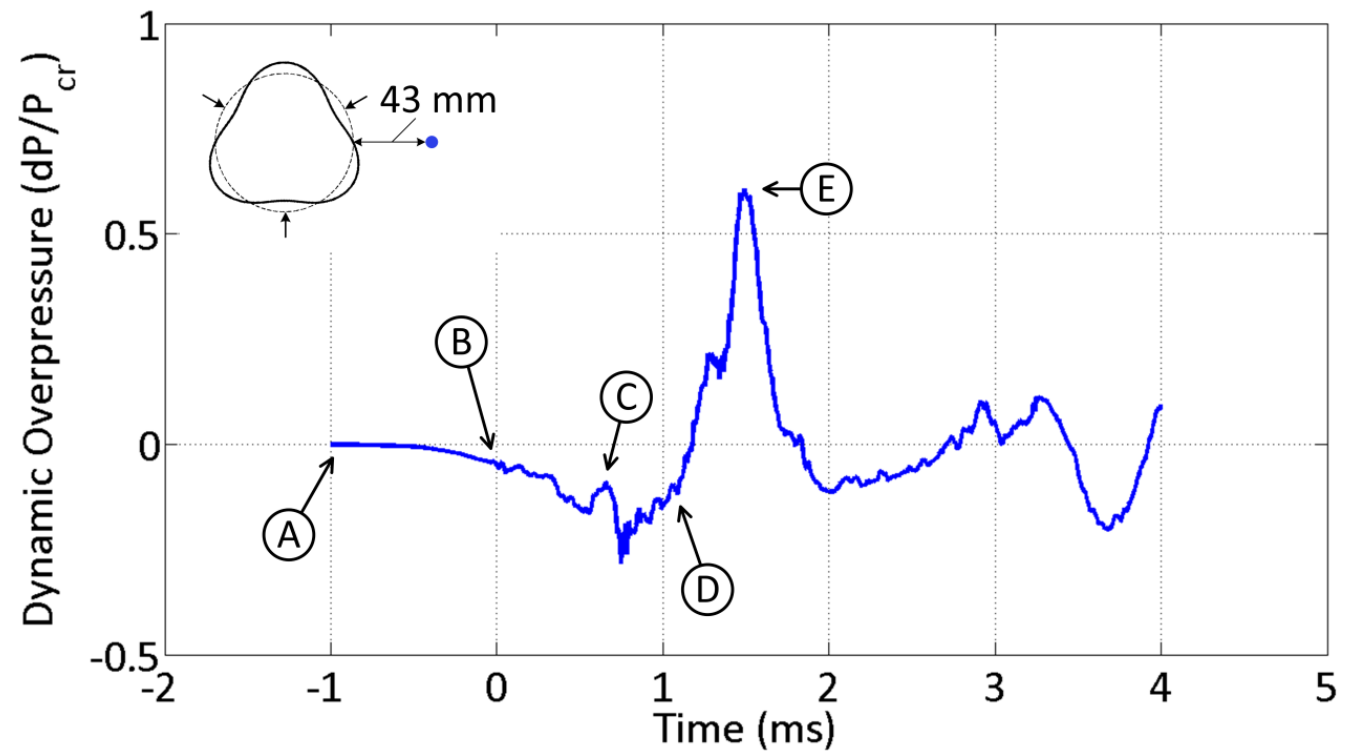

Figure 9: Normalized pressure pulse from case where the outer tube and inner tube collapsed in a singular motion, measured at midsection; (inset, top left) outer tube buckling mode shape and sensor location

\subsubsection{IMPULSE AND ENERGY}

$I_{\text {norm }}$ for various implosion cases is plotted in Figure 10A, with foam core density on the horizontal axis. To allow for direct comparison between cases, the integrals from $t_{2}$ to $t_{3}$ in both the numerator and denominator are taken to be zero for instances where the inner tube did not collapse. The results are constant with foam core density, which implies that the impulse is mainly a function of collapse pressure, and is not directly influenced by core density or other properties. The exception to this trend in the data is the case of the H60 core, which has a lower magnitude normalized impulse. The reason for this is because of the uniquely long time delay between inner and outer tube collapses for these cases, discussed in Section 1.5.3.2. As a result, it can be concluded that foam core properties do not directly affect impulse, with collapse pressure being the dominant factor instead.

A plot of normalized energy values, which present the energy emitted by the implosion event as a function of available hydrostatic energy, is given in Figure 10B. There, 
normalized energy released increases with core density, with more variation in the H60, -80 , and -100 cases. The increase in variation is because the inner tube collapses in the aforementioned cases, and introduces new damage mechanisms. The increase in normalized energy with core density is also significant, as there is a $57 \%$ increase in average normalized energy released between $\mathrm{H} 35$ and $\mathrm{H} 100$ core specimens. This highlights the diminishing returns on energy absorption for higher density cores. Though increasing core density also increases hydrostatic collapse pressure, the energy released by the implosion also increases, and does not scale with increase in hydrostatic energy. Therefore, the amount of energy released in the collapse of double hull tubes increases with hydrostatic energy, and increased core density allows for increased absolute mitigation of implosion energy. These returns do not scale, however, with slightly higher normalized energy released at higher foam core densities.

(A)

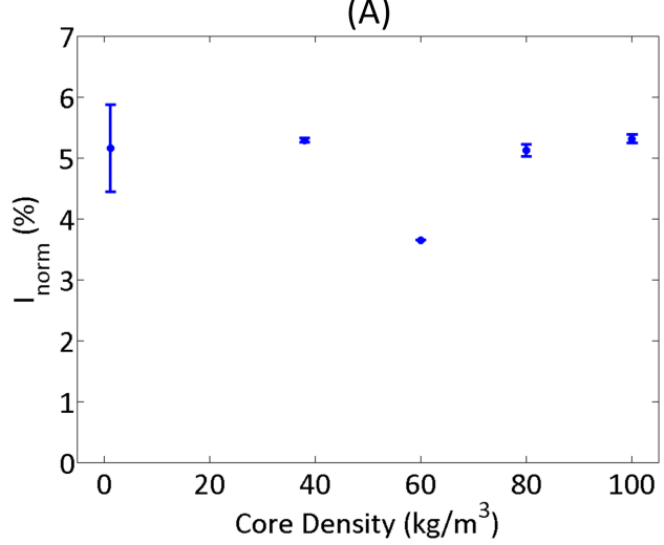

(B)

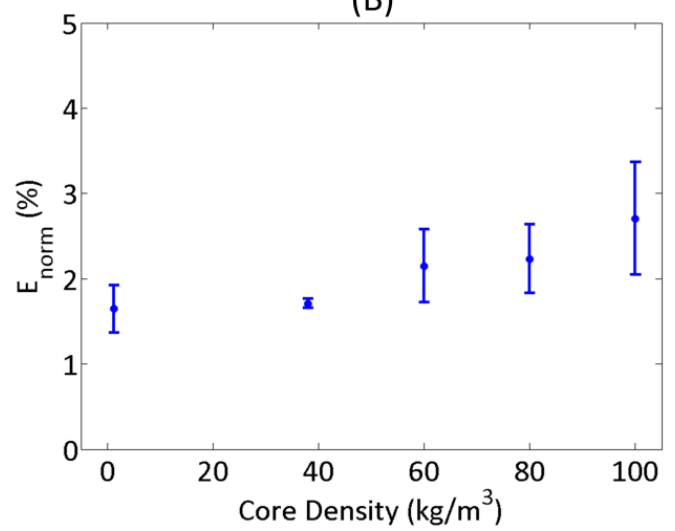

Figure 10: Implosion emissions as a function of core density showing (a) normalized underpressure impulse; (b) normalized waveform energy

\subsubsection{POST-MORTEM SPECIMEN EVALUATION}

The post-mortem analysis of the specimens yields additional insight into the mechanics of the collapse process, and helps to explain the energy mitigation behavior discussed above. Generally, damage in heavier foam core cases is more extensive because 
stronger foam cores enable higher collapse pressures: in the $\mathrm{H} 100$ case, $\mathrm{P}_{\mathrm{cr}}$ is approximately triple that of the $\mathrm{H} 35$ case, and because the inner tube also collapses, the energy of the event is increased even further. This enables new damage mechanisms, which causes greater overall energy absorption in the heavier foam core cases.

\subsubsection{PARTIAL COLLAPSE}

Figure 11 shows post-mortem images of the H35 foam core case, where only the outer tube collapsed. At (A), there are longitudinal, through-thickness cracks in the outer tube, corresponding to the mode 3 shape of the specimen. These connect to cracks in the circumferential direction at the endcaps (B), where complete fiber failure is observed as the endcaps shear the material during the dynamic collapse. At (C), the surviving internal tube can be seen, with little to no apparent damage. The crushing of the foam core in mode 3 shape can be seen at (D), where the foam core has not recovered elastically at the locations where the outer tube buckles inward. A mode 3 buckling shape can clearly be seen in the crushed shape of the core, reinforcing earlier findings suggesting that core crushing absorbs energy during the outer tube's implosion. Finally, note that the outer tube is largely elastically recovered from its imploded shape; this is characteristic of the implosion of all composite tubes, not just double hull specimens. 


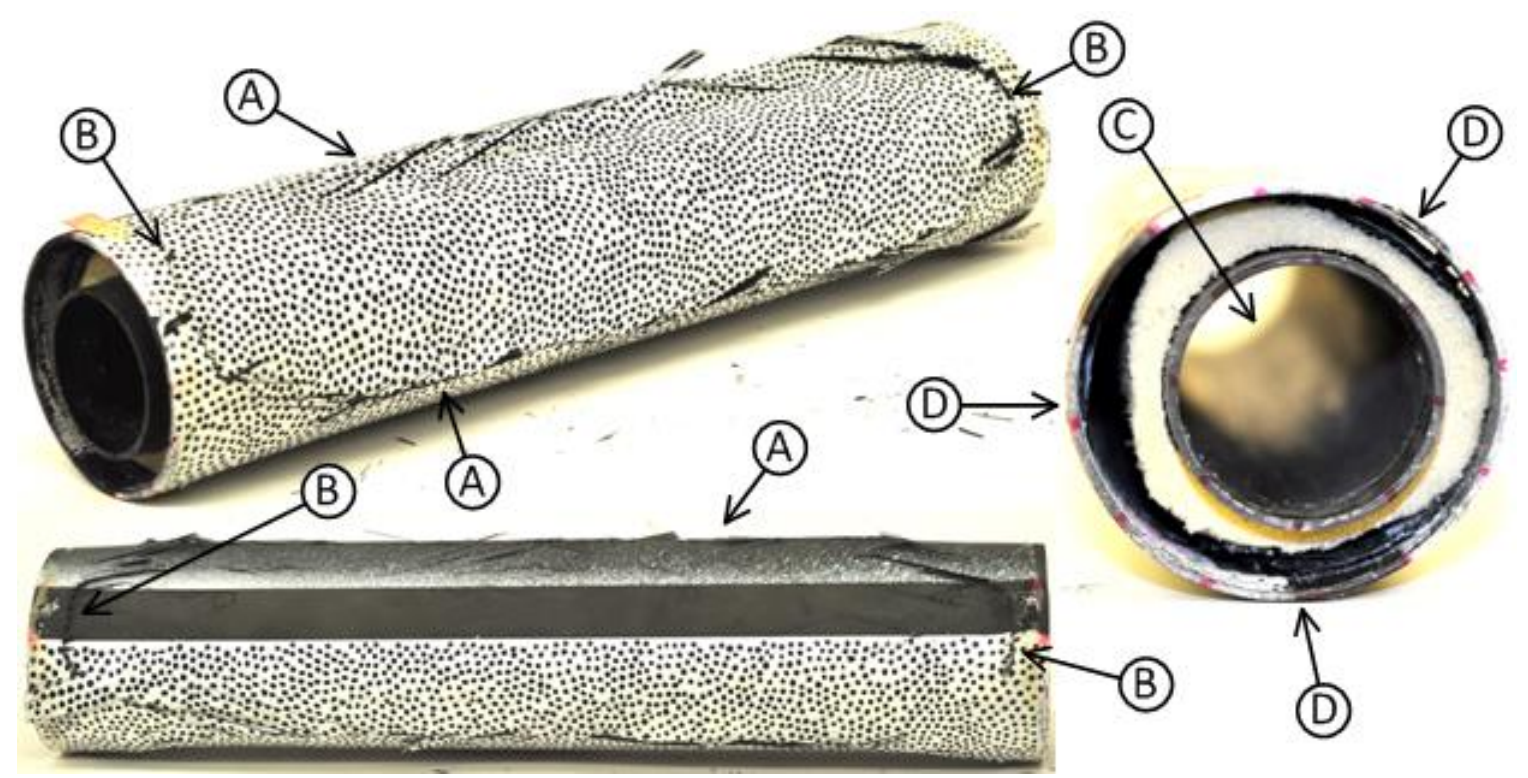

Figure 11: H35 core post-mortem specimen photographs; (top left) isometric view; (bottom left) top view; (right) right view; (A) longitudinal through-thickness cracks in outer tube, corresponding to mode 3 buckling shape; (B) circumferential through-thickness cracks from endcaps; (C) Intact inner tube; (D) foam core crushing in mode 3 shape.

\subsubsection{COMPLETE COLLAPSE, WITH DWELL}

Figure 12 shows post-mortem images of the H100 foam core case, which collapsed completely but with a time delay between tubes. At (A), longitudinal, through-thickness cracks corresponding to a mode 3 shape are seen. In this case, one of those cracks has developed into a complete tear, indicated at (B). One half of the tear folded under the other as the inner tube collapsed in an asymmetric mode 2 shape; this occurs in all specimens where the inner tube implodes in addition to the outer.

Several important instances of damage should be noted at the tear. First, the fibers along the tear have all failed, with substantial fiber pullout visible. There is also significant delamination at the tear face (C), visible at both the ends of the tube as well as the surface of the damage itself. The tear propagated to the foam core (D). The carbon/epoxy material of the outer and inner tubes has also not recovered to cylindrical shape (E) after being removed from the pressurized environment of the water. This is because the broken fibers from the tubes 
intertwine with one another where the tear and fold-under occurs, and also cut into the foam core material. This prevents them from returning to their original shape, and implies the presence of residual stress in the material, even after it is removed from water.

Finally, at (F), circumferential cracks from endcap-induced shear are seen. The cracks extend entirely around the circumference of the specimen on one end and largely around it on the other, and the portion of the outer tube that was supported by the endcap is entirely detached on one end.

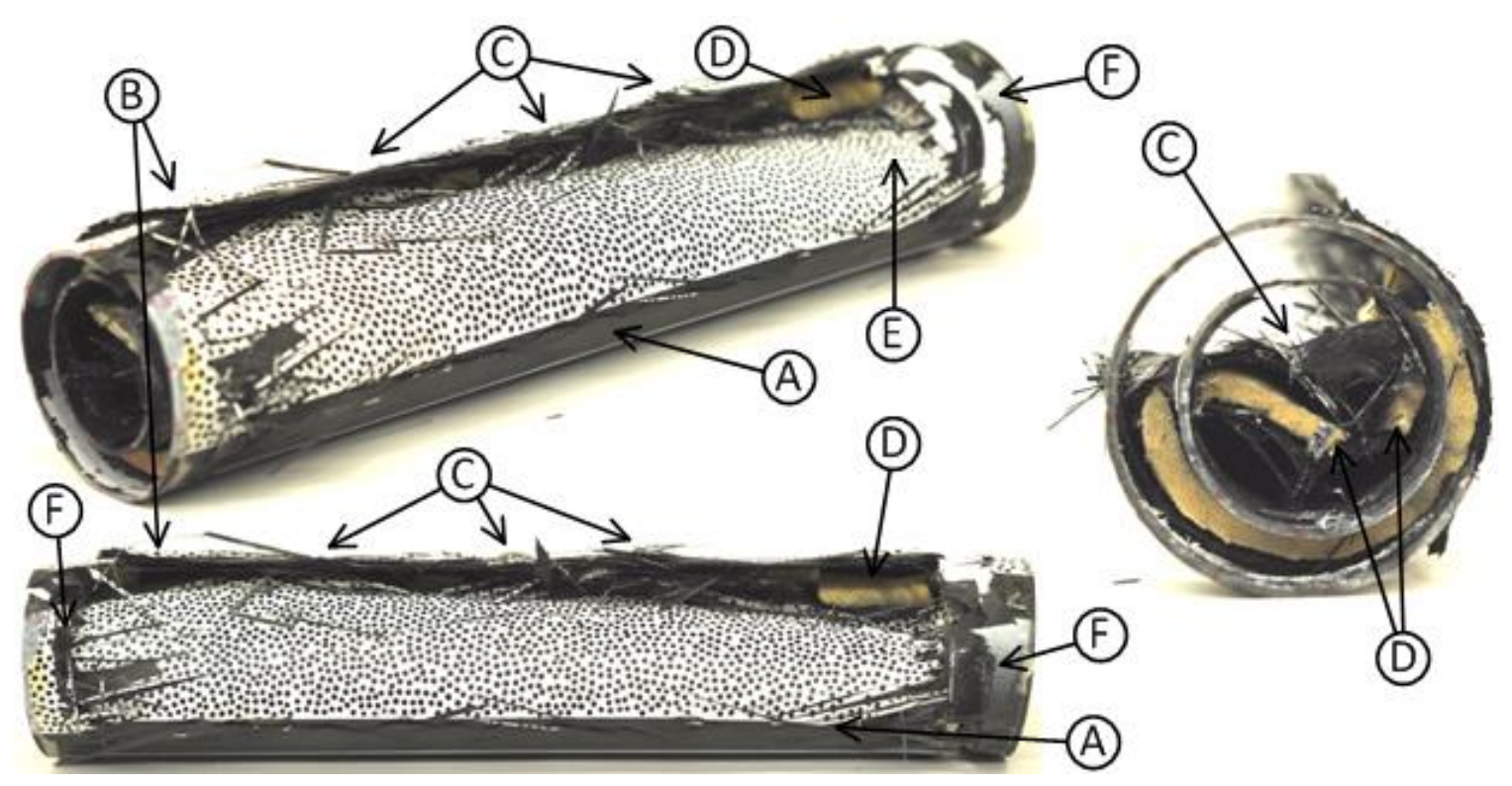

Figure 12: H100 core post-mortem specimen photographs; (top left) isometric view; (bottom left) front view; (right) right view; (A) longitudinal through-thickness cracks in outer tube, corresponding to mode 3 buckling shape; $(B)$ Edge of through thickness tear, where the outer tube has completely cracked and folded under itself; $(C)$ Delamination at tear edge; (D) Torn foam core; $(E)$ Incomplete elastic recovery; $(F)$ circumferential through-thickness cracking from endcap shear.

\subsubsection{COMPLETE COLLAPSE, WITHOUT DWELL}

Figure 13 shows post-mortem images of an H80-core specimen, where the inner and outer tubes both collapsed in a singular motion. At (A), cracks corresponding to a mode 3 buckling shape can be seen. These generally occur on the lobes of the collapse shape, so that the areas between these cracks experience the highest radial velocities inward. At (B), the 
location where the outer tube collapsed on the inner can be seen, with a fold where the inner tube buckled inward. Note that this fold occurred directly between the lobes indicated by cracks (A), and that there is another mode 3 lobe crack on the outer tube, at the exact opposite side of the outer tube. This indicates that collapses with no dwell occur when the directions of the tubes align with one another (Figure 14), which is supported by high-speed imagery from the event [Figure 6 (B) through (E)]. Beyond that, there is complete through-thickness fracture of both the tubes and the foam core at the center of the folded-in location, as well as at the top and bottom hinges where the fold-in occurs $(\mathrm{C})$. There is substantial delamination and fiber pullout in these areas (D). Finally, circumferential cracks created by shear from the endcaps can be seen at (E), which extend almost entirely around the circumference of the tube. 


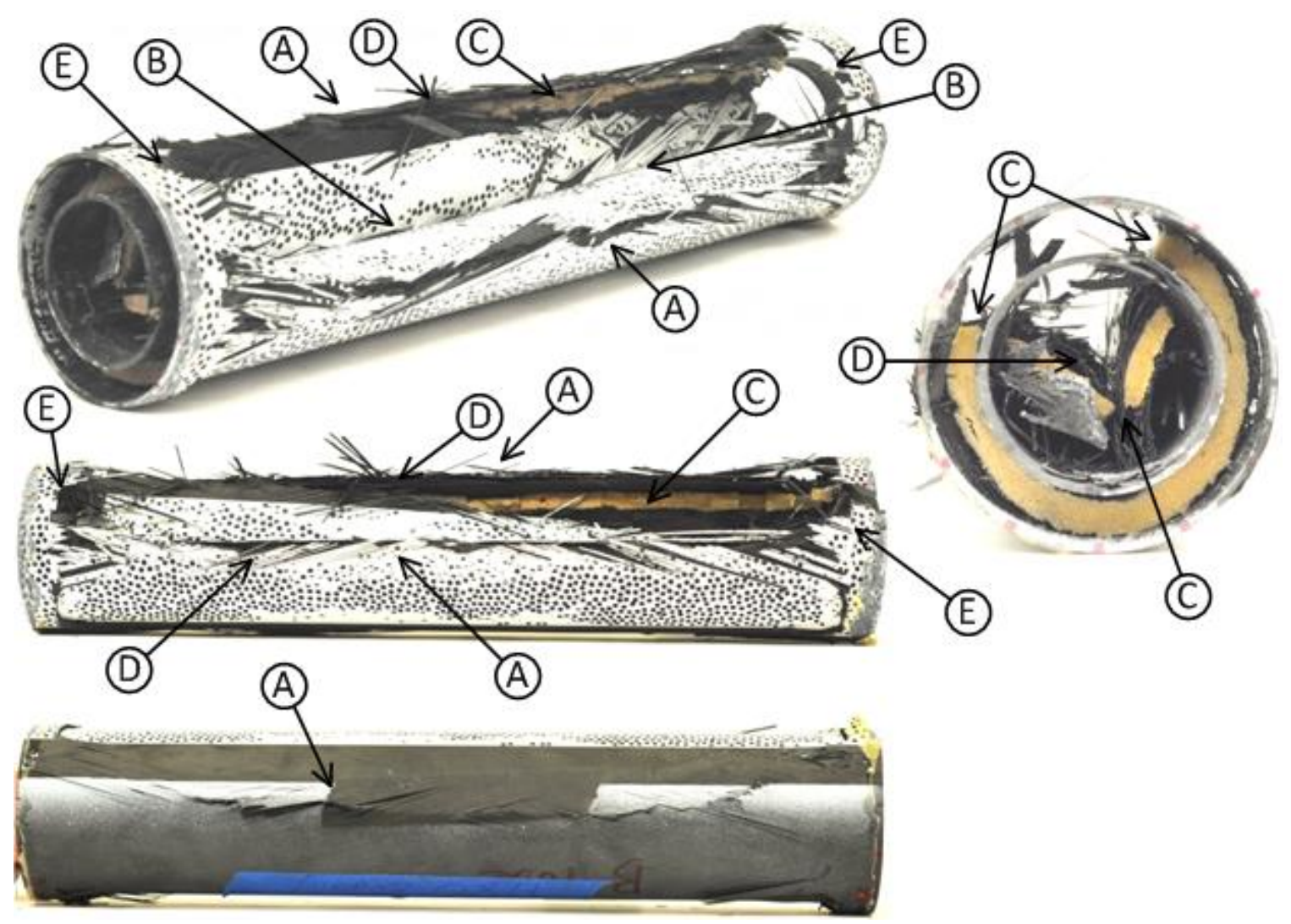

Figure 13: H80 core specimen post-mortem photographs; (top left) isometric view; (center left) front view; (bottom left) bottom view; (right) right view; $(A)$ longitudinal cracking corresponding to lobes of mode 3 buckling shape; $(B)$ center of fold where buckling directions of tubes aligned; $(C)$ Through-thickness tearing of both the tubes and core corresponding to collapse of the inner tube; (D) Delamination and fiber pullout along tear edges; $(E)$

Circumferential cracking from endcaps

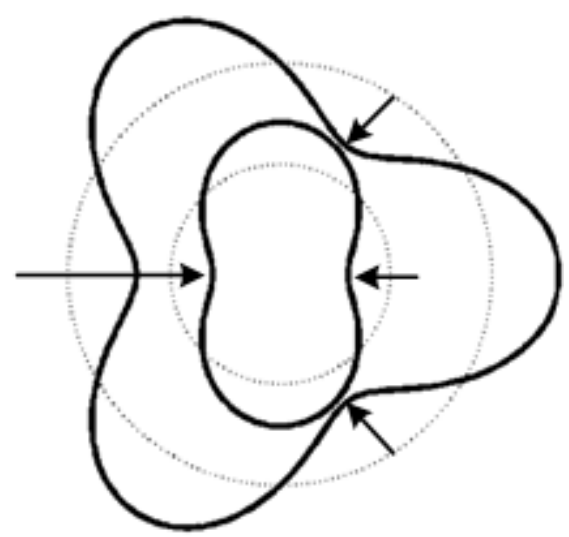

Figure 14: Schematic of buckling mode shapes in case where both tube collapse without a dwell; note collinear buckling direction of inner and outer tubes 


\subsection{CONCLUSIONS}

The hydrostatic implosion of double hull composite cylinders with polymeric foam cores of parametrically graded density was investigated. High-speed photography and dynamic pressure sensors were used to record implosion events in a unique facility, and 3-D, underwater DIC was used to attain full-field displacement data during the collapse. Careful evaluation of the experimental data has enabled the following conclusions to be made:

- The inner and outer facesheets of a double hull structure implode separately from one another, and, depending on collapse pressure, the inner tube may either survive or implode as well.

- Double hull composite structures demonstrate one of three general implosion behaviors: (1) The outer tube implodes but the inner survives; (2) The outer tube implodes, there is a brief time delay, then the inner implodes; (3) The outer and inner tubes implode in a singular motion with no dwell.

- The inner tube implodes if the collapse pressure of the outer tube is higher than the inner.

- The inner and outer tubes collapse in a singular motion if their natural buckling directions are aligned, but a dwell occurs if they are not.

- The increase in critical pressure of the outer facesheet on account of the double hull structure is directly proportional to the strength of the foam core. The proportionality constant has been shown to be a function of geometrical properties of the core.

- In cases where the outer tube collapses but the inner does not, an implosion pulse is generated which is similar to a monolayer tube implosion, but of lower frequency and amplitude. This is created by the outer tube collapsing and flattening against the inner. 
- In situations where both inner and outer tubes implode, the pulse from the outer tube's collapse is followed by a secondary implosion pulse from the collapse of the inner tube. The impulse and amplitude of the second event may match or exceed that of the first.

- After normalizing for collapse pressure, the impulse of a double hull implosion is constant with core density, regardless of whether the inner tube implodes or not.

- Energy released by a double hull implosion, normalized by hydrostatic energy, increases slightly with core density. This demonstrates diminishing efficiency in using higher density cores to mitigate the energy from implosion of double hull composite cylinders.

- Specimens with stronger cores undergo increased damage from implosion, on account of their higher collapse pressures. This increase in damage, combined with the increase in foam core crushing energy, causes higher strength cores to mitigate more energy in absolute terms than lower strength cores.

\subsection{ACKNOWLEDGEMENTS}

The authors would like to acknowledge the Office of Naval Research and Dr. Yapa D.S. Rajapakse for providing financial support for this research under Grant No. N00014-101-0662. The authors would also like to acknowledge the DIAB Corporation (DeSoto, TX) for providing the foam core materials used in this study.

\subsection{REFERENCES}

[1] S. E. Turner and J. M. Ambrico, "Underwater implosion of cylindrical metal tubes," $J$. Appl. Mech., vol. 80, p. 11013, 2012.

[2] S. E. Turner, "Underwater implosion of glass spheres," J. Acoust. Soc. Am., vol. 121, no. 2, p. 844, 2007. 
[3] R. J. Urick, "Implosions as Sources of Underwater Sound," J. Acoust. Soc. Am., pp. 2026-2027, 1963.

[4] M. Orr and M. Schoenberg, "Acoustic signatures from deep water implosions of spherical cavities,” J. Acoust. Soc. Am., vol. 59, no. 5, pp. 1155-1159, 1976.

[5] P. E. Harben and C. O. Boro, "Implosion source development and diego garcia reflections," in 23rd Seismic Research Review: Worldwide Monitoring of Nuclear Explosions, 2001, pp. 23-31.

[6] E. Cartlidge, "Accident grounds neutrino lab," Physics World, 2001. [Online]. Available: http://physicsworld.com/cws/article/news/2001/nov/15/accident-groundsneutrino-lab. [Accessed: 22-Jun-2016].

[7] "Robotic deep-sea vehicle lost on dive to 6-mile depth," 2014. [Online]. Available: http://www.whoi.edu/news-release/Nereus-Lost. [Accessed: 22-Jun-2016].

[8] C. Farhat, K. G. Wang, A. Main, S. Kyriakides, L. H. Lee, K. Ravi-Chandar, and T. Belytschko, "Dynamic implosion of underwater cylindrical shells: Experiments and Computations," Int. J. Solids Struct., vol. 50, no. 19, pp. 2943-2961, 2013.

[9] C. M. Ikeda, J. Wilkerling, and J. H. Duncan, "The implosion of cylindrical shell structures in a high-pressure water environment," Proc. R. Soc. A Math. Phys. Eng. Sci., vol. 469, no. $2160,2013$.

[10] S. Gupta, V. Parameswaran, M. A. Sutton, and A. Shukla, "Study of dynamic underwater implosion mechanics using digital image correlation," Proc. R. Soc. A Math. Phys. Eng. Sci., vol. 470, no. 2172, pp. 20140576-20140576, 2014.

[11] H. Hernandez-Moreno, B. Douchin, F. Collombet, D. Choqueuse, and P. Davies, "Influence of winding pattern on the mechanical behavior of filament wound composite cylinders under external pressure," Compos. Sci. Technol., vol. 68, no. 3-4, pp. 1015-1024, 2008.

[12] S. H. Hur, H. J. Son, J. H. Kweon, and J. H. Choi, "Postbuckling of composite cylinders under external hydrostatic pressure," Compos. Struct., vol. 86, no. 1-3, pp. 114-124, 2008.

[13] C. J. Moon, I. H. Kim, B. H. Choi, J. H. Kweon, and J. H. Choi, "Buckling of filamentwound composite cylinders subjected to hydrostatic pressure for underwater vehicle applications," Compos. Struct., vol. 92, no. 9, pp. 2241-2251, 2010.

[14] C. T. F. Ross, A. P. F. Little, Y. Haidar, and A. A. Waheeb, "Buckling of carbon/glass composite tubes under uniform external hydrostatic pressure," Strain, vol. 47, no. SUPPL. 1, pp. 156-174, 2011.

[15] P. T. Smith, C. T. F. Ross, and A. P. F. Little, "Collapse of composite tubes under uniform external hydrostatic pressure," J. Phys. Conf. Ser., vol. 181, pp. 156-157, 2009. 
[16] C. Yang, S.-S. Pang, and Y. Zhao, "Buckling Analysis of Thick-Walled Composite Pipe under External Pressure,” J. Compos. Mater., vol. 31, no. 4, pp. 409-426, 1997.

[17] M. Pinto, S. Gupta, and A. Shukla, "Study of implosion of carbon/epoxy composite hollow cylinders using 3-D Digital Image Correlation," Compos. Struct., vol. 119, pp. 272-286, 2015.

[18] M. Pinto, S. Gupta, and A. Shukla, "Hydrostatic implosion of GFRP composite tubes studied by Digital Image Correlation," J. Press. Vessel Technol., vol. 137, no. 5, p. 51302, 2015.

[19] M. Pinto and A. Shukla, "Mitigation of pressure pulses from implosion of hollow composite cylinders," J. Compos. Mater., 2015.

[20] J.-H. Han, G. a. Kardomateas, and G. J. Simitses, "Elasticity, shell theory and finite element results for the buckling of long sandwich cylindrical shells under external pressure," Compos. Part B Eng., vol. 35, pp. 591-598, 2004.

[21] J. W. Hutchinson and M. Y. He, "Buckling of cylindrical sandwich shells with metal foam cores," Int. J. Solids Struct., vol. 37, no. 46-47, pp. 6777-6794, 2000.

[22] G. A. Kardomateas and G. J. Simitses, "Buckling of Long Sandwich Cylindrical Shells Under External Pressure,” Jam, vol. 72, no. 4, pp. 493-499, 2005.

[23] A. V. Lopatin and E. V. Morozov, "Buckling of the composite sandwich cylindrical shell with clamped ends under uniform external pressure," Compos. Struct., vol. 122, pp. 209-216, 2015.

[24] J. Shen, G. Lu, D. Ruan, and C. Chiang Seah, "Lateral plastic collapse of sandwich tubes with metal foam core," Int. J. Mech. Sci., vol. 91, pp. 99-109, 2015.

[25] M. Ohga, A. Sanjeewa Wijenayaka, and J. G. A. Croll, "Reduced stiffness buckling of sandwich cylindrical shells under uniform external pressure," Thin-Walled Struct., vol. 43, no. 8, pp. 1188-1201, 2005.

[26] K. Arjomandi and F. Taheri, "Stability and post-buckling response of sandwich pipes under hydrostatic external pressure," Int. J. Press. Vessel. Pip., vol. 88, no. 4, pp. 138 $148,2011$.

[27] K. L. Koudela and L. H. Strait, "Simplified Methodology for Prediction of Critical Buckling Pressure for Smooth-Bore Composite Cylindrical Shells," J. Reinf. Plast. Compos., vol. 12, no. 5, pp. 570-583, 1993.

[28] R. H. Cole, Underwater Explosions. Princeton, New Jersey: Princeton University Press, 1948.

[29] A. B. Arons and D. R. Yennie, "Energy partition in underwater explosion phenomena," Rev. Mod. Phys., vol. 20, no. 3, pp. 519-536, 1948. 
[30] ASTM standard D1621, "Standard Test Method for Compressive Properties Of Rigid Cellular Plastics," ASTM Int., 2016.

[31] R. von Mises, "The Critical External Pressure of Cylindrical Tubes," Zeitschrift des Vereines Dtsch. Ingenieure, vol. 58, no. 19, pp. 750-767, 1914.

[32] R. von Mises, "The Critical External Pressure of Cylindrical Tubes Under Uniform Radial and Axial Load," Stodola's Festschrift, pp. 418-430, 1929. 
CHAPTER 2: SHOCK INITIATED IMPLOSION OF DOUBLE HULL COMPOSITE CYLINDERS

Prepared for submission to Journal of the Mechanics and Physics of Solids

By:

Nicholas DeNardo and Arun Shukla*

Dynamic Photomechanics Laboratory

Department of Mechanical, Industrial, and Systems Engineering

University of Rhode Island, Kingston, RI 02881

*Corresponding author: shuklaa@egr.uri.edu, Phone: 401-874-2283, Fax: 401-874-2355 


\section{ABSTRACT}

An experimental study is performed which investigates the dynamic collapse of double hull composite cylinders under external hydrostatic pressure and shock loading. All experiments are performed underwater in a $2.1 \mathrm{~m}$ diameter semi-spherical pressure vessel that approximates a free-field environment, and Digital Image Correlation (DIC) is used in conjunction with blast transducers to study collapse mechanics. Specimens have carbon-fiber / epoxy facesheets and a PVC foam core that is removed for control in some instances, and are brought to $80 \%$ of their natural buckling pressure before being subjected to an underwater explosion (UNDEX) at varying standoff distances. Results show that double hull specimens implode below their natural collapse pressure when subject to explosive loading, but that the addition of the PVC foam core prevents implosion in some cases and substantially increases structural stability in others. The double hull configuration with foam core is also shown to emit significant pressure pulses despite the noisy environment of the pressure vessel. 


\subsection{INTRODUCTION}

This study seeks to address gaps in the understanding of the collapse mechanics of double hull composite structures during shock-initiated underwater implosion. To that end, a series of experiments was performed to evaluate the response of carbon-fiber composite double-hull cylinders, with and without PVC foam cores, under simultaneous hydrostatic pressure and explosive loading. The completion of this work helps enable implementation of these structures in underwater applications, where they have several key advantages, but have historically seen limited use from lack of complete understanding [1].

There are many benefits of composite materials for underwater structural applications: composites generally have higher specific strength and stiffness, improved corrosion resistance, and reduced weight in comparison with metals. These benefits expand further in double hull composite configurations, where a foam core of relatively low density is sandwiched between two facesheets of higher density and stiffness: this configuration allows for increased acoustic attenuation, as well as improved bending strength, making double hull structures particularly good for preventing buckling. This is important because buckling causes the initiation of an implosion, where structural instability results in the walls of an underwater gas-filled structure rapidly moving inward and contacting each another, collapsing the structure entirely and emitting high-pressure waves in the process [2]. While implosions may be initiated from hydrostatic pressure alone, sufficient instability to collapse the structure may also be caused by shock loading at sub-critical pressure, as in the case of a nearby underwater explosion (UNDEX)[3].

Though underwater implosion has been of interest for several decades, there has been a recent resurgence of experimental work in the field. Turner and Ambrico clarified the collapse mechanics of cylindrical metal shells using experiments and simulations, and Farhat et. al did similarly while using high speed cameras to visualize the stages of the collapse [2], 
[4]. Gupta et al further expanded the literature by using high speed photography in conjunction with digital image correlation (DIC) to study the implosion of metallic tubes[5]. Pinto extended these techniques to the study of composite tubes[6], [7], thus adding to a body of work that had been focused largely on evaluating the collapse pressures of composite cylinders under hydrostatic conditions [8]-[11].

A variety of work has been done on the phenomenon of shock-initiated implosion. Pegg performed a nonlinear finite element analysis of submerged cylinders with combined hydrostatic and impulse loading, and investigated the effect of varying impulse [12]. Tanov et al looked at the response of cylindrical laminated shells under suddenly applied lateral pressure [13]. Brett and Hung et al performed experiments on the UNDEX loadings of submerged cylinders, and compared their results to simulations [14], [15]. Fatt studied the underwater pulse loading of GFRP cylinders analytically using Mathieu equations and computationally, and found good agreement between the two [16]. Ikeda studied the implosion of Brass and Aluminum cylinders under hydrostatic pressure and UNDEX loading experimentally using high-speed imaging [17]. Finally, Pinto used high speed imagining and DIC to study the buckling and implosion of carbon-fiber/epoxy composite structures under UNDEX loading [18].

There is a wealth of literature on the behavior of sandwich structures to impulse and blast loading, both in air and water [19]-[35]. However, this body of work focuses on the behavior of plates and beams with few exceptions, and generally does not account for buckling in cases where cylinders are considered. As such, there is a significant knowledge gap with regards to the behavior of sandwich-structured composite cylinders under combined hydrostatic and shock loading. This study seeks to address that gap experimentally, with results showing that the addition of a foam core substantially increases structural stability by extending the duration of collapse, as well as preventing implosion completely in some cases. 


\subsection{MATERIAL SELECTION AND SPECIMEN DESIGN}

Double hull specimens are created from carbon-fiber/epoxy composite cylinders produced by Rock West Composites (West Jordan, UT), featuring an Epon 862 Resin system. The inner and outer tubes have nominal IDs of $38.6 \mathrm{~mm}$ and $60.4 \mathrm{~mm}$, respectively. The inner and outer tubes have otherwise the same constructions: both have a general purpose $[ \pm 15 / 0 / \pm 45 / \pm 15]$ layup, $356 \mathrm{~mm}$ unsupported length, and $1.7 \mathrm{~mm}$ nominal wall thickness. The outer tube has a random, black-and-white speckle pattern for DIC, applied by hand using flat paint. The inner and outer tubes are assembled concentrically and fixed in place using aluminum endcaps, which are sealed from outside water and one another using o-rings. To provide an additional backup seal, a thin layer of epoxy is applied to the gap between the end of the tube and the endcap. This ensures that water will not enter the inner tube and affect its dynamics if damage allows water to enter the space between inner and outer tubes.

Some cases include a PVC foam core made from H100 foam by DIAB Inc. (De Soto, TX). This core is made by cutting rings of $41.9 \mathrm{~mm}$ ID and $9.2 \mathrm{~mm}$ thickness from a sheet of stock material, then stacking the rings concentrically between the inner and outer tubes. The height of the stack of rings is matched to the unsupported length of the tubes, and the end result is that the volume between inner and outer cylinders is completely filled with H100 foam when a core is included.

\subsection{EXPERIMENTAL PROCEDURE}

Experiments are performed in a semi-spherical pressure vessel of $2.1 \mathrm{~m}$ diameter and maximum static pressure rating of $6.89 \mathrm{MPa}$ (Figure 15). The size of the vessel allows constant hydrostatic pressure to be maintained during collapse, and optical viewports mounted around the mid-height of the tank enable lighting and high speed photography inside the 
chamber. Front-facing viewports have a $17^{\circ}$ viewing angle which is used together with two high-speed cameras (Photron SA1, Photron USA, Inc., San Diego, CA) for stereoscopic recording of the specimen during the experiment, enabling 3-D DIC (VIC3D 2012, Correlated Solutions Inc., Columbia, SC) to be performed during post-processing in the manner of [5], [6], [18]. Viewports on the side of the tank are used with an additional high speed camera to track UNDEX bubble size.

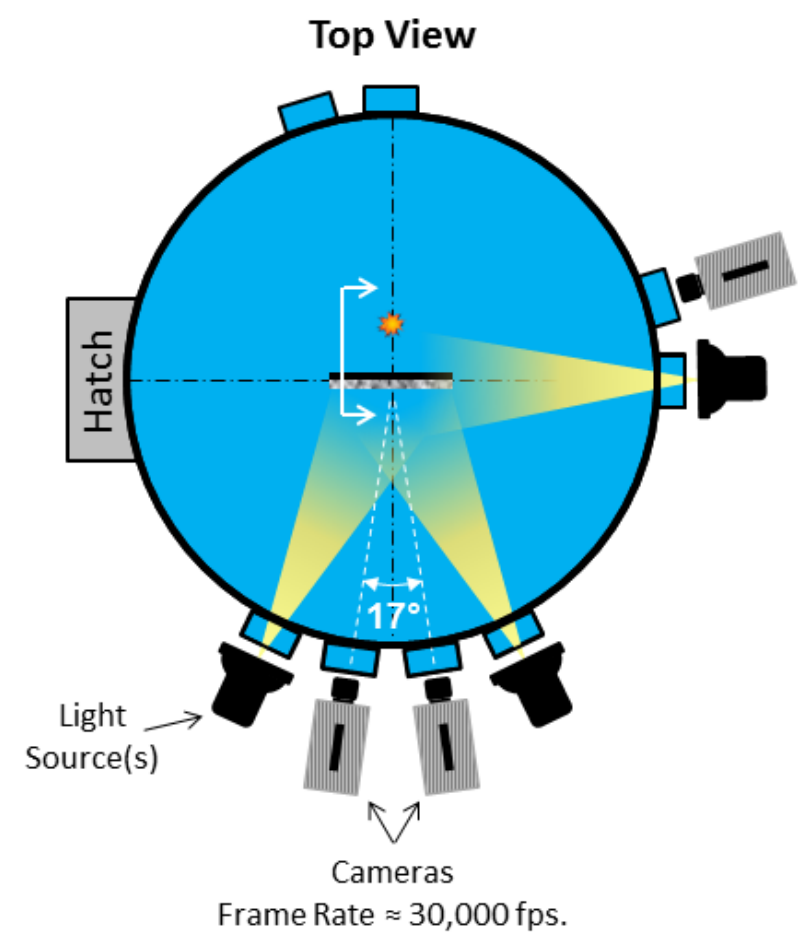

\section{Section View}

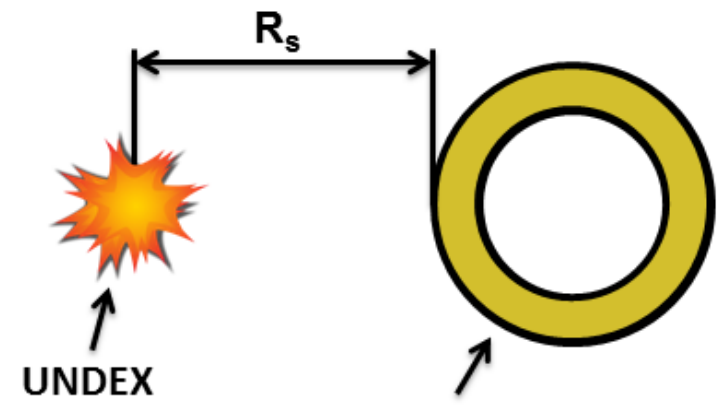

(RP-85)

\section{Composite}

Sandwich Tube

Figure 15: Experimental setup; (left) top section view of pressure vessel through mid-height, showing high speed cameras, specimen, UNDEX, and lighting; (right) section view showing specimen and charge locations

Experiments are performed by mounting the specimen horizontally in the center of the tank using thin cables that provide minimal reflections, and the speckle pattern on the specimen is made to face the front viewports. An exploding-bridgewire detonator of $80 \mathrm{mg}$ PETN and 1,031 mg RDX (RP-85, Teledyne RISI, Inc., Tracy, CA) is mounted directly behind the specimen at a controlled standoff distance $R_{s}$ of either $102 \mathrm{~mm}$ or $203 \mathrm{~mm}$. 
Piezoelectric blast transducers (PCB 138A05, PCB Piezotronics, Inc., Depew, NY) are mounted around the specimen and the explosive to record the pressure environment during and after the event. These transducers are designed for liquids compatible with nylon (including water), have a rise time of less than $1.5 \mu$ s, a resolution of $0.7 \mathrm{kPa}$, and a low frequency response of $2.5 \mathrm{~Hz}$, and are therefore considered valid for this application. The amplified output from the pressure sensors is monitored using an Astro-Med Dash 8HF-HS portable data recorder (Astro-Med Inc., West Warwick, RI) at a sampling rate of $2 \mathrm{MHz}$. After mounting, the tank is sealed and filled with filtered water, then pressurized by introducing nitrogen gas to a small air pocket at the top of the chamber. The water in the vessel is pressurized to $80 \%$ the collapse pressure of the specimen being studied, which is previously measured from identical samples by slowly pressurizing the same setup at a rate of $0.083 \mathrm{MPa} / \mathrm{min}$ until natural collapse occurs. When $80 \%$ collapse pressure is reached in the tank, a high voltage firing box is triggered alongside the cameras and pressure sensors, such that the charge detonates and imagery and pressure data are saved and matched in time.

All trials are duplicated to ensure repeatability between experiments. Average normalized RMSE of pressure signals is $4.3 \%$ for similar trials, with a maximum variation of bubble pulse period of $0.16 \mathrm{~ms}$, and maximum variation in maximum overpressure of 2.18 MPa. Representative data is plotted unless there is significant deviation between trials, in which case differences are highlighted.

\begin{tabular}{cccc}
\hline Specimen Type & Hydrostatic Pressure & Trials performed at & Trials performed at \\
& During Trial (MPa) & $\mathbf{R}_{\mathrm{s}}=\mathbf{1 0 2} \mathbf{~ m m}$ & $\mathbf{R}_{\mathrm{s}}=\mathbf{2 0 3} \mathbf{~ m m}$ \\
\hline Core Removed & 0.979 & 2 & 2 \\
H100 Foam Core & 2.896 & 2 & 2 \\
\hline
\end{tabular}

Table 2: Summary of experiments performed 


\subsection{RESULTS AND DISCUSSION}

\subsubsection{FEATURES OF THE PRESSURE HISTORY}

Pressure-time data recorded from blast transducers near the specimen is presented here, in order to provide complete information about collapse. In each case, plots are taken from a sensor mounted $25 \mathrm{~mm}$ from the back face of the specimen, as well as standoff distance $\mathrm{R}_{\mathrm{s}}$ from the charge (Figure 16). This provides an accurate representation of the pressure experienced by the specimen, as the shock wave arrives at both the sensor and the structure simultaneously. Additionally, time 0 is taken by convention to be the time at which the explosive is fired for a particular case, such that the initial shock wave passes the structure shortly thereafter. This convention is also upheld for image data throughout the paper, so pressure and DIC information can be directly compared in time. All pressure and DIC data presented in this study is unfiltered.

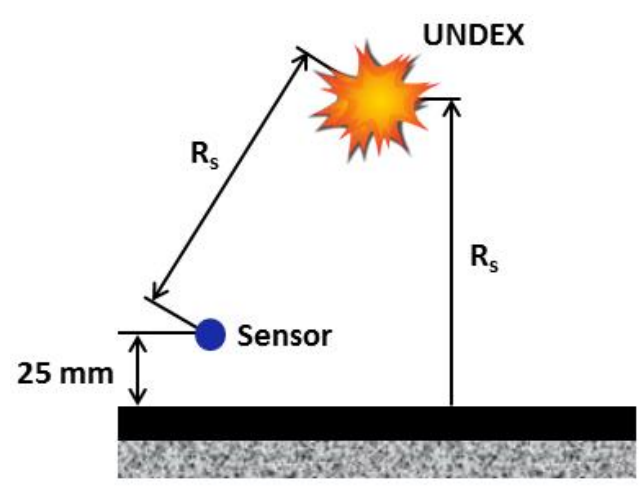

Figure 16: Schematic of sensor position relative to specimen and charge locations

Because the experiments in this study are performed in a closed vessel, reflections from the boundaries of the tank consistently affect the pressure signal by introducing a substantial amount of noise. Based on the $2.1 \mathrm{~m}$ diameter of the vessel, and assuming a constant wave speed of $1500 \mathrm{~m} / \mathrm{s}$ in water, it can be determined that tank reflections will first appear in the pressure signal approximately $1.4 \mathrm{~ms}$ after the initial shock, and will continue to recur at that interval. This is shown to be true here, with initial reflections typically appearing 
as a grouping of smaller pulses on account of the charge's offset from the center of the tank. Reflections which follow the first set are generally less distinguishable, as the amplitude of the pressure wave attenuates significantly over distance and transmission of some energy occurs at the vessel's boundaries.

Another important feature of the pressure histories shown later are the secondary pulses from expansion and collapse of the UNDEX gas bubble. These are identified by tracking bubble size over time via the side view camera of the tank, and recording the times of local minimums in bubble size. Based on the wave speed of water, sensors register bubble pulses $0.07 \mathrm{~ms}$ and $0.14 \mathrm{~ms}$ after the minimum bubble radius is observed, depending on standoff distance. Up to four bubble pulses are reported for any given case, after which the oscillatory motion of the bubble generally becomes less discernible, and definite minimums are not as easy to identify.

Because the hydrostatic pressure at which experiments are performed in foam core cases is much higher (2.9 MPa instead of 1.0 MPa), the time period between bubble pulses is much lower. This is well established theoretically, and given by the following empirical equation[36]:

$$
T=K\left(\frac{Y^{1 / 3}}{P_{0}^{5 / 6}}\right)
$$

Where $\mathrm{T}$ is the period of bubble oscillation, $\mathrm{Y}$ is total energy available (proportional for a given explosive to charge weight), $\mathrm{K}$ is a constant depending on the explosive, and $\mathrm{P}_{0}$ is the ambient hydrostatic pressure during the event. Assuming constant values of $\mathrm{K}$ and $\mathrm{Y}$ between experiments, the relationship between bubble pulse periods at differing hydrostatic pressure is given simply by: 


$$
\frac{T_{1}}{T_{2}}=\left(\frac{P_{0,2}}{P_{0,1}}\right)^{5 / 6}
$$

Where $T_{1}$ and $T_{2}$ are the time periods between bubble pulses at a given hydrostatic pressure, and $\mathrm{P}_{0,1}$ and $\mathrm{P}_{0,2}$ are the corresponding values of hydrostatic pressure. For the experiments in this study, Equation (14) has an average accuracy of $92.5 \%$ between cases at varying hydrostatic pressures. This shows that hydrostatic pressure is the primary factor in differing bubble-pulse periods. Possible sources of experimental error result from the closed environment of the pressure vessel, including changing local pressure from wall reflections and specimen deformation.

\subsubsection{NO CORE, 102 MM STANDOFF CASE}

The collapse of the structure with core removed and a $102 \mathrm{~mm}$ standoff was the fastest of all cases, with the complete collapse of the structure happening in about $7.9 \mathrm{~ms}$. This can be seen through high speed imagery and DIC of the event, with center-point deflections of the outer cylinder presented in Figure 17. At time 0, the explosive is fired and the center-point of the tube soon bows outward before the implosion of the outer cylinder initiates at approximately $1.0 \mathrm{~ms}$, marked A. From there, the outer tube buckles inward and impacts the wall of the inner cylinder at $\mathrm{B}$, but rebounds outward to a maximum at time $3.00 \mathrm{~ms}$, marked C. It is important to note, however, that this measured rebound may be an artifact of the underwater DIC method: the pressure-time history from the experiment (Figure 19) shows tank wall reflections at about this time, and high speed imagery from the event (Figure 18) confirms this with noticeable changes in refractive index. Regardless, the implosion of the inner tube can be seen to initiate at $4.00 \mathrm{~ms}$, marked $\mathrm{D}$, with the buckle inward collinear with that of the outer tube. From there, the walls of the cylinder rebound briefly before continuing 
inward at $\mathrm{E}$ and finally making centerpoint wall contact at $\mathrm{F}$. A phase commonly referred to as "buckle propagation" ([5], [7]) follows, with the walls of the cylinder making contact at increasingly higher longitudinal position, until the walls are completely collapsed at $7.93 \mathrm{ms,}$ marked G.

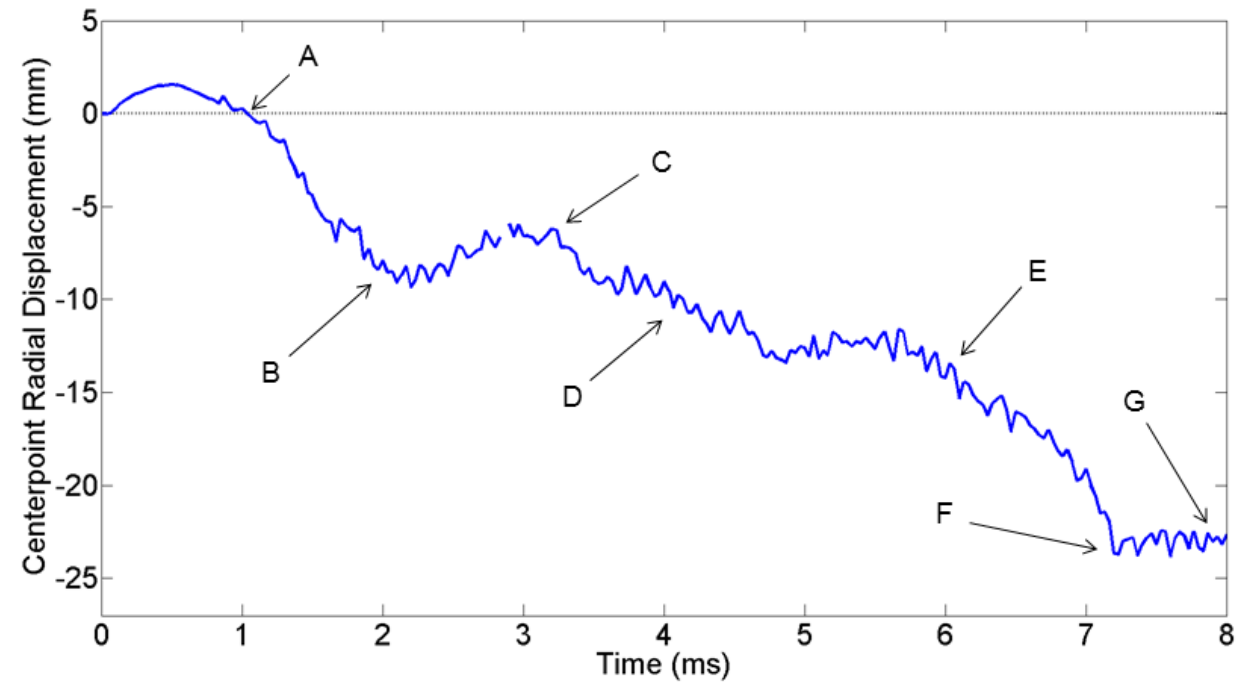

Figure 17: Centerpoint radial displacement data $(d R)$ for a no-core specimen with $102 \mathrm{~mm}$ standoff 


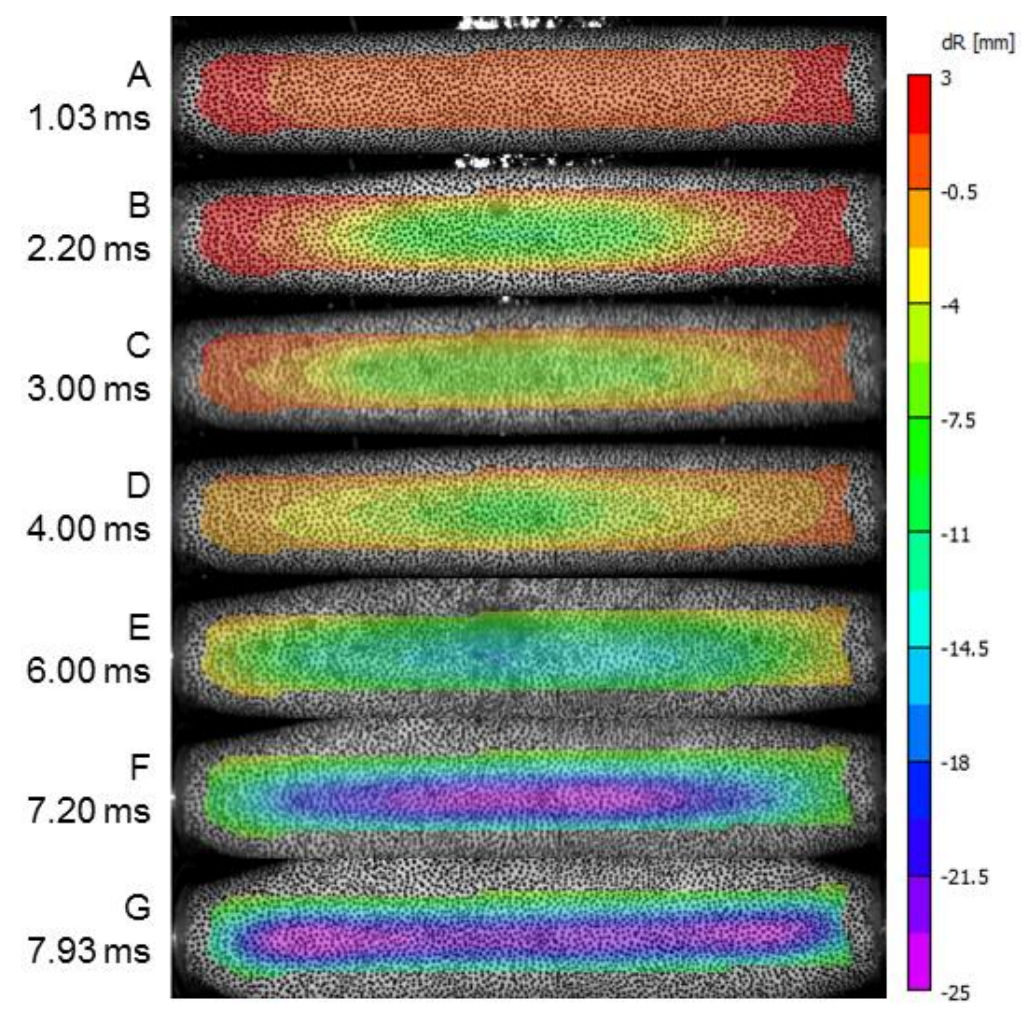

Figure 18: High speed imagery with DIC contours superimposed for a no-core specimen with $102 \mathrm{~mm}$ standoff. Letter-labels to the left of the images correspond to those in Figure 17.

The pressure-time history recorded from the event provides further insight into collapse mechanics, and is plotted in Figure 19. There, it can be seen that the implosion of the outer tube occurs following the initial shock wave, but before any reflections from the tank walls interact with the specimen. As such, it is clear that the initial shock wave alone possesses enough energy to implode the outer tube at this ambient pressure and standoff distance. As noted previously, the second set of reflections can also be seen to begin at around $2.8 \mathrm{~ms}$, and continue during the time of the rebound labeled $\mathrm{C}$ in Figure 17. Interestingly, the first bubble pulse from the UNDEX appears to be concurrent with the buckling initiation of the inner cylinder. Side view photography shows a minimum bubble radius at exactly 4.00 ms, which is the same time as image D in Figure 18, and aligns with the local maximum in pressure marked bubble pulse 1 in Figure 19. From this it may be concluded that the bubble 
pulse is providing the energy to initiate the collapse of the inner cylinder, even though that structure's collapse pressure is much higher than the ambient hydrostatic pressure in the tank. After this point, collapse of the inner tube continues until wall contact is made shortly after 7 ms, which also happens to correspond with the second UNDEX bubble pulse, and buckle propagation continues until approximately $8 \mathrm{~ms}$. It is worth noting that, even though an implosion typically releases high-amplitude pressure waves concurrently with buckle propagation, it is not possible to distinguish that feature in the pressure trace here because the environment is already very noisy.

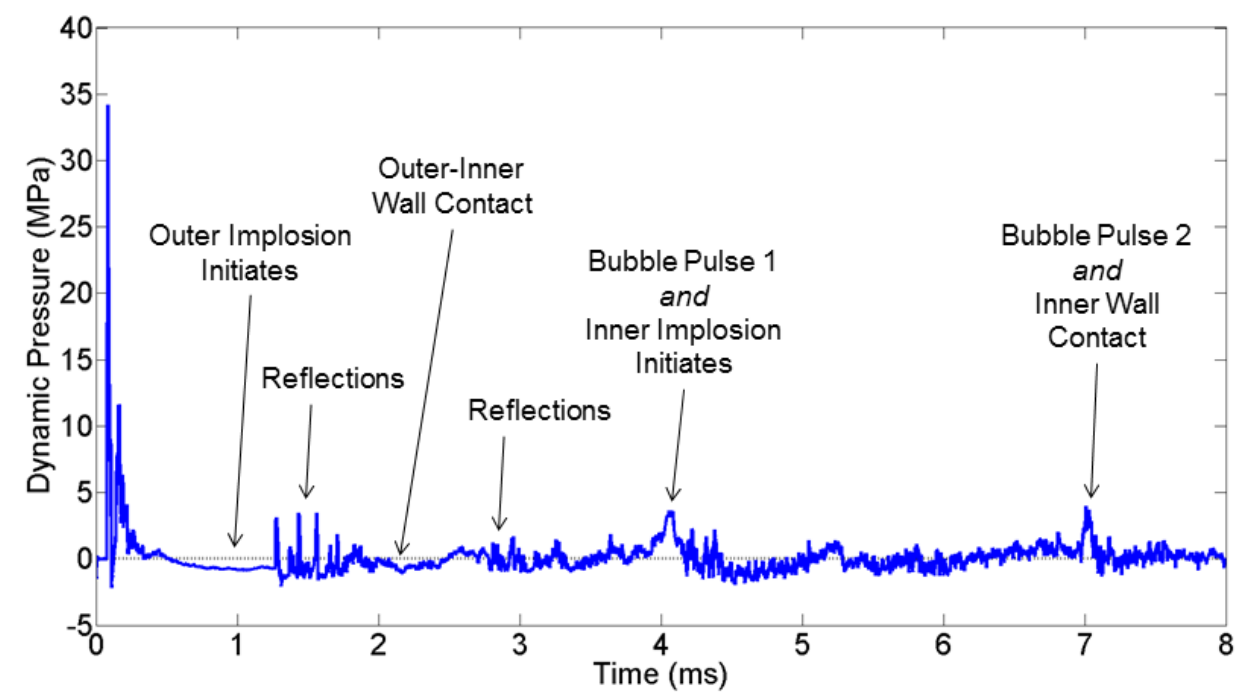

Figure 19: Pressure-time history for a no-core specimen with $102 \mathrm{~mm}$ standoff. Dynamic pressure is plotted, such that 0 on the vertical axis corresponds to ambient hydrostatic pressure.

Post-mortem imagery of the specimen used here is shown in Figure 20, with key areas of damage marked for both the inner and outer tubes. Some of the most extensive damage is shown in areas $\mathrm{A}$ and $\mathrm{D}$, where through-thickness axial cracking runs along the length of both the inner and outer tubes. These cracks occur on the top and bottom of both tubes, and correspond to sections of the tubes that hinged during the Mode 2 collapse of the structure. 
This can be seen by cross-referencing with Figure 18, and show that the tubes absorb energy through damage as they collapse.

Also of interest is the back face circumferential cracking in the outer tube that forms a roughly circular shape and can be seen in areas marked B. This cracking is interesting because it only appears on the back face of the tube, in the direction facing the UNDEX. These circumferential cracks are each about $82 \mathrm{~mm}$ from the midplane of the tube, which is itself $102 \mathrm{~mm}$ from the center of the UNDEX. Using simple trigonometry, it can be determined that this corresponds to a radius of $130 \mathrm{~mm}$ in the initial shock wave, at which point the section of the tube bracketed by these cracks was loaded by the shock but the rest of the tube was not. Given this non-uniform loading and lack of support from a core, the material likely experienced enough stress to fracture, further degrading the stability of the structure and leading to the short duration of collapse. Interestingly, similar cracking can be seen at a corresponding location in the inner tube, marked C in Figure 20. Again, corresponding cracks do not appear on the front face of the inner tube. This implies that the back face of the outer tube impacted the inner with particularly high momentum, causing localized damage in the inner cylinder. 
(i)

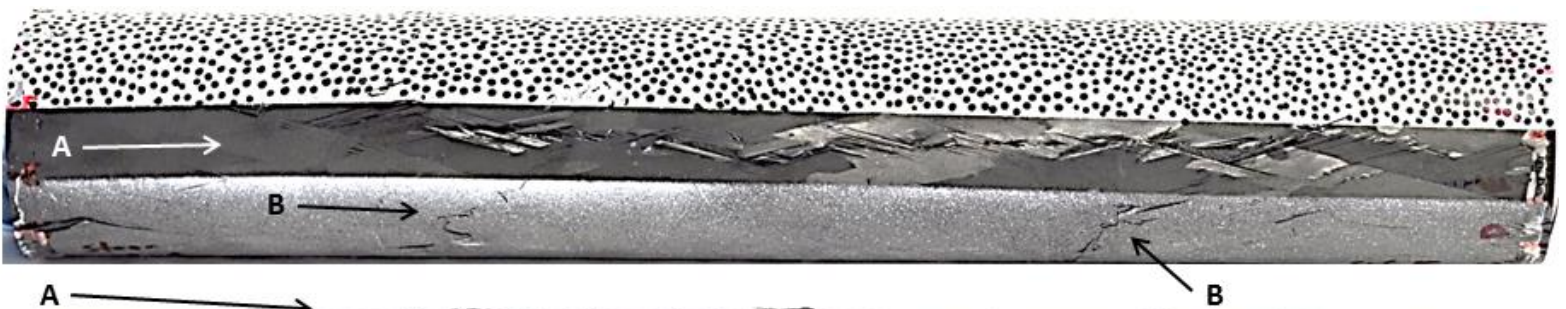

(ii)

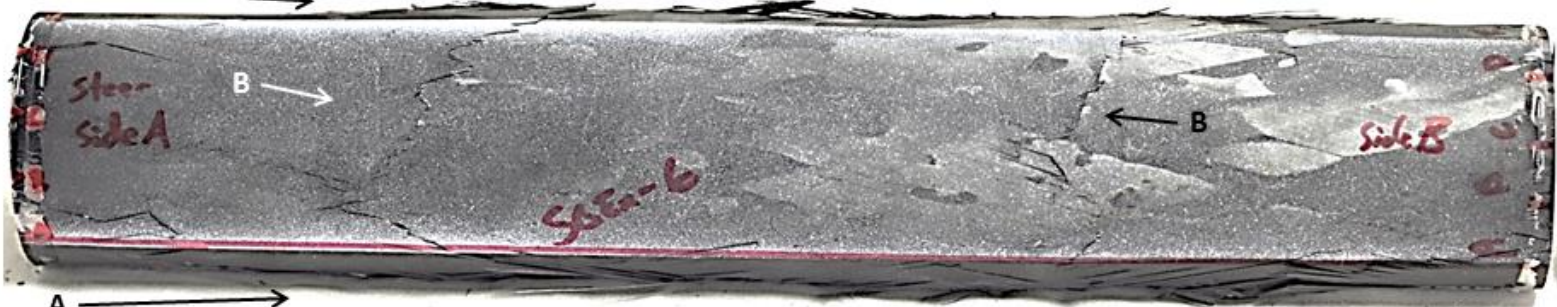

(iii)

$\kappa^{\mathrm{C}} y$

(iv)

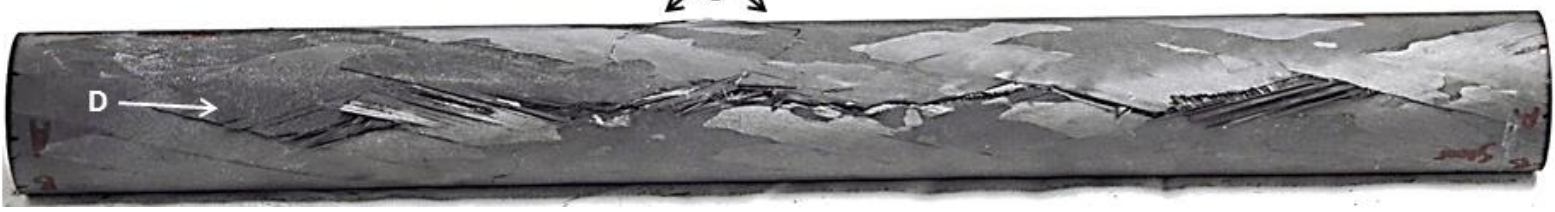

Figure 20: Post-mortem photographs of a no-core specimen with $102 \mathrm{~mm}$ standoff; (i) top view of outer tube; (ii) back view of outer tube; (iii) back view of inner tube; (iv) bottom view of inner tube 


\subsubsection{NO CORE, 203 MM STANDOFF CASE}

The collapse of the structure with core removed and a $203 \mathrm{~mm}$ standoff completes in $13.8 \mathrm{~ms}$ : this is a greater duration than the $102 \mathrm{~mm}$ standoff case, but still much shorter than either case where the foam core is included.

DIC information from the event helps explain the key stages and processes of the collapse process: this is shown in Figure 21, which shows centerpoint radial displacement with key stages of the collapse marked, and Figure 22, which shows high-speed imagery from the marked times in the previous figure. Following the firing of the explosive shortly after time 0 , the outer tube can be seen to oscillate briefly before collapse initiates at $3.33 \mathrm{~ms}$, marked A. Interestingly, this occurs after reflections from the tank walls interact with the specimen, as can be seen in Figure 23. From this, it can be concluded that the initial shock wave alone does not possess enough energy to destabilize the outer tube. Following the initiation of collapse at A, the walls of the outer tube move inward and impact the walls of the inner tube at B. The walls of the inner tube immediately continue inward collinearly with those of the outer tube, but eventually stabilize briefly around $6.67 \mathrm{~ms}$, marked C. Shortly afterwards, the second bubble pulse is observed at $6.83 \mathrm{~ms}$ from side view imagery, and can be seen clearly in Figure 23. This leads to a substantial amount of cavitation in the tank, which causes brief loss of correlation.

The second bubble pulse provides sufficient energy to collapse the inner tube, such that implosion of that structure initiates at $7.57 \mathrm{~ms}$, marked D. This continues until the structure collapses completely and makes wall contact at centerpoint at E. A distinct buckle propagation phase is not observed following centerpoint contact, and the center of the structure appears to rebound outward briefly at $\mathrm{F}$, while the buckle concurrently propagates in the direction of the endcaps, most clearly visible in Figure 22. Finally, the center of the 
structure moves back inwards to complete wall contact at $13.77 \mathrm{~ms}$, marked G, and no further changes in the state of the structure are observed.

It should be noted that the structure does not undergo complete collapse, as can be seen from end-state DIC contours in Figure 22G. This implies that the inner tube of the double-hull structure still has some residual stiffness after the collapse event, and is able to resist complete collapse on account of that. It appears that the inner tube only collapsed because the valley of its buckling mode shape was well aligned with that of the outer tube, and that the timing of the second bubble pulse was enough to partially collapse the inner tube in this configuration.

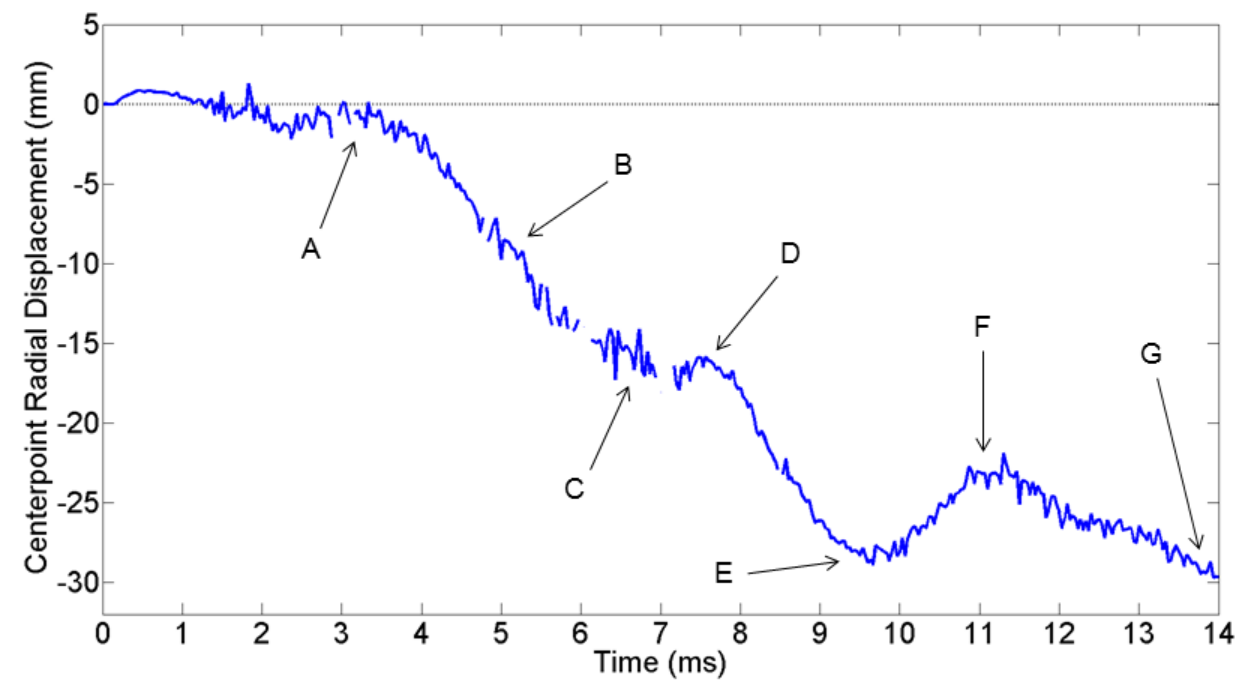

Figure 21: Centerpoint radial displacement (dR) data for the no-core case with $203 \mathrm{~mm}$ standoff 


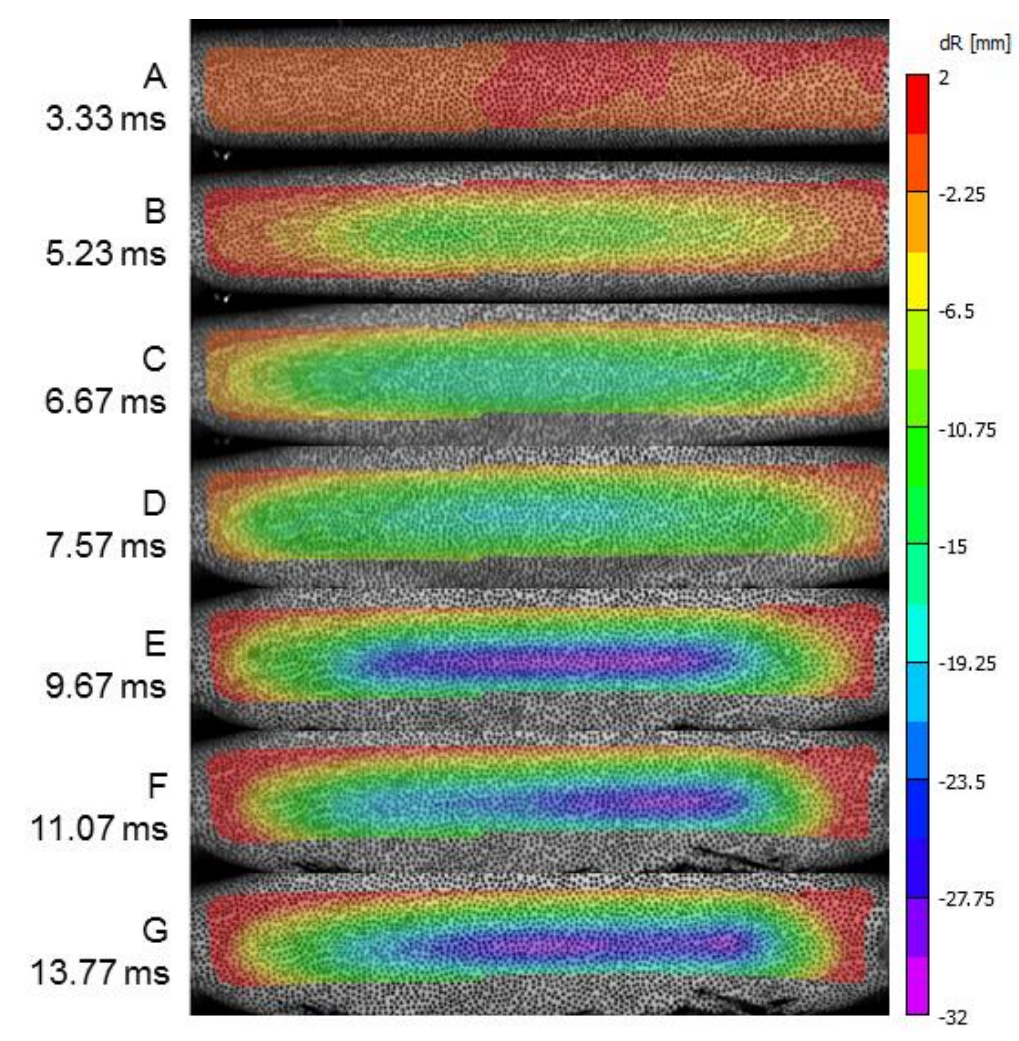

Figure 22: High speed imagery with DIC contours superimposed for the no-core case, with $203 \mathrm{~mm}$ standoff. Letter-labels to the left of the images correspond to labels in Figure 21.

The pressure history from the no core, $203 \mathrm{~mm}$ standoff case is plotted in Figure 23, and investigation of this data can help yield insight into the collapse dynamics seen above. Because the standoff distance of the explosive is much greater, the amplitude of the shock wave is substantially reduced from the $102 \mathrm{~mm}$ configuration, explaining why the outer tube does not collapse until it is subject to additional energy from tank reflections. The first bubble pulse from the UNDEX can also be seen to occur around $4 \mathrm{~ms}$, during which time the walls of the outer tube are collapsing inwards. This adds additional energy to their collapse, and helps drive the inner tube inward after wall contact between inner and outer cylinders is made at $5.23 \mathrm{~ms}$. As noted previously, the second bubble pulse can also be seen to occur shortly before the collapse of the inner tube initiates, which is likely the cause of that event. Finally, it can be seen that the centerpoint rebound in Figure 22F also begins between bubble pulses 3 
and 4, which are not easily distinguishable in the pressure history but can be observed in side view imagery. Because the rebound occurs between pulses, the local pressure in the fluid would be at a relative minimum, helping to explain why the rebound seen above occurs and why residual stiffness in the outer tube would be better able to initiate the rebound during that time.

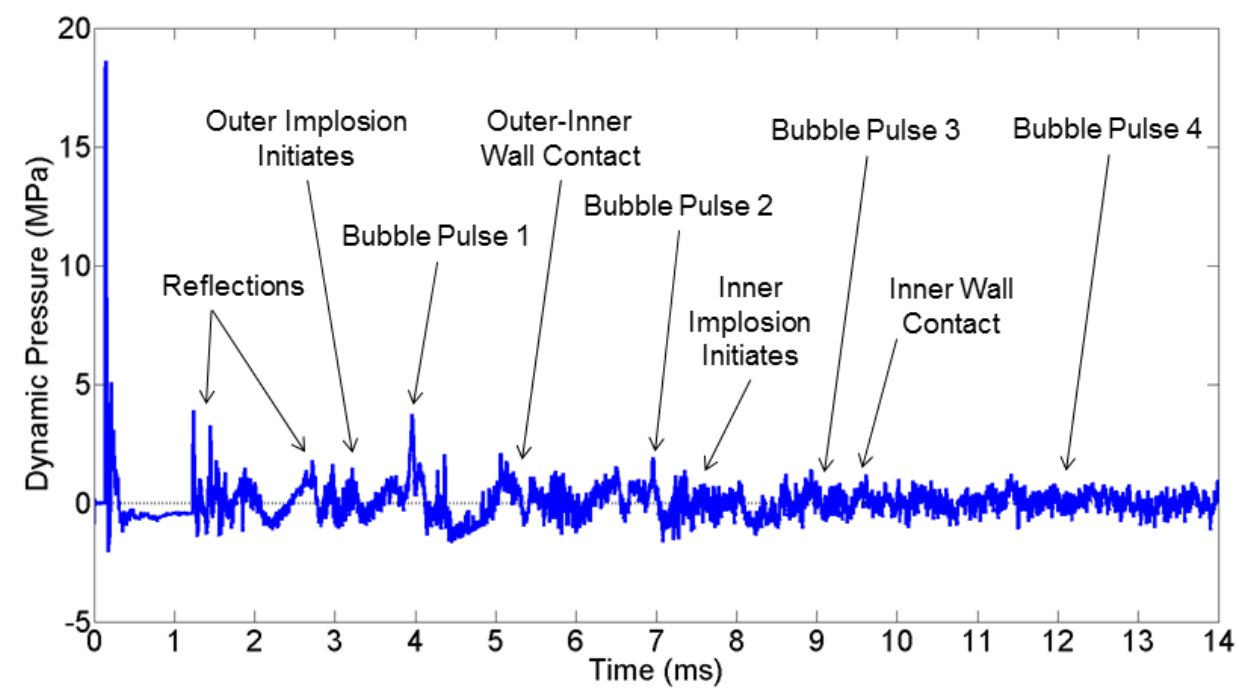

Figure 23: Pressure-time history for no-core case, with $203 \mathrm{~mm}$ standoff. Dynamic pressure is plotted, such that 0 on the vertical axis corresponds to ambient hydrostatic pressure.

Following the experiments, post-mortem specimens were inspected for damage, with Figure 24 showing post-mortem images from the no-core case with $203 \mathrm{~mm}$ standoff. The most prominent damage is again in the form of longitudinal cracking along the length of the inner and outer tubes, marked $\mathrm{A}$ on the outer cylinder and $\mathrm{E}$ on the inner. These longitudinal cracks correspond to the lobes of the mode 2 buckling shape, where the specimen hinged as it collapsed. Back face, circumferential cracking can also be seen on the outer tube, labeled B, though it is not bilateral in the manner of the $102 \mathrm{~mm}$ standoff case, and shows more delamination and fiber pullout than that case as well. Of note, however, is a small circumferential crack on the back face of $\mathrm{C}$, which does not exhibit the extensive damage of the other cracks, but still shows the development of damage in that area. It is also interesting 
to note that damage has developed on the front face of the outer tube, in the area marked D. This is a departure from the $102 \mathrm{~mm}$ standoff case, which did not have damage in this area, though it was subject to a stronger blast. The difference is likely because the duration of the collapse was longer in the $203 \mathrm{~mm}$ case, as a result of the lower-amplitude shock loading. Because of this, damage had a longer time to accumulate in the structure, particularly in the outer tube. The inner tube does not have the back face damage present in the $102 \mathrm{~mm}$ specimen in Figure 20, showing that the impact between inner and outer facesheets was not as violent in the case of the $203 \mathrm{~mm}$ specimen. 
(i)

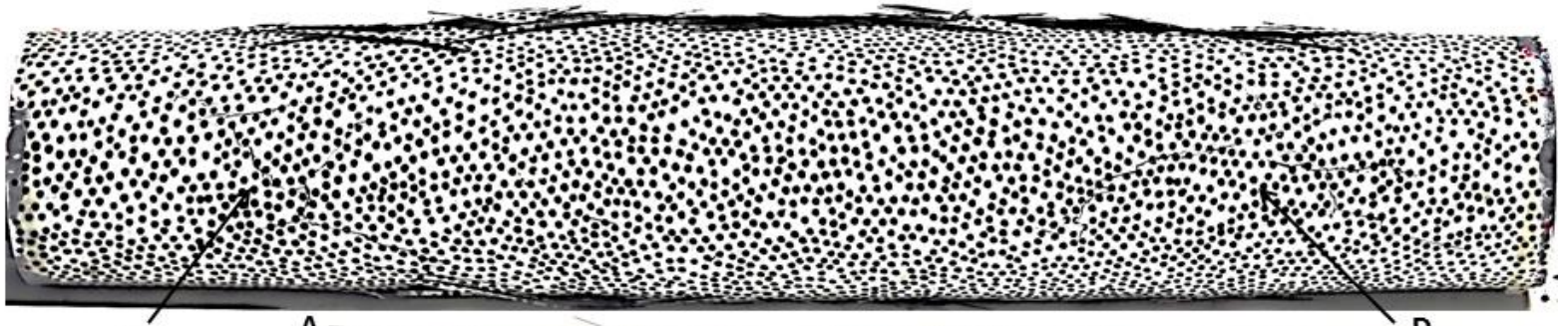

(ii)

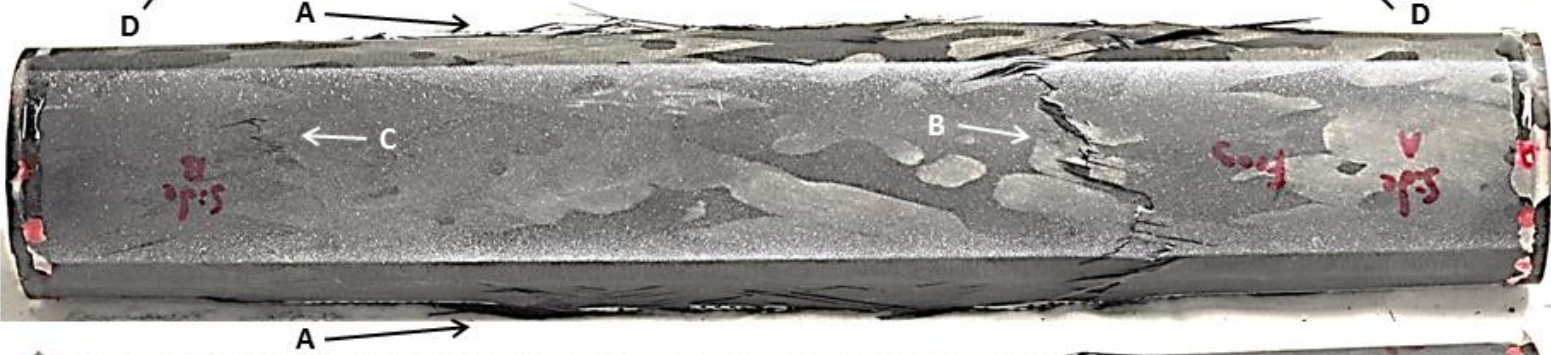

(iii)

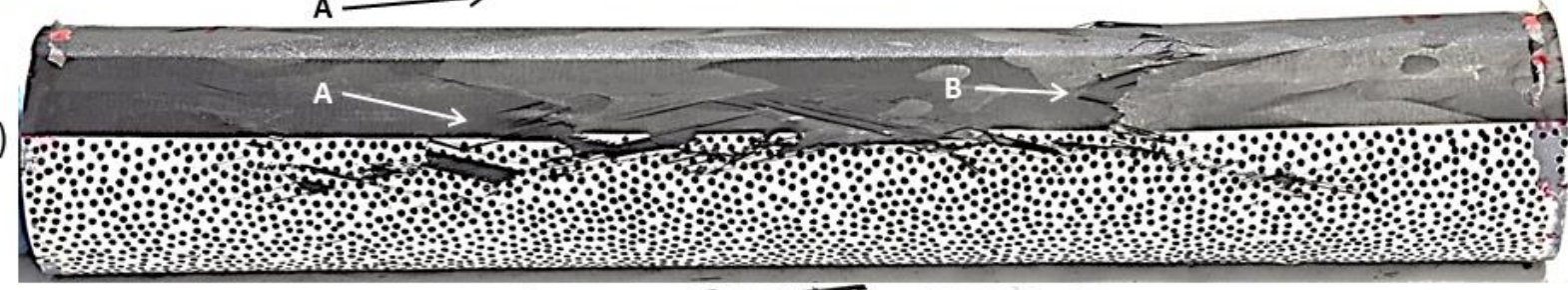

(iv)

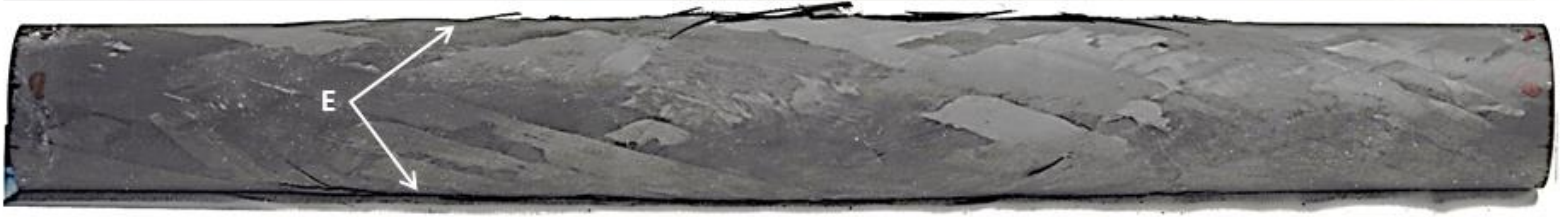

(v)

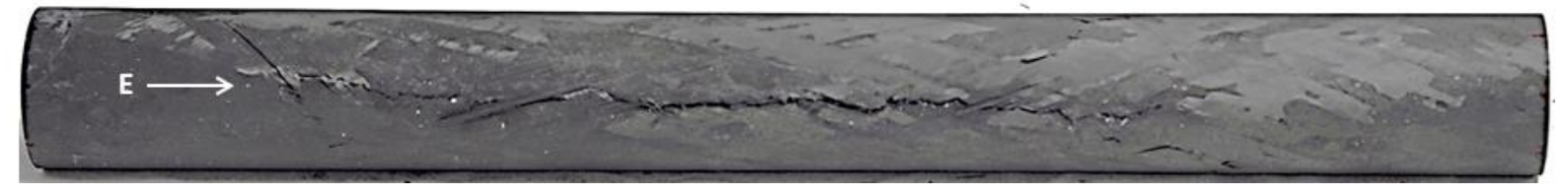

Figure 24: Post-mortem photographs of a no-core specimen, with $203 \mathrm{~mm}$ standoff; (i) front view of outer tube; (ii) back view of outer tube; (iii) bottom view of outer tube; (iv) front view of inner tube; (v) bottom view of inner tube

\subsubsection{FOAM CORE, 102 MM STANDOFF CASE}

The addition of a foam core provides substantially increased stability for the double hull cylinders. This is initially obvious from the $30.2 \mathrm{~ms}$ collapse duration of the H100 core specimen with $102 \mathrm{~mm}$ standoff: this is more than double the duration of the no core, $203 \mathrm{~mm}$ case described in the previous section, even though the shock experienced by the specimen is of greater magnitude here. 
Figure 25 shows centerpoint radial displacement data for the foam core, $102 \mathrm{~mm}$ standoff case, with key stages in the collapse marked. Figure 26 shows high speed imagery from these times with DIC contours superimposed, thus providing information about the rest of the cylinder. It is immediately clear from viewing Figure 25 that the qualitative behavior of the specimen is different when the foam core is added: whereas cases with core removed resulted in collapse of the specimen in a roughly singular motion, it can be seen here that the inner tube oscillates for an extended duration after the collapse of the outer tube, before finally losing stability itself.

Several key stages of the collapse are marked in Figure 25 and Figure 26. Following arrival of the initial shock wave shortly after $0 \mathrm{~ms}$, the tube can be seen to bow outward and oscillate for some time, before implosion of the outer tube initiates at about $4.00 \mathrm{~ms}$, marked A. Cross-referencing with Figure 27, it can be seen that this initiation occurs shortly after the second bubble pulse, indicating that the bubble pulse provided the energy to collapse the outer tube. This highlights the reinforcing effect of the foam core, as the initial shock wave alone was able to collapse the outer tube in the no-core case with the same standoff. Here, the outer tube did not collapse until subject to energy from the initial shock wave, two sets of reflections, and two bubble pulses, as well as a much higher ambient hydrostatic pressure, clearly showing the reinforcing effect of the core. Collapse of the outer tube continues until $\mathrm{B}$, at which point complete densification occurs in the foam core and the inner tube stops the inward motion of the walls. Interestingly, there is substantial damage in the outer facesheet at this time, as evidenced by circumferential cracks that appear to extend around much of the circumference of the structure. These cracks are seen in analysis of post-mortem specimens, and highlighted in Figure 28. After the outer tube crushes against the inner at B, the latter tube begins to oscillate at low frequency and an amplitude of about $4 \mathrm{~mm}$ for $23.1 \mathrm{~ms}$, until collapse of the outer tube is initiated at E. A local minimum and maximum are marked for 
reference during this time as $\mathrm{C}$ and $\mathrm{D}$, respectively. Following initiation at $\mathrm{E}$, the structure continues to collapse asymmetrically before making centerpoint wall contact at $\mathrm{F}$, after which buckle propagation continues along the longitudinal axis of the structure and completes at 30.2 ms, marked G.

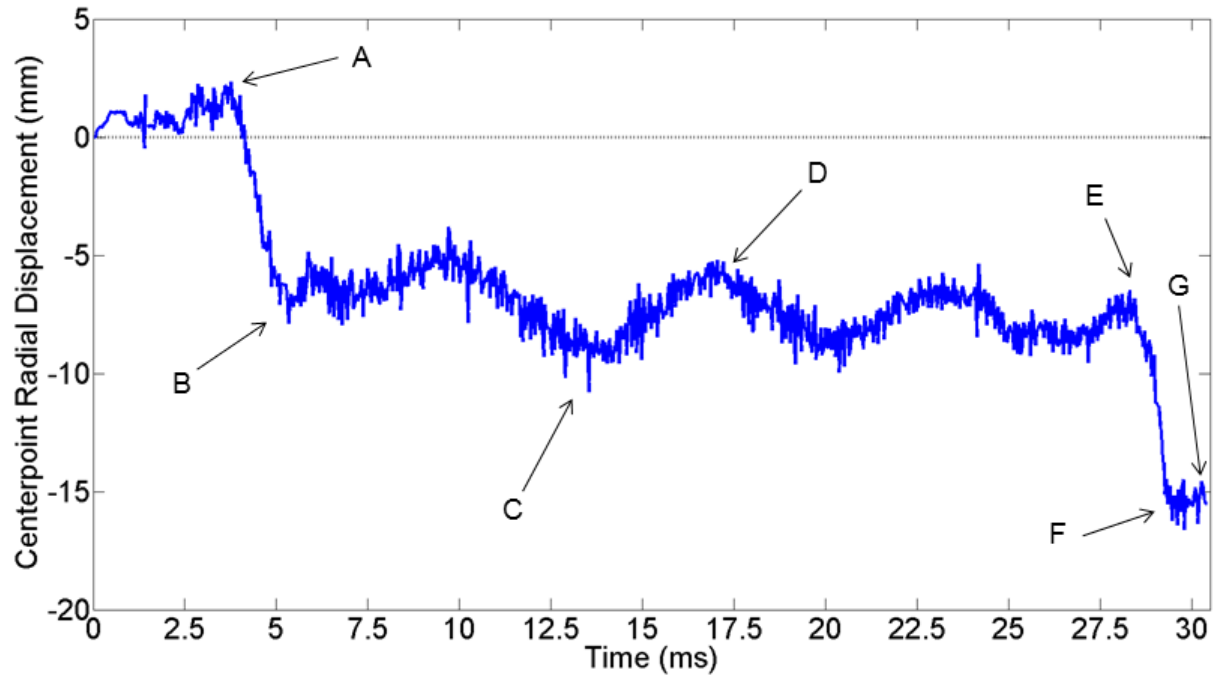

Figure 25: Centerpoint radial displacement (dR) data for the H100 core case, with $102 \mathrm{~mm}$ standoff 


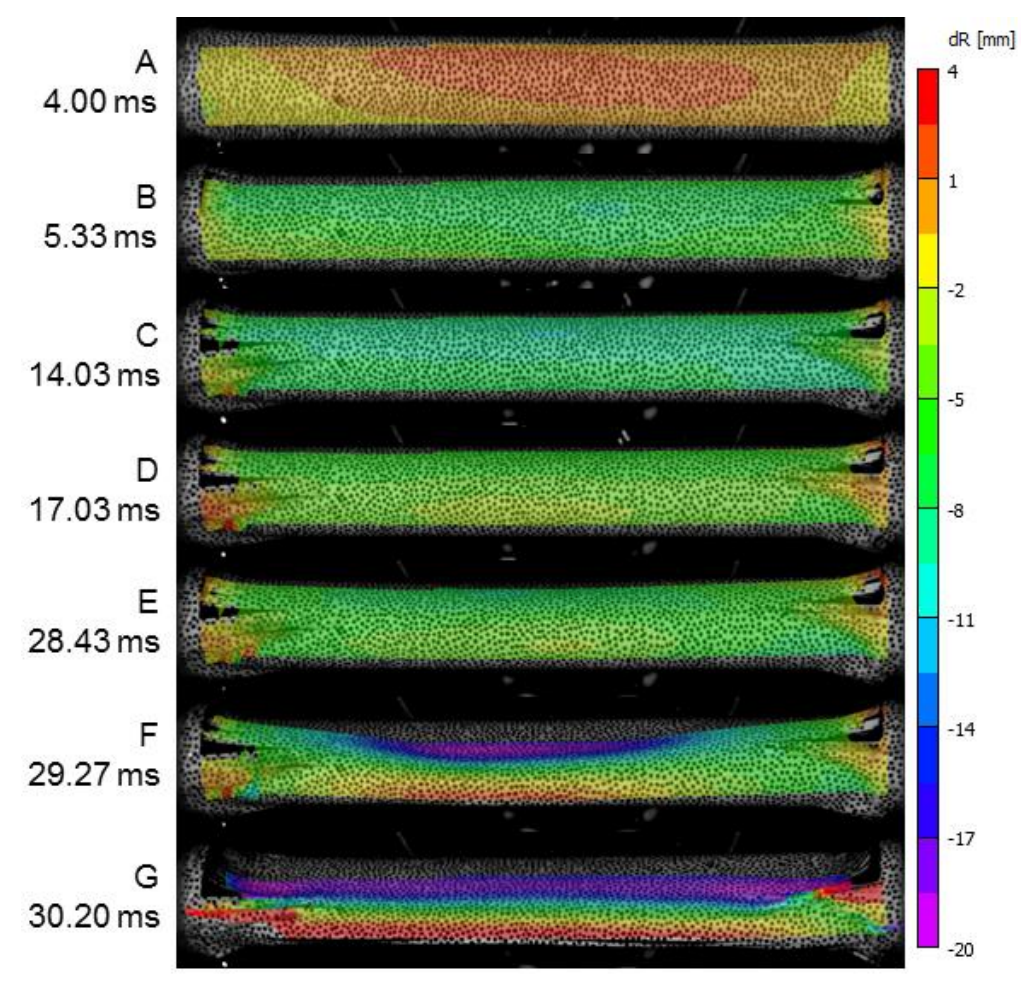

Figure 26: High speed imagery with DIC contours superimposed for the H100 core case, with $102 \mathrm{~mm}$ standoff. Letter-labels to the left of the images correspond to labels in Figure 25.

Pressure profiles recorded during the event help to explain the behavior seen above, and are plotted in Figure 27 with key features labeled. Of particular note is the substantially reduced time period between bubble pulses. This occurs because the ambient hydrostatic pressure is brought to a much higher level in the foam core cases (2.90 MPa vs $1.0 \mathrm{MPa})$, resulting in faster oscillations in bubble radius. This means that the specimen is subject to a greater amount of energy in a given time period than in the no core case, though ambient hydrostatic pressure is $80 \%$ the natural collapse pressure of the specimen in both cases.

Four bubble pulses are recorded in the first six milliseconds of the collapse, with reflections typically occurring every $1.4 \mathrm{~ms}$. Despite this, the outer tube of the specimen does not initiate collapse until $4.00 \mathrm{~ms}$, which clearly shows the stabilizing effect of the foam core. After the outer tube implodes, bubble pulses and reflections continue, though individual pulses and reflections lose energy and become more difficult to discern after $7.5 \mathrm{~ms}$. Over time, a 
gradual attenuation in the amplitude of the pressure trace is seen, so that when implosion of the inner tube initiates, the amplitude of the pressure signal is significantly lower than that seen at $7.5 \mathrm{~ms}$ and earlier. As a result, the outline of a pressure pulse from the implosion of the inner tube can be seen, with a feint drop in pressure preceding wall contact of the inner cylinder at $29.3 \mathrm{~ms}$, followed by a small spike in pressure concurrent with buckle propagation, as is typically emitted during an underwater implosion. This pulse is not usually visible in the noisy environment of the pressure vessel that these explosive-initiated experiments are performed in. However, the extended collapse duration and increased hydrostatic pressure of the foam core specimen allows a small but detectable pulse from the implosion of the inner tube to be registered. 

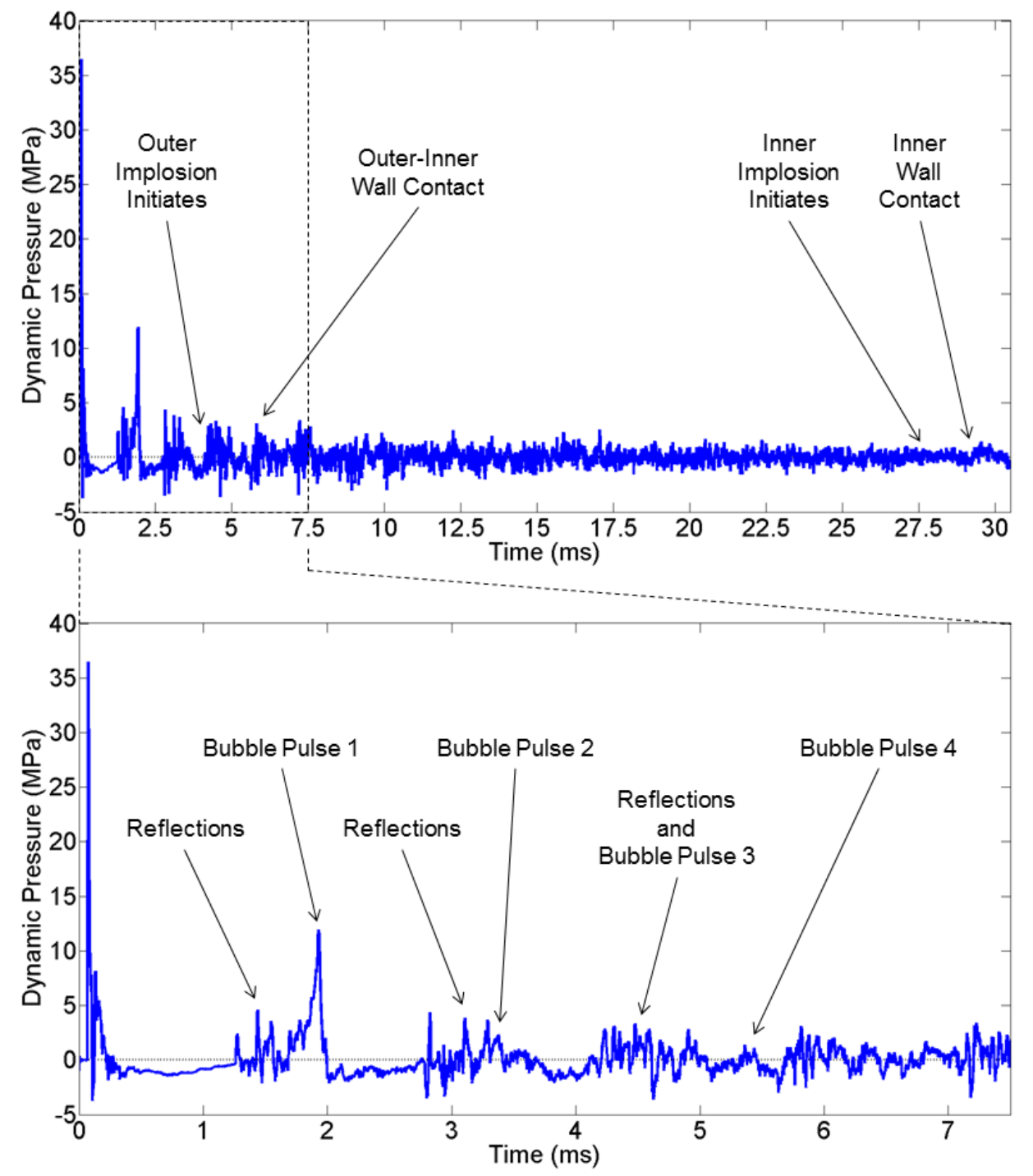

Figure 27: Pressure-time history for $H 100$ core case, with $102 \mathrm{~mm}$ standoff; (top) pressure for duration of collapse; (bottom) inset detailing first $7.5 \mathrm{~ms}$ of pressure history; Dynamic pressure is plotted in both graphs, such that 0 on the vertical axis corresponds to ambient hydrostatic pressure

Investigation of the post-mortem specimens for this case reveals more information about the failure modes of the structure, with images of the specimen shown in Figure 28. The first thing to note is the circumferential tearing in the vicinity of the endcaps of the outer tube, marked A. This damage of this type also appears in the inner tube, at locations marked E. Circumferential tearing does not appear in the specimens with core removed. This is because 
the foam core specimens have a higher collapse pressure, so the experiments on them are performed at a higher hydrostatic pressure. As a result, the cylinders are driven inward more abruptly after losing stability, and undergo substantial tearing from endcap-induced shear. Large-scale delamination of fibers also occurs near the endcaps in regions marked B, and is enabled by the tearing at $\mathrm{A}$, as well as the increased hydrostatic energy of the foam core cases. A massive longitudinal tear can be seen in the back of the specimen, marked by $\mathrm{C}$. This tear extends the full length of the tube, such that the cylinder is fully parted at this location. The face of the tear is marked by large scale delamination and fiber failure, as well as a folding of the bottom portion of the outer facesheet under itself. There, the fibers of the tube have also pierced the foam core, keeping the outer facesheet in place after the specimen is removed from the pressurized environment. This tear and fold-under corresponds to the back portion of the outer tube that folded inwards during the collapse of the inner tube. Damage corresponding to the hinge on the front face can be seen at D, with delamination of the outer ply along the length of the tube visible. The damage is much more significant at $\mathrm{C}$ however, and this is likely a result of accumulation of damage on the side of the specimen facing the UNDEX and subsequent bubble pulses.

Also of note is the crushing of the foam core in an asymmetric mode 2 shape at the regions marked F. This demonstrates that the core is absorbing energy during the collapse of the inner and outer facesheets. Through-thickness longitudinal cracking can be seen in the inner tube at $\mathrm{G}$, and corresponding to the regions that hinged during the collapse of the inner cylinder. This occurs in much the same manner as the no-core specimens; however, the same characteristic cracking does not appear in the outer tube, further implying that the outer cylinder collapsed on account of damage. Finally, it is worth noting that the back-face circumferential cracking seen in the no-core specimens is not present in this case. Here, it 
appears that the foam core provides enough support for the outer tube to prevent that damage from developing.
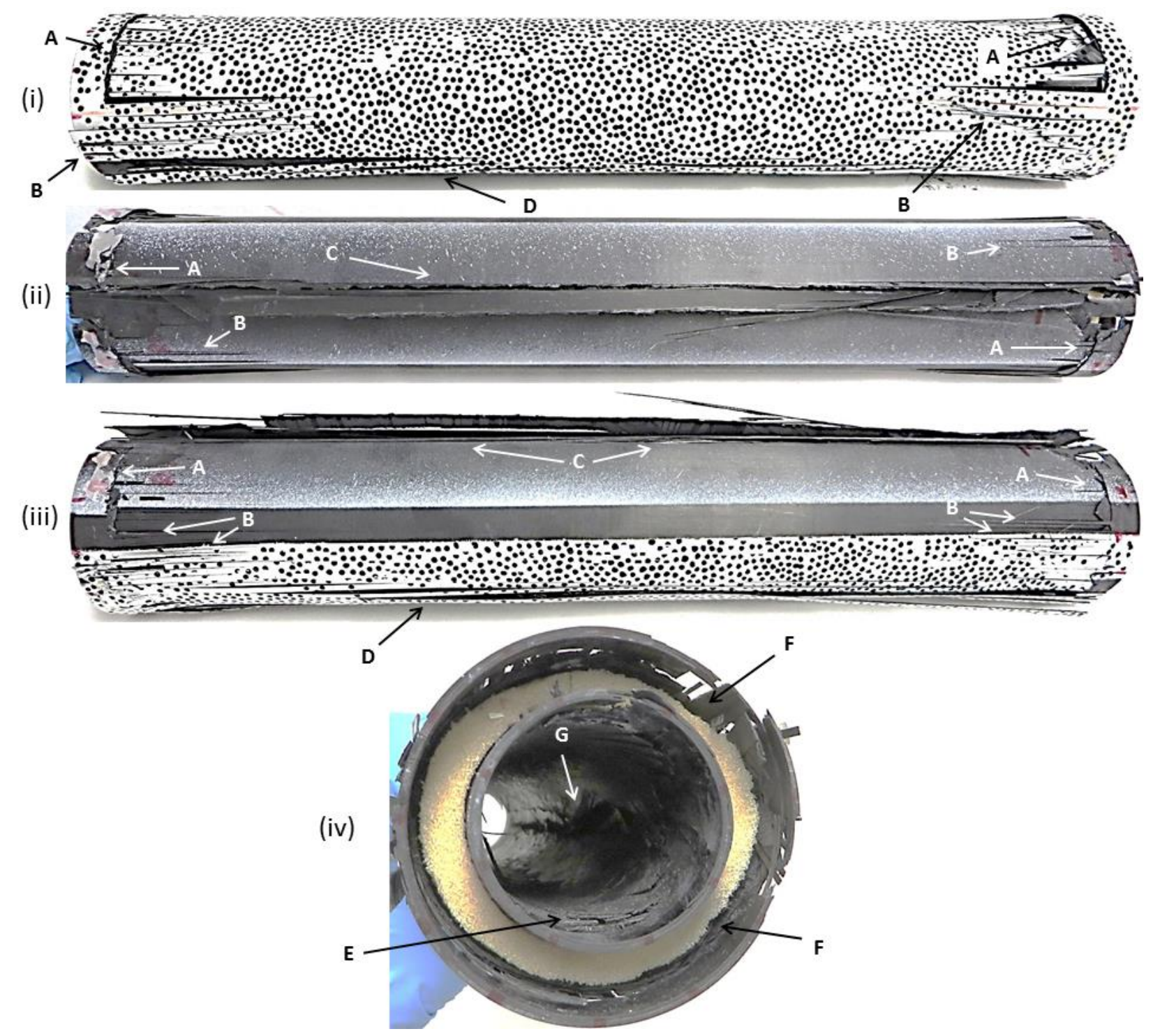

Figure 28: Post-mortem photographs of the foam core specimen with $102 \mathrm{~mm}$ standoff; (i) front view; (ii) back view; (iii) bottom view; (iv) side view

\subsubsection{FOAM CORE, 203 MM STANDOFF CASE}

The case with an H100 foam core and $203 \mathrm{~mm}$ standoff is interesting because the specimens either did not implode at all, or only did so after a very long time relative to other 
cases. For the sake of completeness, the latter trial is focused on in this section, with relevant information included from the no-collapse trial where relevant.

The specimen that imploded did so after $86.9 \mathrm{~ms}$, about triple the duration of the case from Section 2.4.4. Collapse of the outer tube did not initiate until $43.7 \mathrm{~ms}$ after the charge was fired, longer than the entire collapse duration of the specimen with $102 \mathrm{~mm}$ standoff. High speed imagery and DIC information help to explain the mechanics of this collapse process, with centerpoint radial displacement data plotted in Figure 29, with key stages of the collapse labeled. High-speed imagery corresponding to these labels is shown in Figure 30, with DIC contours superimposed. Figure 29 contains data from both trials, though labels only apply to the trail that imploded. In the trial that did not implode, steady-state oscillations can be seen about the horizontal axis, beginning around $10 \mathrm{~ms}$. These oscillations continue indefinitely, though only about $64 \mathrm{~ms}$ of data is recorded.

Key stages of the collapse are labeled in Figure 29 for the trial that did implode. Starting around $10 \mathrm{~ms}$, the deflection from the second trial can be seen to diverge from the first, as the specimen bows outward slightly with positive radial displacement. From there, the specimen oscillates radially with a frequency approximately the same as Trial 1 . This continues until $43.7 \mathrm{~ms}$, marked A, at which point the outer tube loses stability and begins to collapse. Collapse of the outer tube continues until B, at which point the outer facesheet makes a quasi-wall contact with the inner by crushing the foam core fully.

It is important to understand why the first trial did not collapse and the second trial did. This can be answered in part by image B in Figure 30. There, damage in the form of circumferential cracking can be seen near the endcaps of the specimen. An asymmetric collapse of the outer facesheet is also seen, where the bottom of the cylinder is not deformed in the image, but the top is crushed against the inner tube. Combined, these factors indicate that the outer tube did not collapse from a structural instability, as that would result in a 
symmetric modal buckling shape. Rather, it is clear that the outer cylinder lost stability on account of material damage which eventually overwhelmed the structure. It is difficult to identify when this damage would have initiated, as cracking can be too small for visible inspection and half the cylinder is not visible in the images.

After the collapse of the outer facesheet at B, the inner cylinder continues to oscillate radially for $27.6 \mathrm{~ms}$, before collapsing entirely at time $83.6 \mathrm{~ms}$, marked D. Meanwhile, damage in the outer cylinder continues to grow, as is apparent from the more extensive cracking in Figure 30C than in B. Additionally, the inner tube can be seen to slowly trend toward greater negative radial deformation in the time period between $\mathrm{B}$ and $\mathrm{D}$, indicating reduced stiffness of the inner facesheet. After losing stability at D, centerpoint wall contact is made at $86.2 \mathrm{~ms}$, marked E. Buckle propagation then occurs in the specimen, ending at 86.9 ms, marked F.

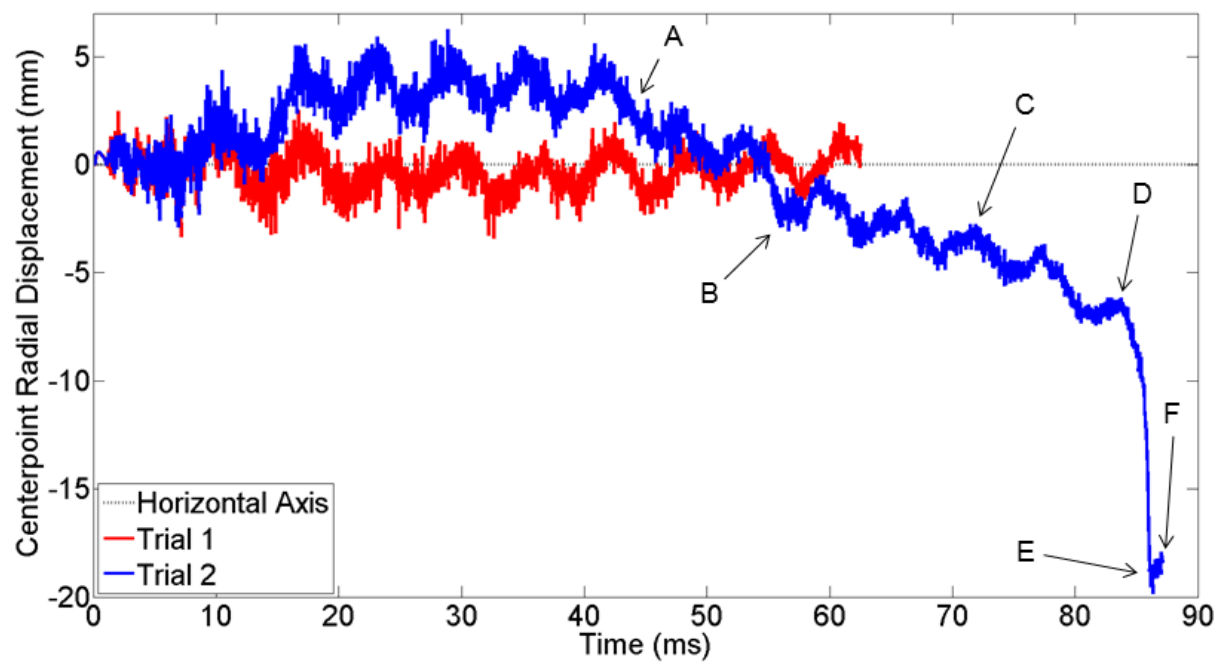

Figure 29: Centerpoint radial displacement (dR) data from the H100 core cases and a 203 mm standoff. The specimen did not implode in trial 1, plotted in red. The specimen did implode in trial 2, plotted in blue. Important stages of the collapse in trial 2 are labeled. 


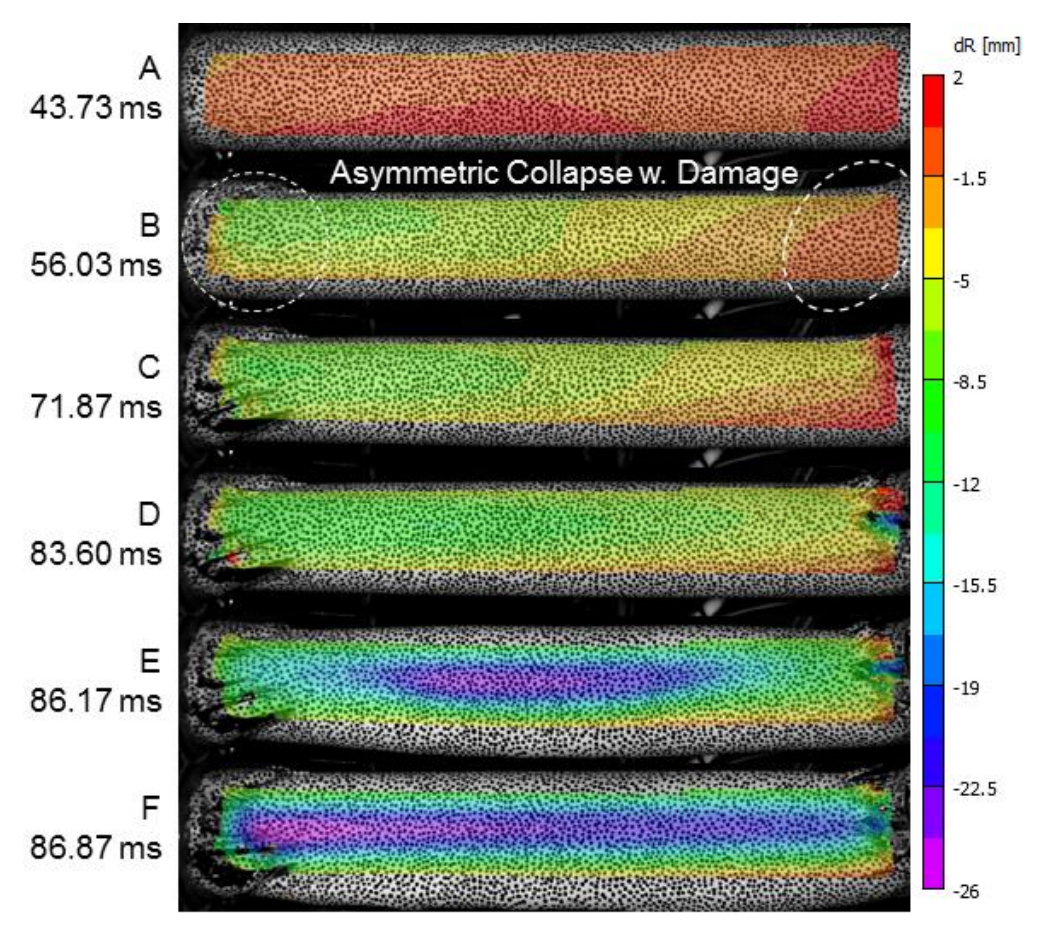

Figure 30: High speed imagery with DIC contours superimposed, from the HIOO foam core specimen with $203 \mathrm{~mm}$ standoff. Letter-labels to the left of the images correspond to labels in Figure 29.

Pressure-time histories provide additional collapse information, with the pressure profile from the foam core, $203 \mathrm{~mm}$ standoff case plotted in Figure 31. The bottom plot in the figure shows the reflections and bubble pulses in the first $7.5 \mathrm{~ms}$ of the collapse, though collapse of the outer tube does not initiate until well after this window. Note the lower magnitude of the initial shock wave in this case as compared to the $102 \mathrm{~mm}$ standoff case, as well as the higher frequency of bubble pulse compared to 1.0 MPa cases. Times of key events are marked in the top plot, but there does not appear to be any unique features corresponding to the collapse of the outer tube. Interestingly, a definite pulse is registered after the implosion of the inner tube. Following an underpressure region associated with the collapse of the inner tube, a peak in pressure is registered shortly after wall contact at $86.9 \mathrm{~ms}$. This peak is concurrent with buckle propagation along the length of the inner tube, as is typically observed during an implosion. As with the $102 \mathrm{~mm}$ standoff case, the pressure pulse from the 
implosion of the inner tube is registered here because noise in the pressure vessel attenuates over time. Because the foam core specimen survives for a long time following the UNDEX event, and the hydrostatic pressure is higher, a small but significant pressure pulse is detected from the collapse of the inner tube. Figure 31 shows only the pressure trace from the trial where the specimen imploded, as the pressure-time history from the other trial is the same with the exception of the inner tube implosion pulse.
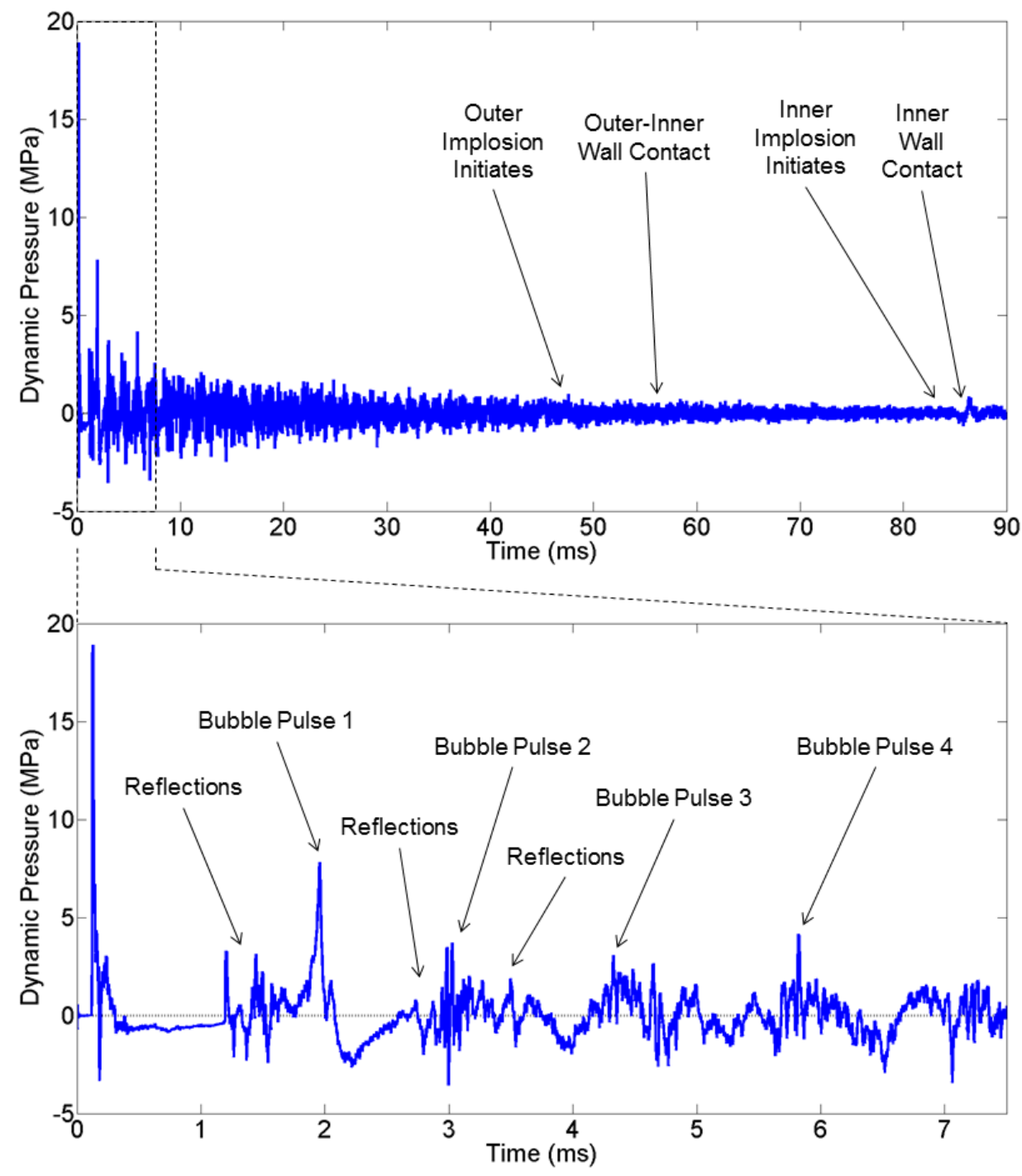

Figure 31: Pressure-time history from the foam core, $203 \mathrm{~mm}$ case; (top) pressure for the entire duration of the collapse; (bottom) pressure for the first $7.5 \mathrm{~ms}$, showing reflections and bubble pulses; Dynamic pressure is plotted, such that 0 corresponds to ambient hydrostatic pressure; data is taken from case where specimen imploded. 
Post-mortem analysis helps complete the understanding of failure and damage modes, with images of foam core specimens at $203 \mathrm{~mm}$ standoff plotted in Figure 32. There, the first thing to note is circumferential tearing around the endcaps at A, as seen in the foam core, 102 mm standoff case. This tearing clearly resulted in loss of stability for the outer tube, though the tearing is less extensive than the $102 \mathrm{~mm}$ case because the magnitude of shock loading was reduced. This allowed the outer tube to survive for a relatively long time before collapsing, at which point the pressure in the fluid from the UNDEX had attenuated even further. As a result, the collapse was less violent after stability was lost, and damage was less extensive. Similarly to the $102 \mathrm{~mm}$ case, axial cracking and delamination of fibers near the endcaps can also be seen at B.

Another similarity to the $102 \mathrm{~mm}$ case is the back-face longitudinal tear extending along the full length of the specimen at $\mathrm{C}$. This tear is again characterized by complete separation of the outer cylinder with itself, as well as massive fiber failure and delamination along the face of the tear. This damage mode occurs where the outer tube folds on the inner as the latter structure collapses. Corresponding damage on the front face is not visible in this case, however, due to the reduced magnitude of shock loading. Large scale delamination of the outer plies of a small grouping of fibers can be seen at D. Again as with the $102 \mathrm{~mm}$ standoff case, an asymmetric mode 2 shape can be discerned in the crushed shape of the foam core at $\mathrm{E}$, and characteristic through-thickness cracking corresponding to hinging in a mode 2 buckling shape can be seen in the inner tube at $\mathrm{F}$.

For reference, a side-view image of the specimen that did not collapse is shown in (v) in Figure 32: note the complete lack of any apparent damage in the inner tube, foam core, and outer tube. As stated previously, there was likely some initial damage in the specimen that did implode, which grew over time as the structure was loaded by the UNDEX, secondary bubble 
pulses, and reflections from the walls of the pressure vessel. The post-mortem images in

Figure 32 (i)-(iv) help reinforce this concept.

(i)

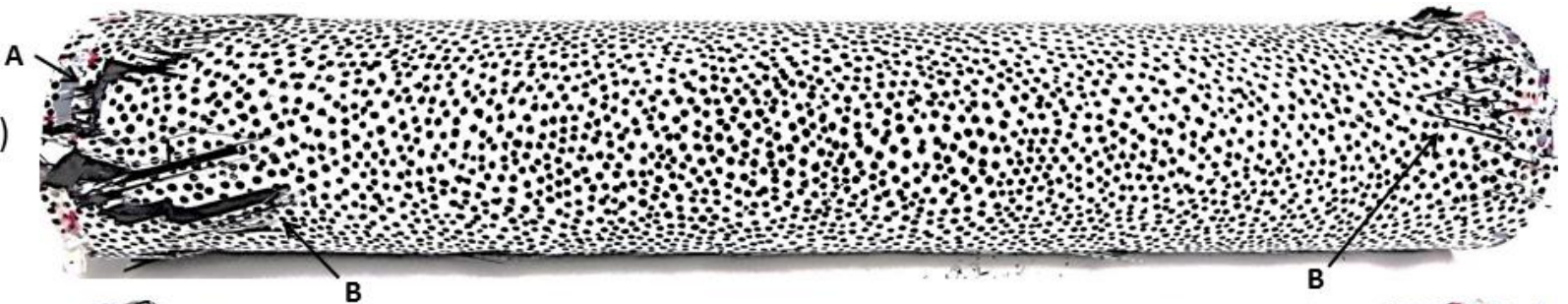

(ii)

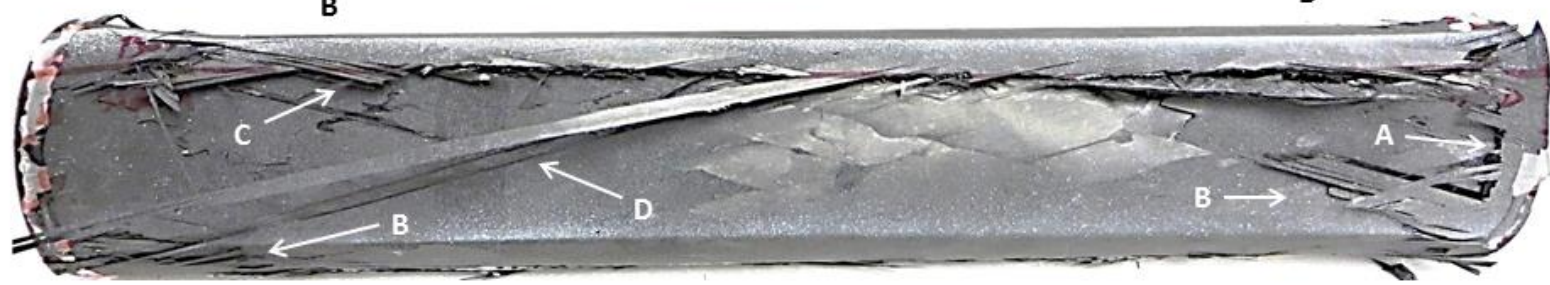

(iii)

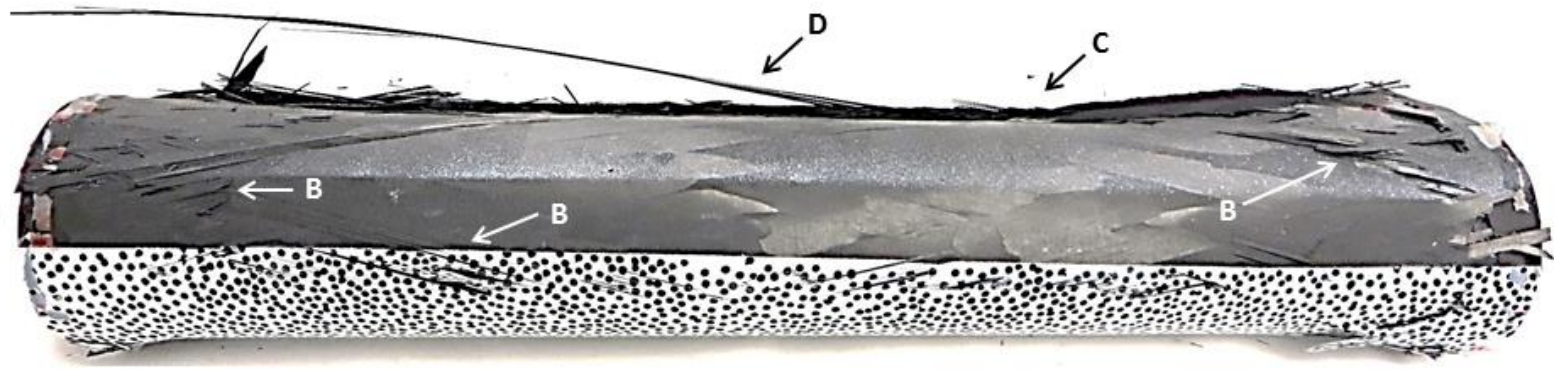

(iv)

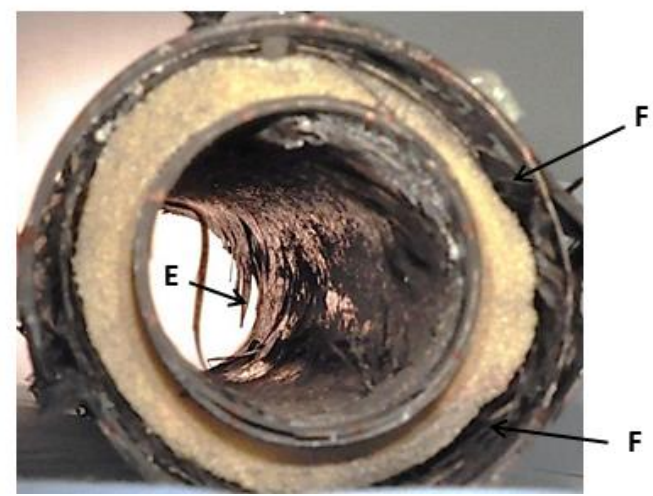

(v)

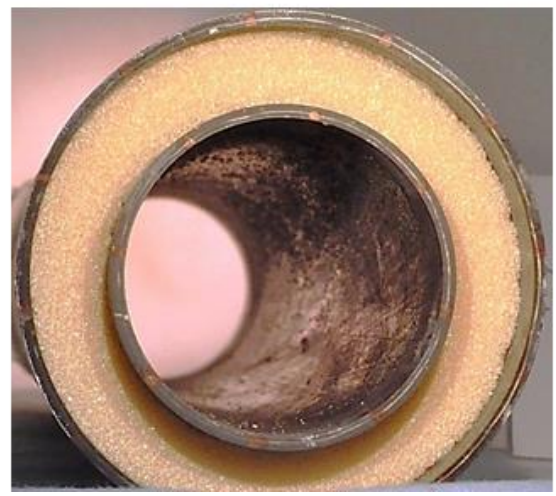

Figure 32: Post-mortem photographs of the foam-core specimens with $203 \mathrm{~mm}$ standoff; (i) front view; (ii) back view; (iii) bottom view; (iv) side view; (v) side view of specimen that did not implode

\subsection{CONCLUSIONS}

An experimental study was performed to study the shock-initiated implosion behavior of double hull composite cylinders at sub-critical hydrostatic pressures. High-speed 
photography, underwater digital image correlation, and high-frequency blast transducers were used to study the mechanics of carbon-fiber / epoxy specimens with and without PVC foam cores under these conditions. As a result of this work, the following conclusions can be made:

- Double hull composite cylinders can implode at hydrostatic pressures $80 \%$ their natural collapse pressure, if they are subject to shock loading.

- These structures may implode from the energy of the initial shock wave, a secondary bubble pulse, or loss of stability due to damage.

- The addition of a foam core substantially increases structural stability: foam cores have been shown to increase the collapse duration of these structures substantially, as well as prevent collapse entirely in some cases.

- The pulse from an implosion in a confined vessel is often insignificant when initiated by an UNDEX. In cases where a foam core is added, the implosion pulse of the inner tube becomes significant, as the core delays collapse until noise in the vessel has attenuated.

- The addition of a foam core may result in a vibrational response of the structure prior to collapse. This can occur in the outer tube, as well as the inner tube after the collapse of the outer.

\subsection{ACKNOWLEDGEMENTS}

The authors would like to acknowledge the Office of Naval Research and Dr. Yapa D.S. Rajapakse for providing financial support for this research under Grant No. N00014-101-0662. The authors would also like to acknowledge the DIAB Corporation (DeSoto, TX) for providing the foam core materials used in this study.

\subsection{REFERENCES}

[1] A. P. Mouritz, E. Gellert, P. Burchill, and K. Challis, "Review of advanced composite structures for naval ships and submarines," Compos. Struct., vol. 53, no. 1, pp. 21-41, 2001.

[2] S. E. Turner and J. M. Ambrico, "Underwater implosion of cylindrical metal tubes," J. Appl. Mech., vol. 80, p. 11013, 2012. 
[3] H. Lindberg and A. Florence, Dynamic pulse buckling: theory and experiment. Springer Netherlands, 1987.

[4] C. Farhat, K. G. Wang, A. Main, S. Kyriakides, L. H. Lee, K. Ravi-Chandar, and T. Belytschko, "Dynamic implosion of underwater cylindrical shells: Experiments and Computations,” Int. J. Solids Struct., vol. 50, no. 19, pp. 2943-2961, 2013.

[5] S. Gupta, V. Parameswaran, M. A. Sutton, and A. Shukla, "Study of dynamic underwater implosion mechanics using digital image correlation," Proc. R. Soc. A Math. Phys. Eng. Sci., vol. 470, no. 2172, pp. 20140576-20140576, 2014.

[6] M. Pinto, S. Gupta, and A. Shukla, "Hydrostatic implosion of GFRP composite tubes studied by Digital Image Correlation,” J. Press. Vessel Technol., vol. 137, no. 5, p. 51302, 2015.

[7] M. Pinto, S. Gupta, and A. Shukla, "Study of implosion of carbon/epoxy composite hollow cylinders using 3-D Digital Image Correlation," Compos. Struct., vol. 119, pp. 272 286, 2015.

[8] S. H. Hur, H. J. Son, J. H. Kweon, and J. H. Choi, "Postbuckling of composite cylinders under external hydrostatic pressure," Compos. Struct., vol. 86, no. 1-3, pp. 114-124, 2008.

[9] P. T. Smith, C. T. F. Ross, and A. P. F. Little, "Collapse of composite tubes under uniform external hydrostatic pressure,” J. Phys. Conf. Ser., vol. 181, pp. 156-157, 2009.

[10] C. J. Moon, I. H. Kim, B. H. Choi, J. H. Kweon, and J. H. Choi, "Buckling of filament-wound composite cylinders subjected to hydrostatic pressure for underwater vehicle applications," Compos. Struct., vol. 92, no. 9, pp. 2241-2251, 2010.

[11] C. T. F. Ross, A. P. F. Little, Y. Haidar, and A. A. Waheeb, "Buckling of carbon/glass composite tubes under uniform external hydrostatic pressure," Strain, vol. 47, no. SUPPL. 1, pp. 156-174, 2011.

[12] N. G. Pegg, "Effects of impulse duration and combined impulse-hydrostatic pressure on buckling stability of cylindrical structures," Sh. Res., vol. 38, no. 2, pp. 164-171, 1994.

[13] R. Tanov, A. Tabiei, and G. J. Simitses, "Effect of static preloading on the dynamic buckling of laminated cylinders under sudden pressure," Mech. Compos. Mater. Struct., vol. 6, pp. 195-206, 1999.

[14] J. M. Brett and G. Yiannakopolous, "A study of explosive effects in close proximity to a submerged cylinder," Int. J. Impact Eng., vol. 35, pp. 206-225, 2008.

[15] C. F. Hung, B. J. Lin, J. J. Hwang-Fuu, and P. Y. Hsu, "Dynamic response of cylindrical shell structures subjected to underwater explosion," Ocean Eng., vol. 36, no. 8, pp. 564-577, 2009.

[16] M. S. H. Fatt and S. G. Pothula, "Dynamic pulse buckling of composite shells subjected to external blast," Compos. Struct., vol. 92, no. 7, pp. 1716-1727, 2010. 
[17] C. M. Ikeda and J. H. Duncan, "Fluid-structure interactions: implosions of shell structures and wave impact on a flat plate," University of Maryland, College Park, 2012.

[18] M. Pinto and A. Shukla, "Shock-initiated buckling of carbon/epoxy composite tubes at sub-critical pressures," Exp. Mech., vol. 56, no. 4, pp. 583-594, 2016.

[19] D. J. Hall, "Examination of the effects of underwater blasts on sandwich composite structures," Compos. Struct., vol. 11, no. 2, pp. 101-120, 1989.

[20] N. a. Fleck and V. S. Deshpande, "The resistance of clamped sandwich beams to shock loading," J. Appl. Mech., vol. 71, no. May, p. 386, 2004.

[21] X. Qiu, V. S. Deshpande, and N. a. Fleck, "Dynamic response of a clamped circular sandwich plate subject to shock loading," J. Appl. Mech., vol. 71, no. September, p. 637, 2004.

[22] V. S. Deshpande and N. A. Fleck, "One-dimensional response of sandwich plates to underwater shock loading," J. Mech. Phys. Solids, vol. 53, no. 11, pp. 2347-2383, 2005.

[23] L. Librescu, S. Y. Oh, and J. Hohe, "Dynamic response of anisotropic sandwich flat panels to underwater and in-air explosions," Int. J. Solids Struct., vol. 43, no. 13, pp. 37943816, 2006.

[24] D. D. Radford, G. J. McShane, V. S. Deshpande, and N. A. Fleck, "The response of clamped sandwich plates with metallic foam cores to simulated blast loading," Int. J. Solids Struct., vol. 43, no. 7-8, pp. 2243-2259, 2006.

[25] M. T. Tilbrook, V. S. Deshpande, and N. A. Fleck, "The impulsive response of sandwich beams: Analytical and numerical investigation of regimes of behaviour," J. Mech. Phys. Solids, vol. 54, no. 11, pp. 2242-2280, 2006.

[26] Y. M. Liang, A. V Spuskanyuk, S. E. Flores, D. R. Hayhurst, J. W. Hutchinson, R. M. McMeeking, and A. G. Evans, "The response of metallic sandwich panels to water blast," $J$. Appl. Mech., vol. 74, no. 1, pp. 81-99, 2007.

[27] G. J. McShane, V. S. Deshpande, and N. A. Fleck, "The underwater blast resistance of metallic sandwich beams with prismatic lattice cores," Trans. ASME. J. Appl. Mech., vol. 74, no. 2, pp. 352-364, 2007.

[28] L. F. Mori, S. Lee, Z. Y. Xue, A. Vaziri, D. T. Queheillalt, K. P. Dharmasena, H. N. G. Wadley, J. W. Hutchinson, and H. D. Espinosa, "Deformation and fracture modes of sandwich structures subjected to underwater impulsive loads," Mech. Mater. Struct., vol. 2, no. 10, pp. 1981-2006, 2007.

[29] A. Vaziri and J. W. Hutchinson, "Metal sandwich plates subject to intense air shocks," Int. J. Solids Struct., vol. 44, no. 6, pp. 2021-2035, 2007. 
[30] R. M. McMeeking, A. V. Spuskanyuk, M. Y. He, V. S. Deshpande, N. A. Fleck, and A. G. Evans, "An analytic model for the response to water blast of unsupported metallic sandwich panels," Int. J. Solids Struct., vol. 45, no. 2, pp. 478-496, 2008.

[31] S. Avachat and M. Zhou, "Dynamic response of submerged composite sandwich structures to blast loading," in IMPLAST Conference, 2010.

[32] S. Avachat and M. Zhou, "Response of cylindrical composite structures to underwater impulsive loading," Procedia Eng., vol. 88, pp. 69-76, 2014.

[33] Z. Liu, Y. L. Young, and M. R. Motley, "Transient response of partially-bonded sandwich plates subject to underwater explosions," Shock Vib., vol. 17, no. 3, pp. 233-250, 2010 .

[34] H. Arora, P. A. Hooper, and J. P. Dear, "The effects of air and underwater blast on composite sandwich panels and tubular laminate structures," Exp. Mech., vol. 52, no. 1, pp. 59-81, 2012.

[35] M. S. Hoo Fatt and H. Surabhi, "Blast resistance and energy absorption of foam-core cylindrical sandwich shells under external blast," Compos. Struct., vol. 94, no. 11, pp. 3174 3185, 2012.

[36] R. H. Cole, Underwater Explosions. Princeton, New Jersey: Princeton University Press, 1948. 